\title{
Spatial Cross-Talk Between Oxidative Stress and DNA Replication in Human Fibroblasts
}

\author{
Marko Radulovic, ${ }^{1,2}$ Noor O Baqader, ${ }^{1}$ Kai Stoeber, ${ }^{3 \dagger}$ and \\ Jasminka Godovac-Zimmermann ${ }^{1^{*}}$
}

${ }^{1}$ Division of Medicine, University College London, Center for Nephrology, Royal Free Campus, Rowland Hill Street, London, NW3 2PF, UK.

${ }^{2}$ Insitute of Oncology and Radiology, Pasterova 14, 11000 Belgrade, Serbia

${ }^{3}$ Research Department of Pathology and UCL Cancer Institute, Rockefeller Building, University College London, University Street, London WC1E 6JJ, UK

*Corresponding author:

Prof J. Godovac-Zimmermann, e-mail: j.godovac-zimmermann@ucl.ac.uk

†Present Address: Shionogi Europe, 33 Kingsway, Holborn, London WC2B 6UF, UK 


\begin{abstract}
MS-based proteomics has been applied to differential network analysis of nuclear-cytoplasmic distribution of proteins between cell cycle arrest: (a) at the origin activation checkpoint for DNA replication, or (b) in response to oxidative stress. Cellular response combines changes in trafficking/total abundance to vary local compartmental abundance. Among 401 proteins with appreciable changes, 245 proteins exhibit cross-talk between oxidative stress and DNA replication and 49 proteins show strong changes for both. Many nuclear processes are influenced by a spatial switch involving \{KPNA2, KPNB1, PCNA, PTMA, SET\} and heme/iron proteins HMOX1 and FTH1. Dynamic spatial distribution data is presented for proteins involved in caveolae, extracellular matrix remodelling, TGF $\beta$ signalling, IGF pathways, emerin complexes, mitochondrial protein import complexes, spliceosomes, proteasomes, etc. The date shows that for spatially heterogeneous cells, cross-compartmental communication is integral to their systems biology, coordinated spatial redistribution for crucial networks underlies many functional changes, and information on dynamic spatial redistribution is essential to obtain comprehensive pictures of function. Spatial data of the type presented provides priorities for further investigation of high-level spatial coordination. We suggest perturbation of constitutive transport processes may be related to cancer and other diseases. A quantitative, spatially resolved nucleus-cytoplasm interaction network is provided for further investigations.
\end{abstract}

Keywords: proteomics, mass spectrometry, oxidative stress, DNA replication, nucleus, organelle, subcellular, transport, moonlighting 


\section{INTRODUCTION}

There have long been indications that proliferation of cells via cell cycle progression is intimately connected to the oxidative status of cells. This has led to the proposal that the cell cycle is in fact a redox cycle. ${ }^{1-3}$ The relationships between the cell cycle and oxidative state are particularly evident in many types of cancer cells, where uncontrolled proliferation is associated with changes in cellular metabolic/oxidative processes. ${ }^{4-6}$ The goal of the present work is to determine how dynamic spatial redistribution of proteins between the nuclear and cytoplasmic compartments impinges on coupling between oxidative stress and DNA replication.

We have previously carried out SILAC differential heavy/light isotope labeling ${ }^{7} \mathrm{MS}^{-}$ proteomics analyses of the changes in nucleus-cytoplasm subcellular abundance and distribution of proteins for IMR90 cells (a human diploid fibroblast adherent cell line) subjected either to: (a) siRNA repression of the CDC7 kinase, which leads to cell cycle arrest at the G1/S transition via the origin activation checkpoint (OAC) for DNA replication ${ }^{8-10}$ or, (b) mild oxidative stress initiated with treatment of the cells with tert-butyl hydrogen peroxide (OXS), which also leads to cell cycle arrest. ${ }^{11}$ In both studies the data was analyzed to obtain SILAC ratios for changes in protein abundance between perturbed/unperturbed cells for the nuclear compartment $\left(S_{n}\right)$, the cytoplasmic compartment $\left(S_{c}\right)$, the total changes in abundance $\left(S_{t}\right)$ and nucleo-cytoplasmic redistribution $\left(S_{n} / S_{c}\right)$. Changes both in total protein abundance and in subcellular distribution resulted in distinctive patterns of changes in protein abundance in the nuclear/cytoplasmic compartments that are the basis of the cellular response to each type of perturbation. In keeping with previous evidence for an intimate relationship between the cell cycle and cellular oxidative status, some of the same proteins were amongst the most significant changes for both OXS and OAC.

The present study further explores cross-talk between oxidative status and the cell cycle/DNA replication using a joint, differential network analysis of 48,001 SILAC ratios. From the overall set of 4048 quantified proteins, we identify a 401-set of proteins that show significant changes in total abundance and/or nucleo-cytoplasmic redistribution and outline how both mechanisms contribute to concomitant changes in nuclear/cytoplasmic compartmental abundance. A majority of these proteins (245/401) show appreciable changes in response to both perturbations, with only $67 / 89$ proteins more specific to OAC/OXS respectively. Biological process information from $\mathrm{GO}^{12}$ indicates that nuclear import-export mechanisms, vesiclemediated protein transport and chaperone-assisted processes all contribute to the subcellular redistribution of the proteins. The data indicate that for the cellular responses to OXS/OAC, subcellular redistribution of proteins is of at least equal importance to changes in total cellular protein abundance by transcription/translation/degradation. A large majority of proteins, notably most of those associated with core functional complexes such as ribosomes, spliceosomes and proteasomes, show very limited change in abundance or subcellular location. However, these complexes all include a few proteins with strong redistribution that may modulate the function of the core complex or signal its functional state to other subcellular functions/locations. A few complexes such as ATP5, ATP6 and the CCT protein-folding complex show evidence for translocation of all or most subunits of the complex to different subcellular locations. The dominant behaviour is the transient redistribution of a relatively small set of proteins between the nucleus and other locations. We identify a 49-set of proteins that show strong changes for both OXS and OAC and suggest that these proteins have a dominant role in spatial cross-talk between the core cellular functional processes of DNA 
replication and of response to oxidative stress.

Using only curated, well-documented binary interactions from STRING, ${ }^{13}$ REACTOME,${ }^{14}$ and CORUM,${ }^{15}$ the overall interaction network contains 134,850 binary interaction pairs between the 4048 proteins. Analysis of the interaction networks for the 401-set and 49-set proteins suggests that measurements of total abundance, whether by transcriptomics or proteomics, as well as measurements of protein complexes by high throughput methods, are incomplete for provision of sufficient information to obtain comprehensive pictures of cellular function. That is, measurements of the transient subcellular redistribution of proteins at a global proteome scale for many cell types and functional contexts are urgently needed. The analysis also suggests that substantial numbers of proteins are "moonlighters"16,17 with different functions at different subcellular locations. Transient modification of their abundance in different subcellular locations seems to be an essential part of higher order functional networks that are crucial to cellular spatio-functional control. The present data on spatial redistribution of proteins identifies protein networks putatively involved in "spatial switches" of cellular function for further investigation. One such switch involving the proteins KPNA2, KPNB1, PCNA, PTMA and SET is analysed in detail and data consistent with other switches is presented. For the 401-set we provide a quantitative binary interaction network resolved spatially $\left(S_{n}\right.$ and $\left.S_{c}\right)$ and mechanistically by changes in total abundance $\left(S_{t}\right)$ or by nuclear/cytoplasmic redistribution $\left(S_{\mathrm{n}} / S_{\mathrm{c}}\right)$ for further investigations.

Some of the proteins that show significant changes in total abundance/distribution are under investigation as therapeutic targets for disease, especially for cancer. This may be in keeping with their participation in different functions at different subcellular locations. The discussion relates the data to increasing indications that spatial switches and the associated dynamic protein transport may involve constitutive processes that are normal in cellular function and whose disruption may be a critical factor in disease. 


\section{METHODS}

IMR90 (ATCC CCL-186), a human diploid fibroblast adherent cell line, was obtained from LGC Standers (Middlesex, U.K.) at population doubling of 12. All experiments with IMR90 cells were done with a PD of less than 22 and tested for senescence using a readymade kit (KAA002) from Millipore Corporation (Billerica, MA). The culturing, SILAC labeling, preparation of nuclear and cytoplasmic fractions of the cells, preparation of MS samples and the MS data collection have been described previously. In each study, the triplicate samples consisted of three parallel fractionations from the same pool of cultured cells. ${ }^{9,11}$ Note that "cytoplasmic" corresponds to "nucleus-depleted" and is used to denote all non-nuclear proteins, i.e. including plasma membrane, extracellular matrix, etc.

Joint MS data processing for all OAC and OXS biological samples using MaxQuant (version 1.5.3.28) $)^{18,19}$ with a common UniProt human proteome set (ftp://ftp.uniprot.org/pub/databases/uniprot/current_release/knowledgebase/proteomes/ downloaded 01-25-2013) was performed as described previously. ${ }^{8,9,11}$ The acceptance of proteins as adequately quantified, which was based on minimum numbers of SILAC ratio counts, at least two replicates and MaxQuant Significance B scores, as well as the selection of the significant sets of proteins (401-set, 49-set, see text), is described in detail in the Supplementary Text.

Data for CORUM complexes ${ }^{15}$ was downloaded (12-29-2014) from http://mips.helmholtzmuenchen.de/genre/proj/corum/. Data from REACTOME ${ }^{14}$ for Homo sapiens was downloaded (04-22-2015) from http://www.reactome.org. Data from STRING v10 ${ }^{13}$ was downloaded (homo sapiens, 04-23-2015; rat, mouse, 06-17-2015) from http://string-db.org/. Data from BioGrid $^{20}$ for human interactions of POLDIP2 was downloaded (07-09-2015) from http://thebiogrid.org. Identifiers were mapped to the UniProt human proteome set used for the MS analyses.

Visualizations of interaction networks used CytoScape v3/v2.8. ${ }^{21,22}$ Clustering of the 401-set interaction network was performed with the T-fit algorithm of the Clust\&See plug-in module ${ }^{23}$ of CytoScape. Gene Ontology (GO) ${ }^{12}$ term enrichment for the clusters was obtained with the ClueGO plug-in of CytoScape. Additional GO annotation was obtained from the QuickGO facility at the European Bioinformatics Institute (http://www.ebi.ac.uk/QuickGO/) with appropriate sets of GO identifiers. 


\section{RESULTS}

The original experiments for CDC7-kinase-depletion-induced cell cycle arrest at the origin activation checkpoint for DNA replication ${ }^{9}$ (OAC hereafter) and for mild tert-butyl-peroxideinduced oxidative stress ${ }^{11}$ (OXS hereafter) have previously been described in detail. Spatially resolved SILAC ratios for nuclear abundance $\left(S_{n}\right)$, cytoplasmic abundance $\left(S_{c}\right)$, total abundance $\left(S_{t}\right)$ and nuclear-cytoplasmic distribution $\left(S_{n} / S_{c}\right)$ were measured for both OXS and OAC. Each study included extensive evidence that the cells remained viable without perceptible cell death and that the protocols used for subcellular fractionation gave highly enriched nuclear fractions with very little nuclear leakage/breakage or cross contamination with other subcellular components such as mitochondria, endoplasmic reticulum, plasma membrane, etc. Flow cytometry analysis indicated cell cycle arrest for both perturbations and no perceptible apoptosis was detected. Fluorescence microscopy and/or Western blotting were used to verify structural integrity of the cells and to confirm the unanticipated subcellular location of selected proteins. ${ }^{9,11}$

For the present study the original MS data from the two experiments were jointly reprocessed under identical conditions against a common UniProt proteome set using MaxQuant ${ }^{18,19}$ and a joint differential network analysis of cross-talk between OXS and OAC was performed. Correlation of the identified peptides across all biological samples detected 4733 distinct proteins. With conservative limits of at least two sequenced peptides and a minimum of three SILAC ratio counts in at least two of the three replicates, 4048 proteins were accepted as adequately quantified. The MS data for this 4048-set of proteins, including all three replicates for both OXS and OAC, is given in Supplementary Table 1. Overall, 48001 SILAC ratios were used in the analyses presented below.

The variation in abundance/location of a substantial number of proteins (401-set, see below) reveals a very complex, intertwined, but tractable set of spatial changes. To aid readers in assimilating the complexity, the following Results Section is divided into five main parts with some introductory sentences, a series of subsections and a brief summary of conclusions for each main section as shown below. We have included a substantial number of subsections to point to the many features and subsystems that are of potential interest to specialist groups. Readers may find it helpful to get an overview of the complexity by first reading section A, the introduction and conclusion sections for sections B-E, and the discussion, and then read those subsections that are of particular relevance to their research interests. Sections 3.2.d, 3.3.a, 3.4.a, and 3.5.a - 3.5.c provide examples of greater depth in key types of analyses.

\subsection{Selection and Classification of the Proteins with the Most Significant Changes.}

3.1.a. Selection of Significant Proteins.

3.1.b. Classification of Proteins with OXS, OAC, SAME, OPPOSITE or MIXED Response.

3.1.c. Trademarks for Oxidative Stress and DNA replication.

3.1.d. Conclusions regarding Significant Proteins.

3.2 Dynamic Behavior of Core Protein Complexes.

3.2.a. The Spliceosome, Proteasome and Ribosome.

3.2.b. Emerin Nuclear Envelope complexes.

3.2.c. The CCT, ATP5 and ATP6 complexes.

3.2.d. Promiscuous proteins and the PCNA nuclear control axis.

3.2.e. Conclusions Regarding Core Protein Complexes.

3.3 Nuclear import/export and vesicle-mediated transport processes.

3.3.a. Clathrin-mediated endocytosis, endosomal-lysosomal sorting, Golgi pathway.

3.3.b. Cytoplasmic vesicles.

3.3.c. Small GTPase mediated signal transduction.

3.3.d. Conclusions regarding transport processes. 


\subsection{Plasma Membrane/Extracellular Matrix - Nucleus Communication.}

3.4.a. Caveolae.

3.4.b. Extracellular matrix proteins.

3.4.c. Other proteins.

3.4.d. Conclusions regarding plasma membrane/ECM - nucleus communication.

3.5 Protein Interaction Networks.

3.5.a. Global Properties of the Functional Interaction Network.

3.5.b. Contributions of Gene Co-expression and Protein-Protein Binding.

3.5.c. An extended PCNA / SET / PTMA / HMOX1 nuclear control axis.

3.5.d. An "orphan" protein-POLDIP2 and Oxidative Stress.

3.5.e. Chaperones and Retrograde Mitochondria to Nucleus Signalling.

3.5.f. Conclusions regarding functional networks.

Note that the samples analyzed correspond to "nucleus" and "nucleus-depleted". At a high level of spatial description, GO uses \{nucleus, cytoplasm, plasma membrane, extracellular region\}. For brevity in the following text and figures, we use nucleus (N) and "cytoplasm" (C) rather than \{cytoplasm, plasma membrane, extracellular region $\}$ (CEP).

\subsection{Selection and Classification of the Proteins with the Most Significant Changes.}

\section{1.a. Selection of Significant Proteins.}

Two general procedures were used to select significant proteins. For Method-1, the MaxQuant Significance B score (SigB hereafter) was used to independently select outlier proteins from each individual experiment (OXS and OAC) using the individual compartmental abundances $\left(S_{n}, S_{c}\right)$ and the mechanisms that produce the changes in compartmental abundance (total abundance changes, $S_{t}$; and redistribution between compartments, $\left.S_{n} / S_{c}\right)$. These selections used the "subcellular spatial razor" methods that we have described in detail previously (Fig. (A,B) ${ }^{9,11}$

In keeping with substantial evidence that there is cross-talk between the cell cycle and oxidative status, ${ }^{1,2,24}$ initial comparison of the OXS and OAC sets of significant proteins identified common proteins that showed strong changes for both cellular perturbations. However, the nature of the cross-talk is complex, as shown by the examples in Fig. 1B. There are proteins with little nuclear-cytoplasmic redistribution but strong changes in total abundance that are the same (FTL) or opposite (COL1A1, RRAS2) for OXS and OAC. Some proteins show strong redistribution with little change in abundance (PCNA), while others show complex mixtures of redistribution and changes in total abundance between OXS and OAC (ACAT1, SET, PYCR1, CALD1). This preliminary comparison hence revealed an important characteristic. Changes in total abundance and in subcellular compartmental distribution are not correlated for a majority of the proteins and both mechanisms contribute strongly to the pattern of changes in local abundance in the nuclear and cytoplasmic compartments that are the basis of cellular response.

For Method-2, proteins with strong similarities or differences between OAC/OXS were selected using "SILAC pairs" (e.g. $S_{n}^{U \times S}, S_{1}^{O A C}$ ) and "joint-spatial-razor" plots (Fig. 1C). This procedure, and the combined use of Method-1 and Method-2, is described in detail in the Supplementary Text. Overall, with restrictive criteria for selection of changes in total abundance $\left(S_{\mathrm{t}}\right)$, nuclear compartment abundance $\left(S_{\mathrm{n}}\right)$, cytoplasmic compartment abundance $\left(S_{\mathrm{c}}\right)$, and nuclear/cytoplasmic redistribution $\left(S_{\mathrm{n}} / S_{\mathrm{c}}\right), 401$ proteins that show the most significant changes for OAC, OXS or both were identified. Supplementary Table 2 summarizes the data for these 401-set proteins. 


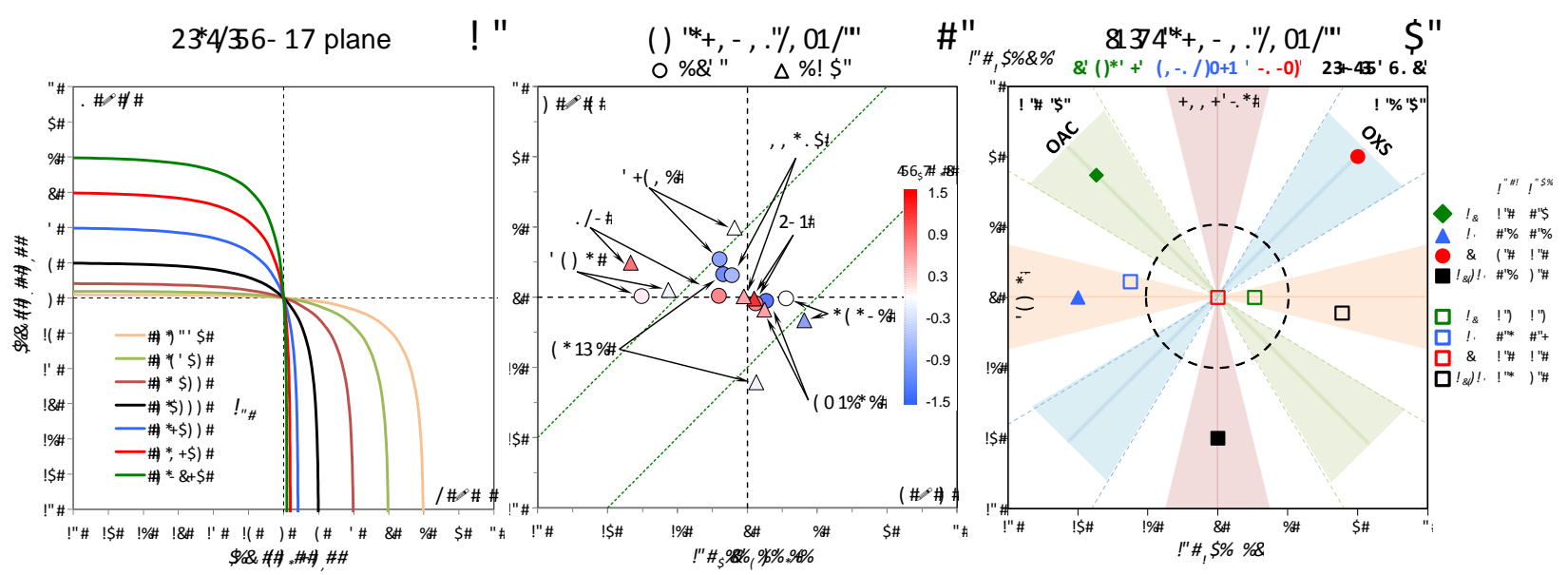

Figure 1. Methods for selection of significant proteins. (A) The theoretical distribution plane $\left\{S_{n} / S_{t}, S_{c} / S_{t}\right\}$ for the subcellular spatial razor. For different values of $f_{u}$ (nuclear fraction of a protein in unstimulated cells), the location in the plane as $f_{s}$ (nuclear fraction of a protein in stimulated cells) varies over $0<f_{s}<1$. The distribution plane is independent of changes in total abundance $\left(S_{t}\right)$ and conservation of mass restricts the data points to the two quadrants for $\mathrm{N} \rightarrow \mathrm{C}$ (nucleus $\rightarrow$ cytoplasm) or $\mathrm{C} \rightarrow \mathrm{N}$ redistribution. (B) 3D subcellular spatial razor plot for selected proteins with strong changes for both OXS and OAC. Changes in subcellular nucleo-cytoplasmic distribution are displayed in the $\left\{S_{n} / S_{t}, S_{c} / S_{t}\right\}$ distribution plane while changes in total abundance are displayed on an orthogonal $S_{t}$ axis that is color-coded according to the scale at the right. The dashed, green lines correspond to $\left|\log _{2}\left(S_{n} / S_{c}\right)\right|=0.8$. For many proteins, changes in total abundance $\left(S_{t}\right)$ and in subcellular distribution $\left(S_{n} / S_{c}\right)$ are not correlated for either OXS or OAC. That is, the changes in compartmental abundance do not simply mirror changes in total abundance (Baqader et al., 2014, Mulvey et al., 2013). (C) Schematic representation of "joint-spatial-razor" plots $\left(S^{O X S} / S^{O A C} v S . S^{O X S} \cdot S^{O A C}\right)$. For a single type of "SILAC pair" such as $\left(S_{n}^{O X S}, S_{n}^{O A C}\right)$, the response to perturbation may be unique to OXS or OAC, SAME or OPPOSITE. SILAC pairs are classified as significant if they lie outside the radial cutoff (dashed circle). For proteins with multiple SILAC pairs $\left(S_{\mathrm{n}}, S_{\mathrm{c}}\right.$, $S_{\mathrm{t}}, S_{\mathrm{n}} / S_{\mathrm{c}}$ ), the combination of basal compartmental distribution with changes in total abundance and distribution may result in only some of the SILAC pairs being accepted as significant. Details of the joint-spatial-razor selection procedure are given in the Supplementary Text and experimental examples are shown in Fig. 2.

\section{1.b. Classification of Proteins with OXS, OAC, SAME, OPPOSITE or MIXED Response.}

For the 401-set proteins, Fig. 2A shows a "joint spatial razor" plot for the 1164 pairs of SILAC ratios quantified in both experiments (average of 2.9 "SILAC pairs" per protein). Some proteins are present in only one of the nucleus/cytoplasm compartments and others show very strong basal skewing of abundance between the two compartments in unperturbed cells. Hence, with the conservative limits on ratio counts/replicates used, all four SILAC pairs $\left(S_{\mathrm{n}}, S_{\mathrm{c}}, S_{\mathrm{t}}\right.$, $\left.S_{\mathrm{n}} / S_{\mathrm{c}}\right)$ were obtained for 192 proteins, 2-3 SILAC pairs for 184 proteins and 1 SILAC pair $\left(S_{t}\right)$ for 25 proteins. A total of 876 SILAC pairs (average of 2.2 per protein) were classified as significant using the selection procedure described in the Supplementary Text. These significant SILAC pairs were assigned to one of four regions in the joint spatial razor plot (OXS, OAC, SAME, OPPOSITE, Fig. 2B,C).

Each protein was then classified according to the (up to four) SILAC pairs for the protein $\left(S_{\mathrm{n}}\right.$, $\left.S_{\mathrm{c}}, S_{\mathrm{t}}, S_{\mathrm{n}} / S_{\mathrm{c}}\right)$. For example, for Complement component 1Q subcomponent-binding protein (C1QBP), Fig. 2E shows that two significant SILAC pairs $\left(S_{\mathrm{c}}, S_{\mathrm{n}} / S_{\mathrm{c}}\right)$ lie in the OAC-dominant region and two $\left(S_{\mathrm{n}}, S_{\mathrm{t}}\right)$ lie in the region near the origin, i.e. no change classified as significant was observed in the nuclear compartment or in total abundance in either experiment. The dominant change for $\mathrm{C} 1 \mathrm{QBP}$ is $\mathrm{N} \rightarrow \mathrm{C}$ (nucleus $\rightarrow$ cytoplasm) redistribution for $\mathrm{OAC}$ that leads to a substantial increase in cytoplasmic abundance. The projections of the points in the joint spatial razor plot onto the OAC and OXS axes are, of course, the actual SILAC ratios for each individual experiment. The magnitudes of these for C1QBP are shown in the table inset in Fig. 2. Based on their behaviour, C1QBP and Serine hydroxymethyltransferase (SHMT2) were 


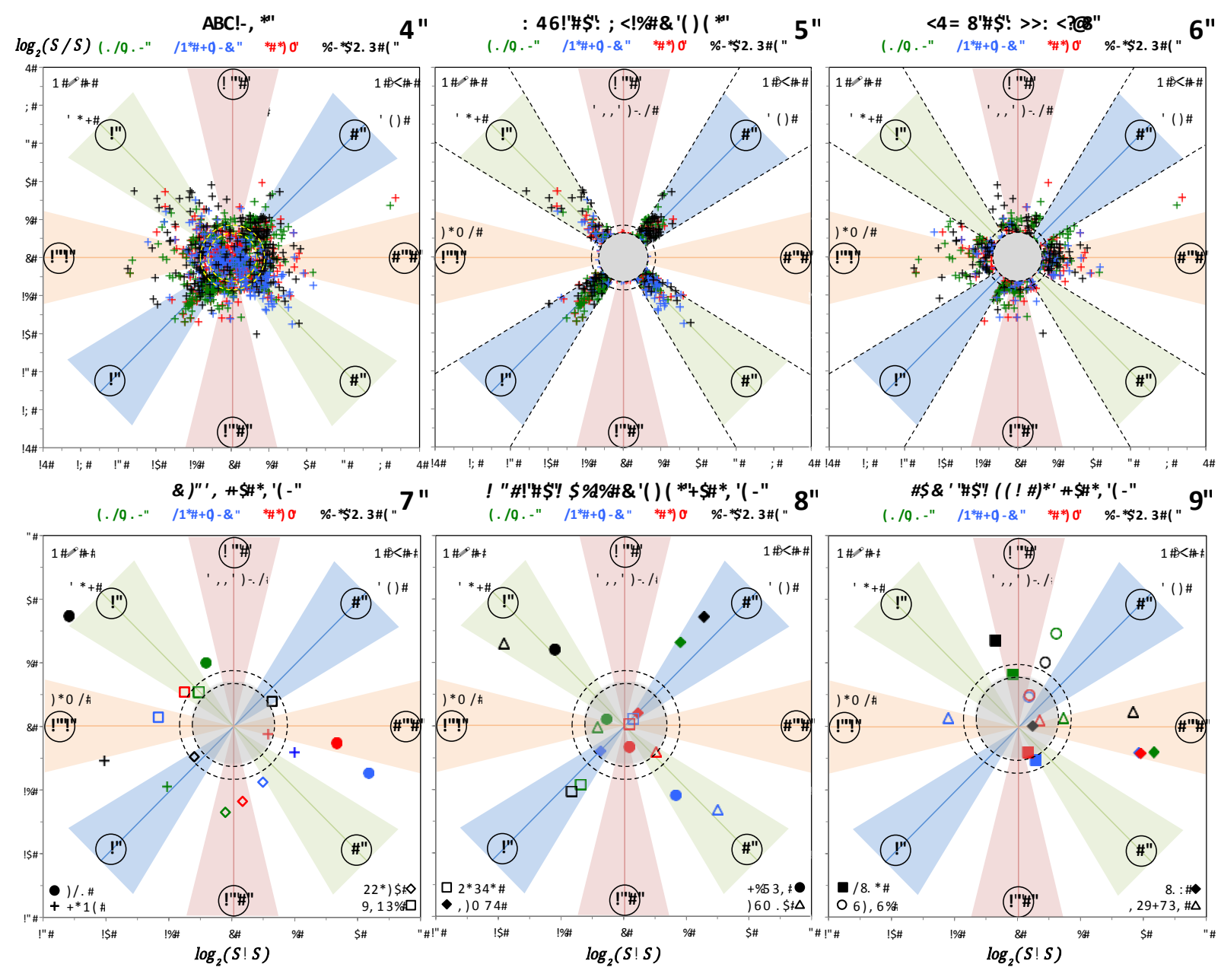

\begin{tabular}{|c|c|c|c|c|c|c|c|c|c|c|c|c|}
\hline \multirow[b]{2}{*}{4585} & \multirow[b]{2}{*}{$<="(5: 8 \% ; @ 5$} & \multirow[b]{2}{*}{ Al; $\gg$} & \multirow[b]{2}{*}{46 \%:" !" \#:' ; !\%=" ' 5>\$\% ; @5 } & \multirow[b]{2}{*}{$46 \%$} & \multicolumn{4}{|c|}{$9 \$ M^{2}$} & \multicolumn{4}{|c|}{$9 "$ !? } \\
\hline & & & & & $! " \#_{5} \%$ & "! "\#s\% & \%!"\#落 & !" \#\$ & !"\#s\% & !"\#落\% & $6 ! " \#_{5} \%$ & $6 ! " \# \$$ \\
\hline !"\#\$ & $! \%()^{*}$ &,$+ \$-$. & $\% / \%$ ( ' D345( 66* 0P\% 7D3( G/ ' /\%*4' & $89: ; ;<=>>?$ & )$_{+}^{*}$ & ; $(0=$ & ;@A & $1-\$$. & B @C & $*_{t}^{*} *$ & ; & $1 *+10$ \\
\hline LL" $\$$ & 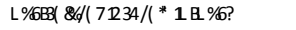 &,$+ \$-$. & 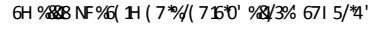 & $89: ; ; ;$ O?KC & $1 *+3$ & B @= & $1^{*}+1^{*}$ & )$^{*}+10$ & ${ }^{*}+2 \$$ & ${ }^{*}+2$ & $*+2 /$ & B @K \\
\hline$M N$ & ,64P43H P 1 PF $34 / /^{*}$ MN N &,$+ \$-$ & 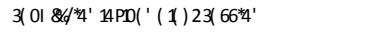 & $89: ; ;<; C K>$ & ; & $*+\$$ & $*^{*} 7^{*}$ & B @A & )$^{*}+y^{*}$ & -+02 & $*_{+} /$/ & $1 \$+2$ \\
\hline ! <QGF & 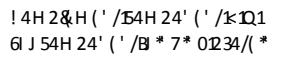 & $9 " !$ & 'H H I ' (B) 624' 6) & $89: ; ; ; K=D D$ & B @> & $B$ B @A & B @A & ; @D & B @ $@=$ & ${ }^{*}+2$ & ; @< & $1+1$ \\
\hline L" GD" & L\%BS( \&d 7 D34/( * 1\% B" & $9 \$ M$ & 3/5(2/43日 ( 7\%///71' 745T/46' & $89: ; ; ; K>=>$ & $*^{*_{t}-}$ & ; @A & ; @K & $1 *+0$ & ; @? & ; @? & ; @A & ; @; \\
\hline vaw & $\mathrm{V}\left(33^{*}{ }^{*} 180 \mathrm{~S} / \mathrm{BS} \%{ }^{*}\right.$ & $M+-$ & '34' 仵' $54 \mathrm{H}(46 / \% 6$ & $89: ; ;$ DD; O? & $*_{+}$ & $*+1$ & ${ }^{*}+2$ & ; @? & $-\$$ & -+1 & -+ & ; @? \\
\hline FLE! . GF & 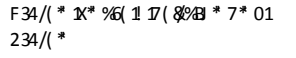 & $M+-$ & & & ; (1)A & )$^{*} \mathbf{2}^{*}$ & ;@? & $-+^{*} 3$ & ; ; & )$^{*}+1^{*}$ & ; @A & ${ }^{*_{t}} *$ \\
\hline$-M^{\prime \prime}$ & 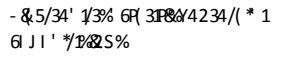 & $9 \mathrm{FF} 9 \mathrm{M}, \mathbb{N}$ & $3 / 62$ 3\%/44311 \&5/34' 1/3\% 6243/5S\%* & $89: ; ; ? ?=; C$ & ; & B @? & В @? & ${ }^{*}+0$, & $1^{*}+00$ & ;@< & ;@= & )$^{*}+1$ \\
\hline
\end{tabular}

Figure 2. Assignment of significant proteins to behavior classes. (A) Joint spatial razor plots $\left(S^{O X S} / S^{O A C} v s . S^{O X S} \cdot S^{O A C}\right)$ for 401 -set proteins that have pairs of the same SILAC ratio $\left(S_{\mathrm{n}}, S_{\mathrm{c}}, S_{\mathrm{t}}\right.$, or $\left.S_{\mathrm{n}} / S_{\mathrm{c}}\right)$ quantified in both experiments and have at least one SILAC pair with one or both of the SILAC ratios in the pair significant in OXS/OAC. SILAC pairs with radius greater than the outer dashed circle are strongly significant and SILAC pairs within the inner dashed circle were not considered significant for assignment to a class (see the Supplementary Text for details of the selection/classification procedures). The circled + and - symbols denote increases/decreases in abundance $\left(S_{n}, S_{c}, S_{t}\right)$ or $\mathrm{C} \rightarrow \mathrm{N} / \mathrm{N} \rightarrow \mathrm{C}$ redistribution $\left(S_{n} / S_{c}\right)$ respectively. (B) Assignment of significant SILAC pairs to OXS-dominant and OAC-dominant regions. The angular aperture of the colored slices for OXS/OAC corresponds to a $\geq$ four-fold ratio in the magnitude of $\left|\log _{2}(S)\right|$ between the OXS and OAC SILAC ratios of a pair. The two regions define two sets of data points that are strongly disjoint. (C) Assignment of SILAC pairs to SAME and OPPOSITE regions, where the response trend between OXS/OAC is similar or opposed, but of varying magnitude. (D-F) Examples of the classification of proteins according to the distribution of their SILAC pairs over the four regions defined in B and C. (E) Proteins with all significant SILAC pairs in the OXS-dominant or OAC-dominant regions. (F) Proteins with all significant SILAC pairs in the SAME or OPPOSITE regions. (D) Proteins that show MIXED behavior and have significant SILAC pairs in more than one of the four regions. Table. Numerical data for the proteins shown in (D-F). Details of the classification procedure are given in the Supplementary Text. A summary of data for all 401 significant proteins is given in Supplementary Table 2, which also includes an interactive plot for selection of individual proteins or of defined subsets of proteins. 
assigned to the OAC set of proteins, i.e. proteins that showed significant changes predominantly for cell cycle arrest at the origin activation checkpoint. Similarly, 26S proteasome non-ATPase regulatory subunit 5 (PSMD5) and RAB5A were assigned to the OXS set of proteins (Fig. 2E), Protein kinase C delta-binding protein (PRKCDBP) and Ferritin light chain (FTL) were assigned to the SAME set of proteins, and electron transfer flavoprotein subunit A (EFTA) and heat shock protein 105kDa (HSPH1) were assigned to the OPPOSITE set of proteins (Fig. 2F). Note that for the OAC, OXS, SAME and OPPOSITE sets of proteins, changes both in total abundance $\left(S_{\mathrm{t}}\right)$ and in redistribution $\left(S_{\mathrm{n}} / S_{\mathrm{c}}\right)$ contribute to the compartmental changes in abundance $\left(S_{\mathrm{n}}\right.$ and $\left.S_{\mathrm{c}}\right)$. Overall, there were 89, 67, 87 and 61 proteins in the OXS, OAC, SAME and OPPOSITE sets. In fact, the combination of two mechanisms (changes in total abundance, compartmental redistribution) and two compartments (nuclear, cytoplasmic), together with different skewing for different proteins of the basal distribution between the two compartments in unperturbed cells, led to more complex behaviour for 97 proteins (the MIXED set, Fig. 2D). For example, Protein SET shows a substantial increase in total abundance for OAC and OXS, but strong $\mathrm{N} \rightarrow \mathrm{C}$ redistribution predominantly for OAC. This results in strong increase in cytoplasmic abundance for both OAC/OXS, but strong decrease/moderate increase in nuclear abundance for OAC/OXS.

Overall the data shows that a majority of proteins (245/401) show substantial changes for both OXS and OAC. Only a minority of proteins were more specific to OAC (67) or to OXS (89). Changes in total abundance and in nuclear/cytoplasmic distribution both contribute to significant changes in nuclear or cytoplasmic abundance and both are crucial in the intertwining of the responses to the two perturbations. Many proteins achieve significant changes in nuclear and/or cytoplasmic compartmental abundance through a combination of these two mechanisms. The identity of all proteins assigned to each response class is shown in Supplementary Table 2 (filter: CLASS = OAC, OXS, SAME, OPPOSITE, or MIXED).

Finally, although 401 proteins show changes of varying amplitudes, only 49 proteins within the 401-set were classified as showing strong changes for both of OAC/OXS (Supplementary Table 2, filter: SELECTION = OAC;OXS;RADIAL). This group of proteins, referred to as the 49-set hereafter, suggests that cross-talk between OAC and OXS may be dominated by a relatively small set of crucial proteins (see below).

\section{1.c. Trademarks for oxidative stress and DNA replication.}

"Guilt by association" strategies to predict gene function from multiple, large sets of correlations in transcript/protein expression, or to identify genes characteristic for complex diseases from large population studies of mutations, often run into problems with so-called "multi-functional" proteins. ${ }^{25-28}$ Our hypothesis is that such proteins tend to correspond to core cellular processes such as control of oxidative state or of cell cycle state. Furthermore, we hypothesize that these core processes can be ubiquitously engaged/affected to greater or lesser degree in response to a plethora of more specific perturbations, e.g. exposure to a hormone or a pharmaceutical, or to specific mutational changes. If so, defined "trademarks" that are specific for core cellular processes could aid in factoring out core responses ("multi-functional" proteins) and be helpful in the discovery of the crucial changes characteristic of more specific cellular perturbations. 
Figure 3 shows a heat map of the changes observed for the disjoint sets of proteins assigned to the classes OXS, SAME and OAC. The strong orthogonality of the OXS and OAC sets is consistent with their use as trademarks. Evidence for the relevance of this type of unbiased screening is exemplified by the enzymes of the glycolytic cascade, where the two isoforms of hexose kinase (HK1, OXS; HK2, OAC) show different features that seem to complement known roles of these proteins in determining the metabolic fate of glucose and in the metabolism of cancer cells (Supplementary Figure S-1).

For the 97 proteins in the SAME class, there is substantial similarity between OAC and OXS. For all four parameters $\left(S_{n}, S_{c}, S_{t}, S_{n} / S_{c}\right)$ there is

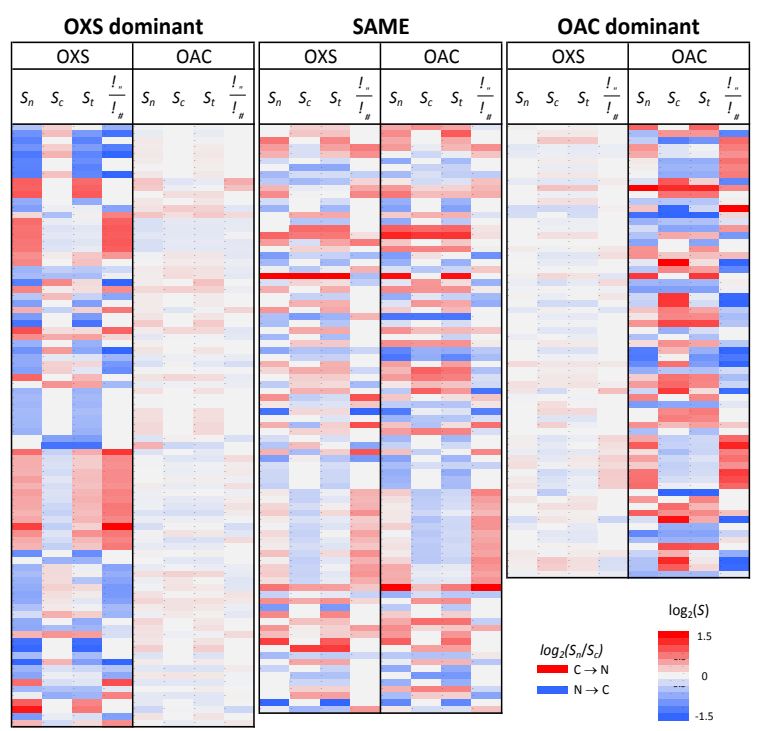

Figure 3. Heat maps for $S_{\mathrm{n}}, S_{\mathrm{c}}, S_{\mathrm{t}}$ and $S_{\mathrm{n}} / S_{\mathrm{c}}$ ordered top to bottom by gene name for the disjoint sets of proteins assigned to the OXS, SAME and OAC classes $(89,87,67$ proteins). Identities are given in Supplementary Table 2.

a reasonably high degree of correlation $\left(0.61<\mathrm{R}^{2}<0.75\right)$ with slopes $\sim 1$ (Supplementary Figure S-2). This indicates similar response to OXS and OAC in both direction and magnitude in the network of these proteins and is further evidence for strong intertwining of the OXS and OAC processes. The possible uses of such "trademarks" are considered further in the Discussion.

\section{1.d. Conclusions regarding Significant Proteins.}

Although both OXS and OAC are strong perturbations that cause cell cycle arrest, the 401-set of significant proteins indicates that only about $5 \%$ of all proteins show appreciable changes in compartmental abundances for either perturbation. Changes for total abundance $\left(S_{t}\right)$ and for distribution $\left(S_{n} / S_{c}\right)$ both contribute to significant changes in compartmental abundance $\left(S_{n}\right.$ and/or $S_{c}$ ) for many proteins. Oxidative stress and suppression of DNA replication at the origin activation checkpoint are strongly intertwined. For the 401-set of significant proteins, appreciable changes for both perturbations were observed for 245 proteins and only 89/67 proteins were more specific to OXS/OAC respectively. Only about 1-2\% of proteins (49-set) show strong changes in abundance and/or distribution for both OXS and OAC. That is, changes in relatively small numbers of proteins may dominate spatial coordination of function across cells.

\subsection{Dynamic Behaviour of Core Protein Complexes.}

We began the search for subsystem networks in cellular response to OAC/OXS by examination of the 1846 (partially redundant) curated and experimentally verified human protein complexes with well-defined functional context that are compiled in the CORUM database. ${ }^{15}$ Our experiments monitored 797 proteins included in at least one CORUM protein complex. For the 401-set, 196 proteins were part of 381 CORUM complexes. Supplementary Table 3 shows these 381 complexes and the monitored/significant proteins. 
We focussed on the 49-set of proteins that showed strong changes for both OAC and OXS. There were 65 CORUM complexes that included one or more of the 49-set proteins. They include 447 unique proteins, of which 355 were monitored in the experimental 4048-set and 19/74 proteins were in the 49-set/401-set of proteins with significant changes. Construction of an $r=1$ overlap matrix to test for the inclusion of proteins in multiple complexes (Supplementary Figure S-3) indicated that the proteins partition to 16 groups of complexes (Table 1). Apart from complexes associated with ribosomes and ribosome biogenesis, there was only very limited overlap of proteins between different groups (Supplementary Figure S-3). Notable is that for both OAC and Table 1. Partitioning of 49-set proteins over 65 CORUM complexes

\begin{tabular}{|c|c|c|c|c|}
\hline Group & CONTEXT & number $^{1}$ & $\begin{array}{c}\text { significant changes }^{2} \\
\text { 49-set } 401-\text { set }\end{array}$ & $\begin{array}{c}\text { type } \\
\text { 49-set }\end{array}$ \\
\hline 1 & $\begin{array}{l}\text { collagen, integrin, } \\
\text { plasma membrane }\end{array}$ & $9,14,6$ & COL1A1 ITGA5 ITGB1 & $\begin{array}{l}\text { MIXED, } \\
\text { SAME }\end{array}$ \\
\hline 2 & ECM, TGFB1 signalling & $2,5,3$ & MMP14 & SAME \\
\hline 3 & Hox7 transcription & $1,8,2$ & TGFBI & SAME \\
\hline 4 & iron homeostasis & $1,4,4$ & TFRC & SAME \\
\hline 5 & growth factor signallng & $1,3,2$ & GNB2L1 & MIXED \\
\hline 6 & cell adhesion & $1,4,3$ & CTNNA1 CTNNB1 SDCBP & SAME \\
\hline 7 & $\begin{array}{l}\text { POLR2A transcription; HES1 } \\
\text { repression; mRNA maturation }\end{array}$ & $7,28,22$ & FUS HNRNPU HSPA4 NCL NPM1 & MIXED \\
\hline 8 & spliceosome; mRNA decay & $\begin{array}{c}5,180 \\
161\end{array}$ & $\begin{array}{c}\text { HIST1H4A HNRNPF HNRNPK } \\
\text { HNRNPU IGF2BP3 NPM1 NUDT21 } \\
\text { PABPC1 SRRM2 SSB U2AF1 }\end{array}$ & $\begin{array}{l}\text { MIXED, } \\
\text { MIXED }\end{array}$ \\
\hline 9 & $\begin{array}{l}\text { DNA replication; DNA repair; } \\
\text { DNA methylation; cell cycle }\end{array}$ & $27,50,22$ & $\begin{array}{c}\text { DNMT1 PCNA RFC2 RFC3 RFC4 RFC5 } \\
\text { XRCC5 XRCC6 }\end{array}$ & SAME \\
\hline 10 & nuclear envelope & $1,16,14$ & G3BP1 HNRNPK LMNB1 SSB & MIXED \\
\hline 11 & transcriptional activation & $1,2,2$ & SET & MIXED \\
\hline 12 & nuclear protein transport & $1,3,3$ & KPNB1 & MIXED \\
\hline 13 & ribosome biogeneisis & $3,107,90$ & $\begin{array}{l}\text { C1QBP DDX21 H1FX HNRNPU } \\
\text { IGF2BP1 LUC7L2 NCL NPM1 PRMT1 } \\
\text { RPL11 RPL12 RPL13 RPL13A RPL15 } \\
\text { RPL17 RPL18 RPL19 RPL21 RPL22 } \\
\text { RPL27A RPL29 RPL30 RPL35A RPL6 } \\
\text { RPL9 RPLP0 RPLP2 RPS17 RPS2 } \\
\text { TUFM U2AF1 YBX1 }\end{array}$ & $\begin{array}{l}\text { MIXED. } \\
\text { MIXED, } \\
\text { SAME, } \\
\text { MIXED }\end{array}$ \\
\hline 14 & ribosome & $3,81,73$ & $\begin{array}{l}\text { RPL11 RPL12 RPL13 RPL13A RPL15 } \\
\text { RPL17 RPL18 RPL19 RPL21 RPL22 } \\
\text { RPL27A RPL29 RPL30 RPL34 RPL35A } \\
\text { RPL6 RPL9 RPLP0 RPLP2 RPS10 } \\
\text { RPS17 RPS2 RPS27A RPS3 RPS4X }\end{array}$ & $\begin{array}{l}\text { MIXED, } \\
\text { SAME }\end{array}$ \\
\hline 15 & $\begin{array}{l}\text { TNF alpha / NF kappa B } \\
\text { signalling complex }\end{array}$ & $1,25,13$ & KPNA2 & SAME \\
\hline 16 & iron storage, mitochondria & $1,7,5$ & ATP5L HSPA9 HSPD1 SDHA & MIXED \\
\hline
\end{tabular}

OXS the cellular response seems to include a wide variety of different processes and of different subcellular organelles/locations.

\section{2.a. The Splicesome, Proteasome and Ribosomes.}

Table 1 includes large, core complexes such as the spliceosome, proteasomes and ribosomes. Extensive coverage was obtained for the spliceosome (133/143 proteins quantified for both OXS and OAC), ribosomes (73/81) and the proteasome (38/40), and each had some proteins included in the 401-set. Figure 4 shows the behaviour of proteins from these complexes.

For the spliceosome, 129 of 133 proteins showed very modest changes for both OXS and OAC with no significant change in abundance in either the nuclear or cytoplasmic compartments (Fig. 4). Over these 129 proteins, the average changes in SILAC ratios $\left(S_{n}, S_{c}, S_{t}\right.$ and $\left.S_{n} / S_{c}\right)$ were $(1.07,0.94,1.07,1.14)$ for OXS and $(0.92,0.97,0.94,0.92)$ for OAC. Only four proteins showed significant changes in compartmental abundance. Various types of changes that may represent regulation of the spliceosome or signalling to other subcellular locations about spliceosome function were observed for Serine/arginine repetitive matrix protein 2 (SSRM2, classified as OPPOSITE), Polyadenylate-binding protein 1 (PABPC1, MIXED), Insulin-like growth factor 2 mRNA-binding protein 3 (IGF2BP3, MIXED), and Cleavage and polyadenylation specificity factor subunit 5 (NUDT21, OAC). The spliceosome is grouped with complexes involved in mRNA decay in Table 1 and other proteins such as SSB were 


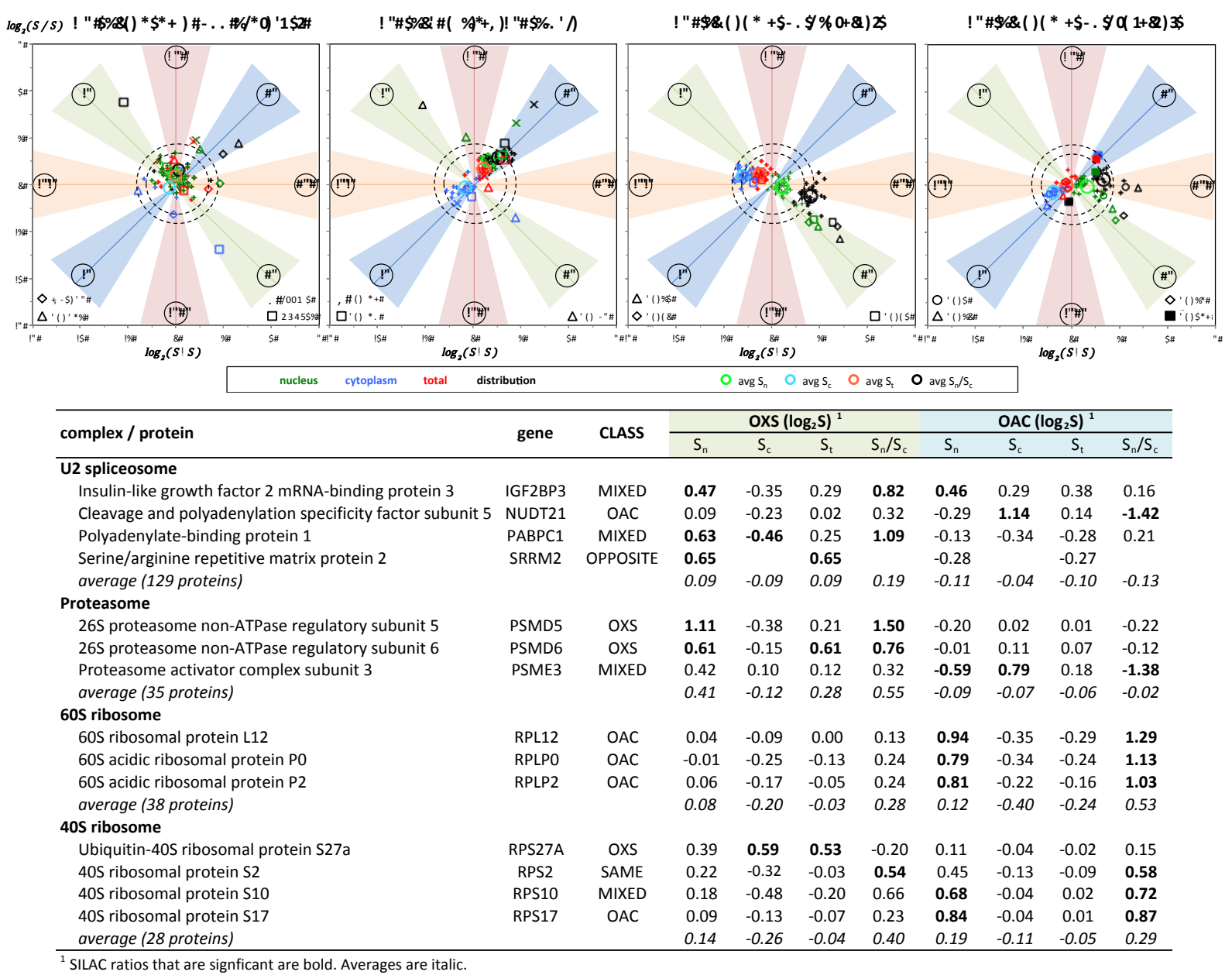

Figure 4. Joint spatial razor plots and numerical data for proteins included in the spliceosome, proteasomes and cytoplasmic ribosomes. Outlier proteins had significant changes in the nuclear and/or cytoplasmic compartments.

included in CORUM complexes with overlapping sets of proteins that are associated with mRNA decay. That is, there are indications for cross-talk between mRNA processing/decay in response to OXS/OAC.

A similar pattern was observed for ribosomes. The only outlier for OXS was RPS27A, which showed appreciable increase in total, nuclear and cytoplasmic abundance. RPS27A has been shown to interact with the MDM2/p53 signaling system involved in response to ribosomal stress by binding to MDM2, suppressing MDM2-mediated p53 ubiquitination and degradation, leading to p53 activation and cell cycle arrest. ${ }^{29}$ RPS27A is synthesized as an ubiquitin-S27a fusion protein precursor from which ubiquitin is released. There is evidence that the monoubiquitin component released from RPS27a is not important for the MDM2/p53 signaling system and has other functions that seem to involve the nuclear envelope. ${ }^{29,30}$ RPS27a apparently binds to a different domain of MDM2 than some other ribosomal proteins, ${ }^{29}$ suggesting these effects might be parallel or alternative to well-studied effects of ribosomal/nucleolar stress proteins such as RPL5 or RPL11. ${ }^{31}$ The possible connections to oxidative stress revealed by the increase in nuclear RPS27A (Fig. 4) have been little researched, but we note that no indications for apoptosis or for caspase activation were perceptible under the conditions used for the OXS experiment. ${ }^{11}$

The OAC data also seems to reveal new features related to ribosomes. The large ribosomal subunit and small subunit each had three clear outlier proteins (RPL12, RPLP0, RPLP2, RPS2, RPS10, RPS17) that showed substantial increase in nuclear abundance for OAC. These proteins have not been identified in studies of p53-related ribosomal stress. A recent review of 51 
ribosomal proteins with reported functions outside of ribosomes only included that RPS10 and RPS17 have been correlated with Diamond-Blackfan anemia ribosomopathies ${ }^{32}$ that involve erythroid precursor failure. ${ }^{33} \mathrm{We}$ note that nucleophosmin (NPM1) has been connected to certain aspects of ribosomal stress, ${ }^{32}$ is included in the 401 -set and shows a parallel increase in nuclear abundance for OAC. These proteins seem to represent a previously unknown response to arrest of DNA replication that might be related to other ribosomal/nucleolar stress or ribosomal biogenesis pathways that are being identified in mammals, ${ }^{33}$ where there are also indications of appreciable differences to model systems such as yeast. ${ }^{34}$

For both OXS and OAC there was a trend of moderate average decrease in cytoplasmic ribosomal abundance that resulted in the inclusion of 18 other ribosomal proteins in the 401-set (Table 1). An interesting feature was that the average decrease in cytoplasmic abundance of the large $\left(\bar{S}_{\bar{L}}^{U X . i}=0.87\right)$ and small $\left(\bar{S}_{\bar{L}}^{U X . i}=0.83\right)$ ribosomal subunits changed in parallel for OXS, but decreased more strongly for the large subunit $\left(\bar{S}_{c}^{\text {Uat: }}=0.76\right)$ than for the small subunit $\left(\bar{S}_{c}^{U \times S}=0.93\right)$ for OAC (Figure 4). There was considerable overlap of 401-set proteins between ribosomes and ribosomal biogenesis (Table 1, Supplementary Figure S-3). Analysis of the Nop56p complex (96/104 proteins quantified for both OXS/OAC) and of proteins in FIBassociated complexes (3/6) identified 13 proteins with appreciable changes (Supplementary Figure S-4) that suggest possible differences in ribosome biogenesis between OXS and OAC that may contribute to the balance of large/small ribosomal subunits. These included RPLP0, RPLP2 and RPS17 noted above as well as the DDX21 RNA helicase that has recently been suggested to be required for association of late-acting snoRNPs with human pre-ribosomal complexes. ${ }^{35}$

Of the 38 proteins monitored for proteasomes, 35 had similar changes in nuclear or cytoplasmic abundance (Fig. 4). These showed a slight increase in total abundance and modest $\mathrm{C} \rightarrow \mathrm{N}$ redistribution that slightly increased average nuclear abundance for OXS only $\left(\bar{S}_{n}^{u \times s}=1.33\right)$ and resulted in inclusion of 16 proteasomal proteins in the 401-set. Three proteins showed different behaviour. 26S proteasome non-ATPase regulatory subunits 5 and 6 (PSMD5, PSMD6) had more substantially increased nuclear abundance for OXS only. Proteasome activator complex subunit 3 (PSME3, MIXED) showed very strong $\mathrm{N} \rightarrow \mathrm{C}$ redistribution for OAC that strongly increased its cytoplasmic abundance and reduced substantially its nuclear abundance, leading to a 2.6-fold change in its nuclear/cytoplasmic distribution. Note that the proteasome is not included in Table 1. That is, proteasomal response to OXS/OAC seems to be largely orthogonal and not to include strong cross-talk (Fig. 4).

A general feature for these large core complexes was that most component proteins exhibited at most limited changes, leading to modest average changes for the complex, which may nonetheless be functionally important. The significant changes in limited numbers of outlier proteins could be consistent with regulation of the activity of the large complex by specific proteins, e.g. changes in PSME3 and PSMD5,6 may differentially regulate proteasomal activity in the cytoplasm/nucleus. Alternatively, redistribution could involve transmission of selective messages about the level of functional activity of the complex to other subcellular locations/processes, e.g. the redistribution of spliceosomal NUDT21 to the cytoplasm for OAC. Of the 235 proteins monitored for spliceosomes, proteasomes and ribosomes, 13 showed significant changes in nuclear or cytoplasmic abundance. Mechanistically, these changes were dominated by redistribution between compartments for 9 proteins, change in total abundance 
for 2 proteins, and by a combination of both for 2 proteins, i.e. subcellular redistribution was more prominent than changes in total abundance.

\section{2.b. Emerin Nuclear Envelope Complexes}

Table 1 contains one group of proteins assigned to an emerin complex that provides an example of a different pattern for participation of complexes in cellular response. The nine different emerin complexes included in CORUM include 59 proteins that are involved in nuclear envelope interactions. There was essentially no change in the total $\left(S_{t}=0.97 / 1.05\right.$ for $\mathrm{OXS} / \mathrm{OAC}$ ) or compartmental abundance of emerin. However, of the 44 monitored proteins, 8 showed significant changes. The sets of proteins included in the different emerin complexes are partially overlapping, but further analysis (Supplementary Figure S-5) indicated that the predominant changes are in the three emerin complexes 24, 25 and 52. Emerin complex 24, which includes DNA replication licensing factors MCM2,4,6, shows proteins with significant changes only for OAC. Emerin complexes 25 and 52 appear to have crosstalk between OXS and OAC mediated by IQGAP1 and SSB. However, rebalancing of the relative abundance of the three complexes as a consequence of changes in total abundance and distribution of individual proteins could result in functional intertwining of all three complexes.

\section{2.c. The CCT, ATP5 and ATP6 Complexes}

The selective variation of small numbers of component proteins in the above complexes is in contrast to a few complexes for which the changes encompassed all or most proteins in the complex. For example, all eight subunits of the CCT protein-folding complex showed strong C $\rightarrow \mathrm{N}$ redistribution solely for OXS that strongly increased their nuclear abundance with little or no change in total abundance (Supplementary Figure S-6). This was associated with strong increase in total and nuclear abundance for Ubiquitin-associated protein 2-like (UBAP2L), which is involved in membrane fusion processes with the CCT complex. Similarly many subunits of ATP synthase (ATP5) showed strongly decreased nuclear abundance only for OXS. For the human V-type ATPase (ATP6) complex, one subunit (ATP6V0D1) was included in the 49-set. An increase in nuclear abundance, mediated both by increases in total abundance and by $\mathrm{C} \rightarrow \mathrm{N}$ redistribution was observed for many subunits of $\mathrm{V}$-type ATPase for both OXS/OAC, with indications that differential behaviour of the V0 and V1 subcomplexes may contribute to differential cross-talk between OAC/OXS (Supplementary Figure S-6).

\section{2.d. Promiscuous Proteins and the PCNA Nuclear Control Axes.}

A general property of the complexes compiled in CORUM is that there are some proteins that are shared between many different complexes (Table 2). For example, CORUM includes 27 different complexes for PCNA (Table 1). In other cases proteins of the same type combine in many different ways, e.g. integrins and collagens. The present evidence suggests that such proteins may be dynamically involved in multiple, different complexes in response to cellular perturbations and that redistribution

\begin{tabular}{|c|c|c|c|c|c|c|}
\hline \multirow{3}{*}{$\begin{array}{c}\text { proteins } \\
\text { number } \\
\text { complexes }\end{array}$} & \multirow{2}{*}{\multicolumn{2}{|c|}{$\begin{array}{c}\text { CORUM } \\
1176\end{array}$}} & \multirow{2}{*}{\multicolumn{2}{|c|}{$\begin{array}{c}\text { 4048-set } \\
797\end{array}$}} & \multirow{2}{*}{\multicolumn{2}{|c|}{$\begin{array}{c}\text { 401-set } \\
196\end{array}$}} \\
\hline & & & & & & \\
\hline & $\begin{array}{l}\text { number } \\
\text { proteins }\end{array}$ & $\%$ & $\begin{array}{l}\text { number } \\
\text { proteins }\end{array}$ & $\%$ & $\begin{array}{l}\text { number } \\
\text { proteins }\end{array}$ & $\%$ \\
\hline 1 & 330 & 28.1 & 203 & 25.5 & 65 & 33.2 \\
\hline 2 & 281 & 23.9 & 198 & 24.8 & 47 & 24.0 \\
\hline 3 & 142 & 12.1 & 96 & 12.0 & 28 & 14.3 \\
\hline 4 & 103 & 8.8 & 85 & 10.7 & 20 & 10.2 \\
\hline 5 & 79 & 6.7 & 56 & 7.0 & 11 & 5.6 \\
\hline 6 & 53 & 4.5 & 34 & 4.3 & 6 & 3.1 \\
\hline 7 & 21 & 1.8 & 11 & 1.4 & 0 & 0.0 \\
\hline 8 & 28 & 2.4 & 17 & 2.1 & 4 & 2.0 \\
\hline$>8$ & 139 & 11.8 & 97 & 12.2 & 15 & 7.7 \\
\hline \multirow{2}{*}{ average } & \multicolumn{6}{|c|}{ number complexes / protein } \\
\hline & 4.4 & & 4.6 & & 3.8 & \\
\hline
\end{tabular}
over such groups of complexes may provide dynamic cellular control axes. 
For PCNA (Table 1, 49-set), the $r=1$

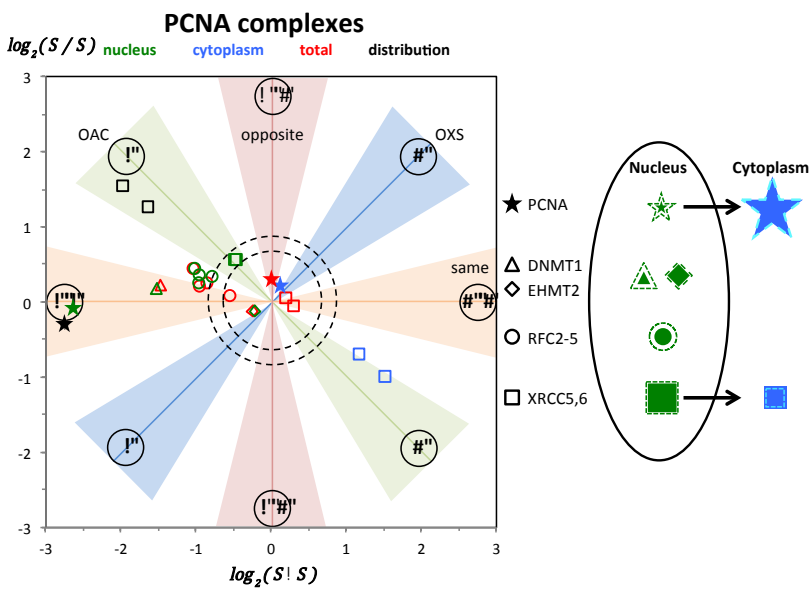
overlap matrix included components of three key PCNA complexes: \{PCNA, RFC2-5 $\},\{$ PCNA, XRCC5,6 $\}$ and PPCNA, DNMT1, EHMT2\}, all of which except EHMT2 were included in the 401-set. Variation of the proteins in these complexes contributes to both the OXS and OAC response networks (Fig. 5). For example, for PCNA the dominant feature for both OXS and $\mathrm{OAC}$ is strongly reduced nuclear abundance occasioned by strong $\mathrm{N} \rightarrow \mathrm{C}$ translocation, with little change in total or cytoplasmic abundance. For the complex \{PCNA, RFC2-5\}, which is intimately involved in DNA replication, ${ }^{36-38}$ all four RFC proteins also decrease in nuclear abundance for both OAC and OXS (more strongly for $\mathrm{OAC}$ ), but this is a consequence of decreased total RFC2-5 protein abundance. For the complex \{PCNA, DNMT1, EHMT2\}, which is involved in chromatin replication and methylation of both DNA and histones, ${ }^{39}$ DNMT1 nuclear/total abundance decreases strongly,

Fig. 5. Changes in total and compartmental abundance for protein complexes containing PCNA. Left. Joint spatial razor plot for the constituent proteins of three complexes: (PCNA, RFC2-5), (PCNA, DNMT1, EHMT2) and (PCNA, XRCC5,6). Right. Cartoon of the changes in abundance relative to basal abundance for the nuclear and cytoplasmic compartments. The relative size of the dotted (basal) and solid (perturbed) symbols denotes the direction of the change in abundance in each compartment for the individual proteins (symbol sizes between different proteins are not meaningful). The arrows indicate the direction of compartmental redistribution. RFC2-5, DNMT1 and EHMT2 were detected only in the nuclear compartment. For PCNA and XRCC5,6 the size of the symbols is an approximate indication of the ratio of the protein abundance in the two compartments, e.g. the data is consistent with a basal distribution of PCNA strongly skewed to the cytoplasmic compartment. The small proportion of PCNA in the nuclear compartment is strongly reduced for both OXS and OAC.

but no evidence of change for EHMT2 was

detected (with a small number of SILAC counts). The decreased nuclear abundance for the components of these two complexes is consistent with decreased DNA replication and cell cycle arrest for both OXS and OAC. Finally, for the \{PCNA, XRCC5,6\} complex, which is based on colocalization at sites of DNA damage ${ }^{40}$ and might be indirect, there is a modest decrease/strong increase in the nuclear/cytoplasmic compartmental abundance of XRCC5,6 only for $\mathrm{OAC}$ as a consequence of strong $\mathrm{N} \rightarrow \mathrm{C}$ redistribution. That is, for this complex all changes in nuclear abundance are dominated by redistribution without significant changes in total abundance of the proteins.

These proteins are involved in 77 non-redundant CORUM complexes. Scanning of these complexes identified 76 further proteins that were quantified for both OXS and OAC, but only two that were included in the 401-set: DNA-dependent protein kinase catalytic subunit (PRKDC) and Vigilin (HDLBP). The \{PRKDC, XRCC5, XRCC6 $\}$ complex is best known for DNA damage repair processes, but PRKDC has also been shown to be involved in numerous other activities including innate immune response, response to hypoxia, metabolic control, and transcriptional control. ${ }^{41}$ The vigilin $\{$ HDLBP, PRKDC, XRCC5, XRCC6 \} complex is thought to participate in chromatin silencing. ${ }^{42}$

To further explore the involvement of complexes related to PCNA in the response to OAC/OXS, we constructed an $r=2$ overlap matrix for PCNA-related complexes using a slightly expanded search set to identify 77 CORUM complexes containing 160 unique proteins. The resulting overlap network (Fig. 6) together with the experimental data suggests that the 
three core complexes $\{$ PCNA, RFC2-5 $\},\{$ PCNA, XRCC5,6 $\}$ and $\{$ PCNA, DNMT1, EHMT2 have crucial roles in response to both OXS and OAC. The three core complexes define four largely independent branches for the 160 component proteins of the 77 complexes. For example, 139/160 proteins are found in only one branch. PCNA is the only protein shared by the DNMT1 branch with other branches. PCNA, RPA1 and TOP2A are the only proteins shared between the 41 proteins of the PCNA branch and the 65 proteins of the XRCC5,6 branch. The slightly greater overlap between the PCNA and RFC2-5 branches (15 proteins) largely involves a couple of highly similar complexes which do/do not contain PCNA/RFC2-5.

The proteins in the 401-set of significant changes are exclusively in the three core complexes or the associated vigilin complex. A striking feature is that the three core PCNA complexes are not subsumed into larger complexes, with the exception of the novel clamp loader complex \{PCNA, RFC2-5, CHTF18, DSCC1, POLH\}. Instead, subsets of the three core complexes participate in many other "peripheral" complexes. That is, the dominant feature of the response to OXS and OAC may be dynamic redistribution of the amounts of the different "peripheral" nuclear complexes as a consequence of changes in total abundance and compartmental distribution of a few constituents of the three core complexes. That such redistribution over the abundance of different complexes may be a major control mechanism is consistent with the observation that globally the protein components of many crucial transcriptional and chromatin remodelling complexes do not show significant changes in total or compartmental abundance for the individual proteins (Table 3), even though both OXS and OAC are strong perturbations that lead to cell cycle arrest. A salient feature is that changes in both total abundance and in compartmental redistribution are intimately intertwined in the control axis. More extensive analysis of nuclear interaction networks suggests that other proteins may also be involved (see below).

\section{2.e. Conclusions Regarding Core Protein Complexes.}

All of the analysed complexes show dynamic changes for OXS and/or OAC. One extreme involves changed spatial distribution of the entire complex, e.g. the increased nuclear abundance of the CCT protein folding/membrane fusion complex. Another extreme involves various large "molecular machines" for which only a few "messenger" proteins show changes, e.g. the spliceosome and IGF2BP1, NUDT21, PABPC1, SRRM2; the proteasome and PSMD5,6, PSME3; and, ribosomes and RPL12, RPLP0, RPLP2, RPS2, RPS10, RPS17, RPS27A. "Promiscuous" proteins such as PCNA and its partners XRCC5,6, HDLBP, DNMT1, PRKDC and RFC2-5 seem to change the distribution of abundance over many, but specific nuclear complexes, with corresponding rebalancing of many different functions. Coordinated changes of several proteins may redistribute abundance among groups of related complexes, e.g. emerin nuclear envelope complexes 24, 25 and 52 and C1QBP, G3BP1, HNRNPK, HNRNPU, IQGAP1, LMNB1, MCM2, SSB. Identification of proteins that are dynamic participants in core complexes and show changes in total abundance and/or compartmental distribution depending on functional context provides prioritized target lists of key proteins. The alternative spatial locations/functions of such "promiscuous" and "messenger" proteins should be prime targets for studies of spatial coordination of cellular function, with special emphasis on those where the major change involves a different compartment than the "molecular machine", e.g. NUDT21 and the spliceosome. 


\section{PCNA nuclear control axis}

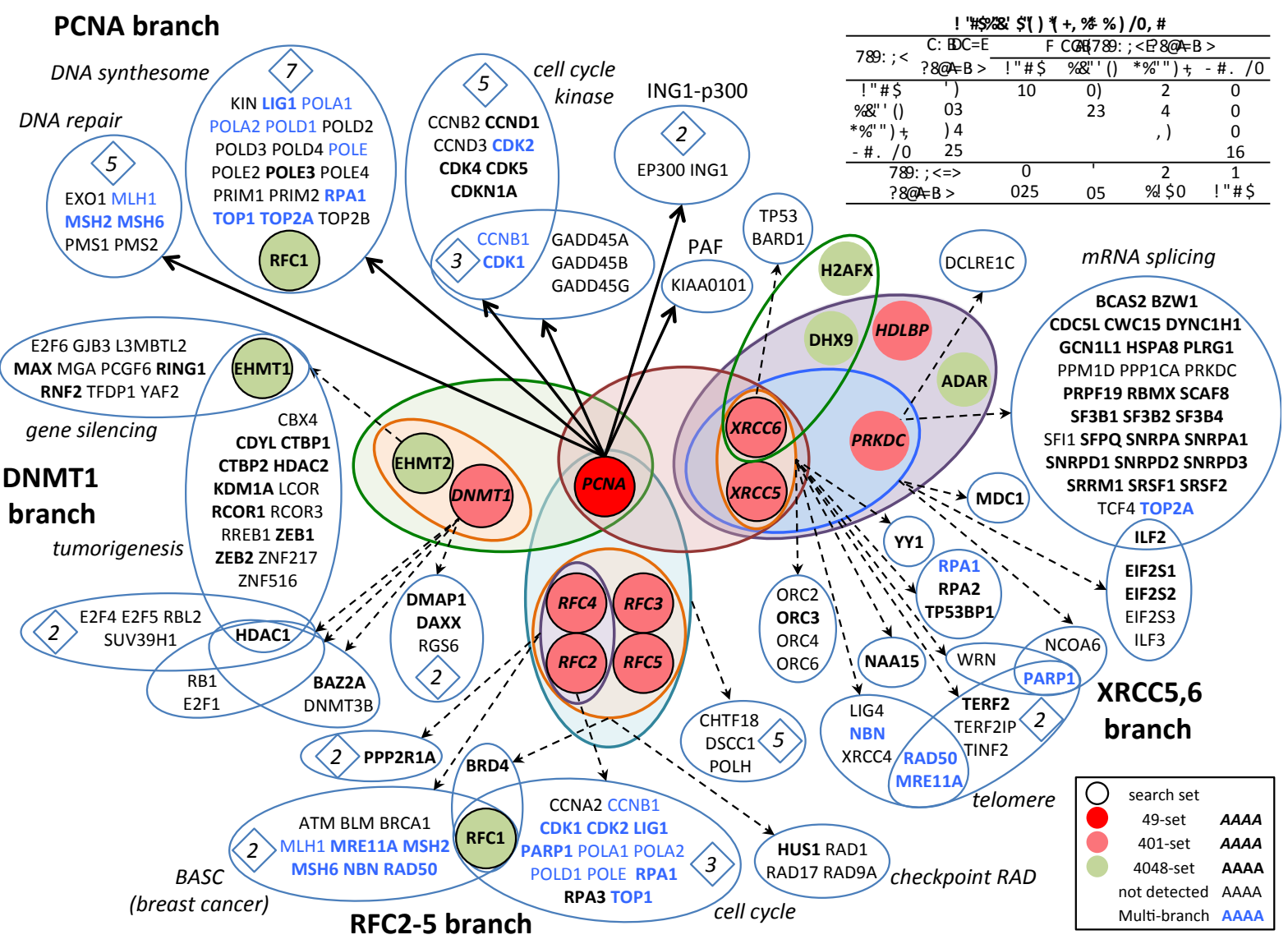

Figure 6. Mapping of 401-set and 49-set proteins to an $r=2$ overlap matrix for 77 complexes found with the indicated search set. In addition to the seven changed proteins of the 401-set contained in the $r=1$ overlap matrix for PCNA (Table 1), we added RFC1, which forms a complex with RFC2-5, as well as EHMT1,2 (EHMT2 for the PCNA-DNMT1-EHMT2 complex and EHMT1 as an alternative possibility for histone methylation since EHMT2 showed little change). The assignment of the proteins to different experimental sets is indicated by the legend at lower right. The numbers enclosed in diamonds indicate the number of highly overlapped CORUM complexes that were combined to simplify visualization. For the four indicated branches the table inset shows the number of: unique proteins, total proteins (diagonal), and shared proteins (off-diagonal) as well as the total number of proteins that are contained in one to four branches.

Table 3. Exemplary Transcriptional and Remodelling Complexes ${ }^{1}$

\begin{tabular}{|c|c|c|c|c|}
\hline Complex name & $\begin{array}{c}\text { CORUM } \\
\text { ID }\end{array}$ & $\begin{array}{c}\text { number of } \\
\text { subunits }\end{array}$ & $\begin{array}{c}\text { matches to } \\
4048 \text {-set / } \\
401-\text { set }\end{array}$ & detected in 4048-set (gene name) \\
\hline RNA polymerase II holoenzyme complex & 103 & 24 & $19 / 0$ & $\begin{array}{l}\text { ERCC2;ERCC3;GTF2B;GTF2E2;GTF2F1;GTF2F2;GTF2H1;GTF2H2;GTF2H3;GTF2H4; } \\
\text { POLR2A;POLR2B;POLR2C;POLR2D;POLR2E;POLR2G;POLR2H;POLR2I;POLR2J }\end{array}$ \\
\hline Mediator complex & 230 & 32 & $21 / 0$ & $\begin{array}{l}\text { CCNC;MED1;MED10;MED12;MED14;MED15;MED16;MED17;MED18;MED20; } \\
\text { MED23;MED24;MED25;MED27;MED28;MED29;MED30;MED4;MED6;MED7;MED8 }\end{array}$ \\
\hline DRIP complex & 548 & 14 & $10 / 0$ & MED1;MED12;MED14;MED16;MED17;MED23;MED24;MED4;MED6;MED7 \\
\hline BRG1-SIN3A complex & 713 & 14 & $14 / 0$ & $\begin{array}{l}\text { ACTL6A;ARID1A;HDAC2;PRMT5;RBBP4;SIN3A;SMARCA4;SMARCB1;SMARCC1; } \\
\text { SMARCC2;SMARCD1;SMARCD2;SMARCD3;SMARCE1 }\end{array}$ \\
\hline BRM-SIN3A-HDAC complex & 806 & 12 & $12 / 0$ & $\begin{array}{l}\text { ACTL6A;ARID1A;HDAC2;PRMT5;SIN3A;SMARCA2;SMARCB1;SMARCC1;SMARCC2; } \\
\text { SMARCD1;SMARCD2;SMARCE1 }\end{array}$ \\
\hline SIN3 complex & 54 & 7 & $7 / 0$ & HDAC1;HDAC2;RBBP4;RBBP7;SAP18;SAP30;SIN3A \\
\hline MeCP1 complex & 659 & 9 & $9 / 0$ & CHD4;GATAD2B;HDAC1;HDAC2;MBD2;MBD3;MTA2;RBBP4;RBBP7 \\
\hline SWI/SNF chromatin-remodeling complex & 5184 & 5 & $5 / 0$ & HDAC1;MECP2;SIN3A;SMARCA2;SMARCE1 \\
\hline NuA4/Tip60 HAT complex & 529 & 16 & $12 / 0$ & $\begin{array}{l}\text { ACTL6A;BRD8;MEAF6;DMAP1;EP400;MORF4L1;MORF4L2;MRGBP;RUVBL1; } \\
\text { RUVBL2;TRRAP;YEATS4 }\end{array}$ \\
\hline Integrator complex & 1153 & 12 & $11 / 0$ & CPSF3L;INTS1;INTS10;INTS12;INTS3;INTS4;INTS5;INTS6;INTS7;INTS8;INTS9 \\
\hline NCOR1 complex & 1413 & 10 & $10 / 0$ & $\begin{array}{l}\text { HDAC3;NCOR1;SF3A1;SF3B3;SMARCA4;SMARCB1;SMARCC1;SMARCC2;SRCAP; } \\
\text { TRIM28 }\end{array}$ \\
\hline NCOR2 complex & 1505 & 7 & $6 / 0$ & HDAC1;HDAC2;HDAC3;NCOR1;SAP30;SIN3A \\
\hline TFIID complex & 509 & 12 & $6 / 0$ & TAF10;TAF15;TAF4;TAF5;TAF6;TAF9 \\
\hline TFIID subcomplex (stable core) & 3010 & 5 & $4 / 0$ & TAF4;TAF5;TAF6;TAF9 \\
\hline
\end{tabular}

${ }^{1}$ Many additional complexes are shown in Supplementary Table 3. 
Although they are suggestive of systematic changes at many subcellular locations, the above analyses based on protein complexes only accounted for 19 of the 49-set of proteins with strong changes for both OAC and OXS. We therefore investigated other mechanisms of cellular control based on protein transport processes.

In concert with the concept that the subcellular location of many proteins is dynamic, a substantial proportion of proteins in the 401-set correspond to proteins classified by GO as involved in nuclear import/export/maintenance/localization (Table 4A) or involved in endocytosis/exocytosis/vesicle-mediated protein transport (Table 4B). For both of these general classes of subcellular transport, a large number of child processes were monitored by our experiments. Examples are shown in Table 4. The full lists of the GO identifiers, the significant proteins and their partitioning over the different processes are given in Supplementary Table 4 (nuclear import-export) and Supplementary Table 5 (vesicle trafficking). Examples of joint spatial razor plots for specific processes are given in Supplementary Figures S-7 (GO:0006913; nucleocytoplasmic transport) and S-8 (GO:0006897; endocytosis).

For any given transport process, the 401-set typically included only a small minority of the 4048-set proteins annotated to the process, which is consistent with selective changes in the subcellular transport processes engaged for OXS and OAC. Similarly, only a minority of the 401-set proteins were included in the 49-set, which is consistent with the possibility that such

Table 4.Summary of Data for Subcellular Transport Processes

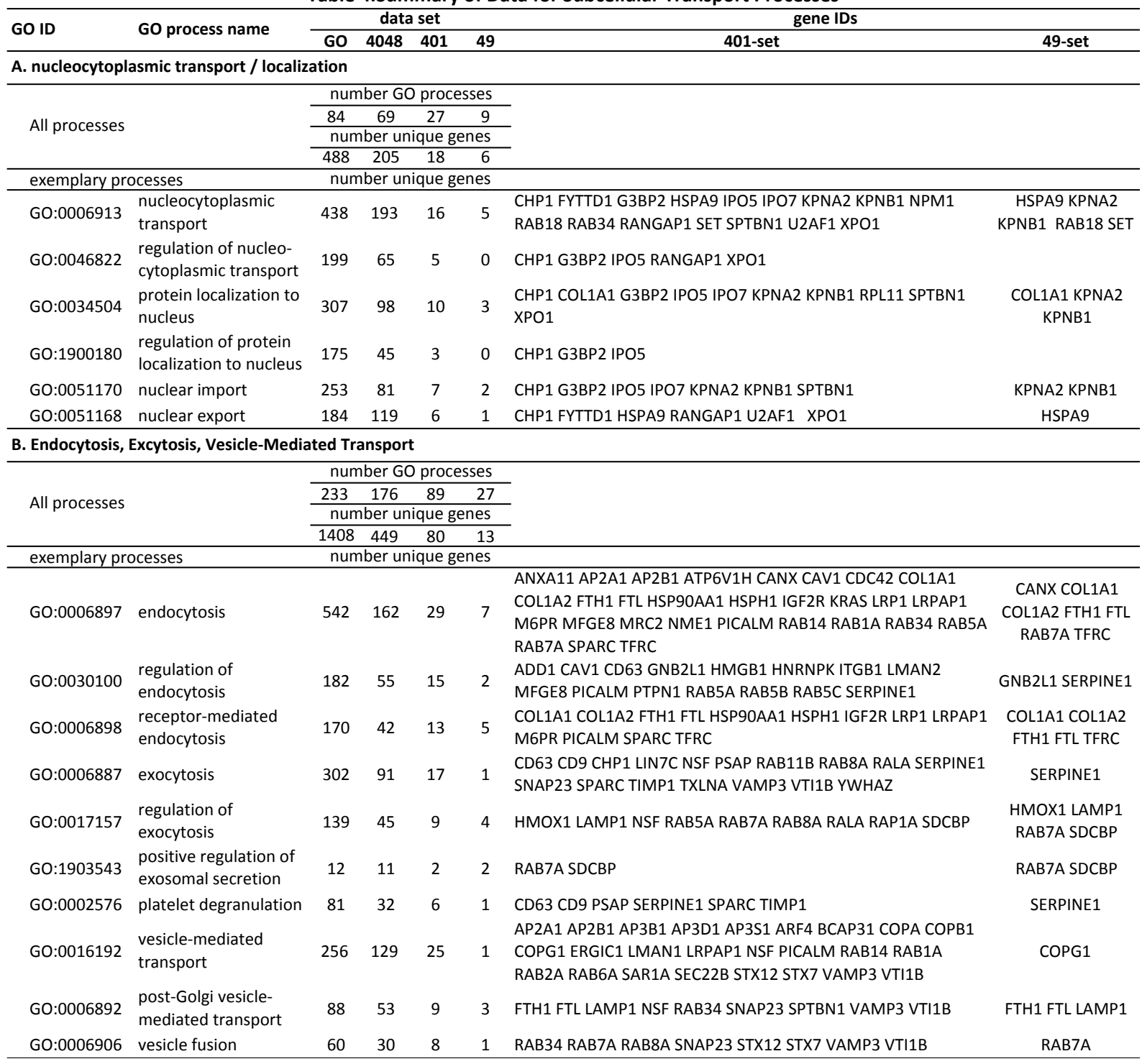


processes might be modified by changes mainly in a few key proteins.

Conversely, many proteins are annotated to multiple processes. For example, RAB7A is annotated to "endocytosis", "regulation of exocytosis", "positive regulation of exosomal secretion" and "vesicle fusion" (Table 4B) as well as a further three child processes in the GO ontology (Supplementary Table 5). For each of these processes, the group of 401-set proteins varies considerably, which is consistent with the idea that RAB7A can interact with different sets of proteins to participate in a variety of different subcellular transport processes. Similar characteristics are observed for many other proteins (Table 4, Supplementary Tables 4 and 5).

\section{3.a. Clathrin-mediated endocytosis, endosomal-lysosomal sorting, Golgi pathway.}

There are indications in the data that fluxes in the subcellular transport of proteins are systematically altered by OXS/OAC. For example, constituents of the AP3 adaptor complex showed strongly decreased total and cytoplasmic abundance only for OAC (Fig. 7A). This complex controls intracellular trafficking pathways through its role in regulating the delivery of proteins to late endosomes and lysosomes by a scaffolding function which brings together membrane lipids, sorting signals present in the cytosolic domains of membrane proteins, components of the vesicle fusion machinery and additional components of the vesicle formation apparatus. $^{43}$ In contrast, components of the AP2 complex showed little change in total or cytoplasmic abundance, but an increase in nuclear abundance only for OAC that is produced by $\mathrm{C} \rightarrow \mathrm{N}$ redistribution. This complex is crucial for clathrin-mediated endocytosis, ${ }^{44,45}$ but no significant change was observed for clathrins (CLTA, CLTB, CLTC, CLTCL1; Supplementary Table 1). Conversely, a series of RAB proteins (RAB1A, 2A, 6A, 8A) showed decreased nuclear abundance with little change in total or cytoplasmic abundance only for OXS. These proteins are annotated to a wide variety of subcellular transport processes including endocytosis, exocytosis, and Golgi vesicle transport (Supplementary Table 5). In contrast, COPI coatomer proteins showed C $\rightarrow \mathrm{N}$ redistribution that produces increased nuclear abundance with little change in total

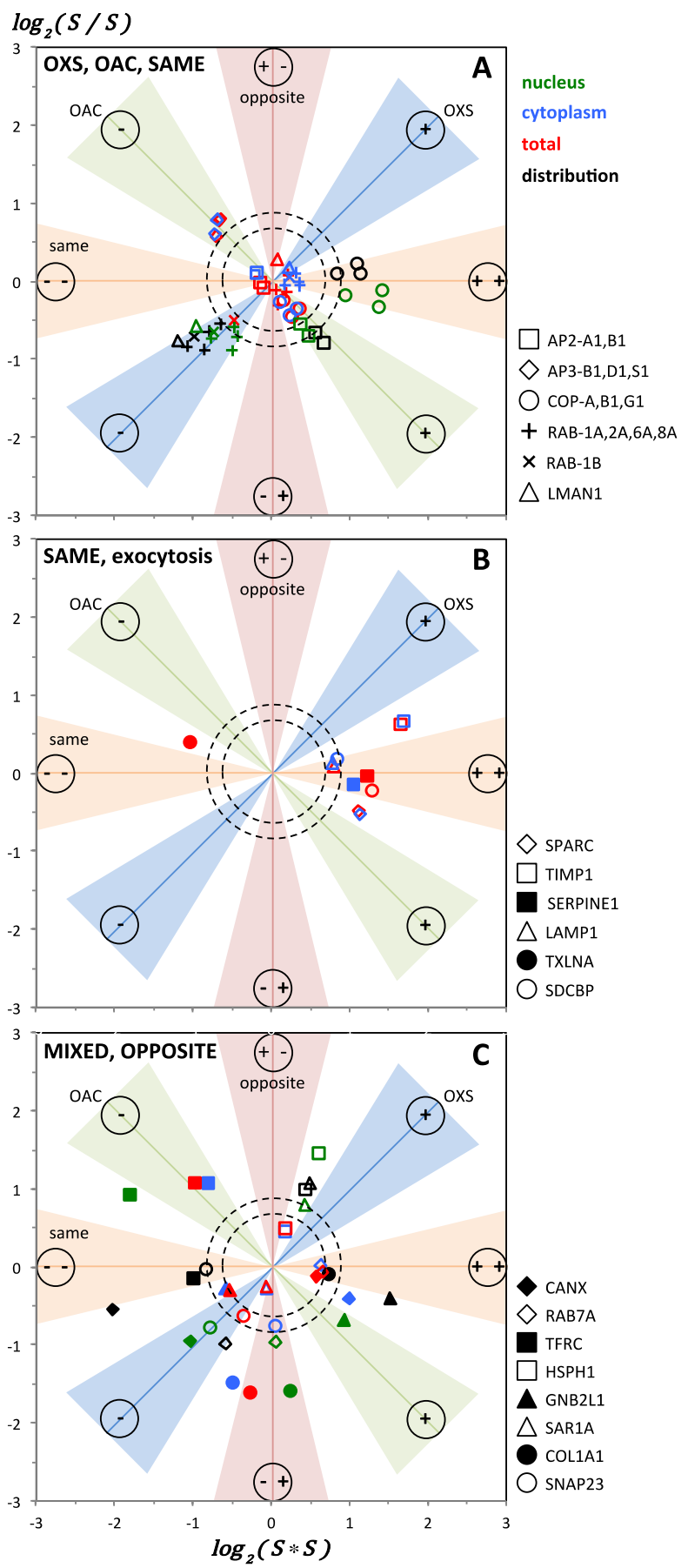

Figure 7. Joint spatial razor plots for selected proteins involved in subcellular protein transport. or cytoplasmic abundance for both OXS and OAC (Fig. 7A). These proteins are intimately involved in Golgi vesicle transport. ${ }^{46}$ Of these four subsystems, three are dominated by changes 
in subcellular distribution rather than changes in total protein abundance. The nuclear changes appear to represent directed, selective changes in protein fluxes to/from the nucleus since most of these proteins show little change in total or cytoplasmic abundance.

\section{3.b. Cytoplasmic vesicles.}

Other processes seem to be controlled by changes in total abundance. For example, we identified a set of proteins classified as SAME that show strong changes in total abundance, that are annotated to cytoplasmic vesicles and that are involved in exocytotic processes as well as in degranulation of a variety of different cell types including platelets, mast cells and natural killer cells (Fig. 7B). Conversely, HMOX1, which showed very strong SAME increase in total, nuclear and cytoplasmic abundance (far outside the scale of Fig. 7B, see Fig. 2C), belongs to this group and has roles as the rate-limiting enzyme in the oxidative catabolism of heme- $b$, maintenance of iron homeostasis, and cytoprotection against cell death by inhibiting apoptosis, oxidation, inflammation and cell proliferation (Morse-2009). HMOX1 is also annotated to regulation of exocytosis and negative regulation of mast cell degranulation by GO. That is, it is unclear whether exocytosis might be a common response to both OXS and OAC or whether these changes reflect a generalized change in fluxes of vesicle-mediated trafficking for both perturbations.

\section{3.c. Small GTPase mediated signal transduction.}

The importance of subcellular trafficking in response to OAC/OXS is further emphasized by changes in proteins that are associated with small GTPase mediated signal transduction and/or with GTPase activity (Table 5). For example, the 401-set contains 36 proteins annotated by $\mathrm{GO}$ to these identifiers. Eleven of the proteins were assigned to the OXS class. RAP2B is the only protein assigned to the OAC class. The majority of the proteins were assigned to the SAME, OPPOSITE and MIXED classes, including six MIXED proteins included in the 49-set (RAB7A, RAB18, RRAS2, COL1A2, GNB2L1, TUFM). The changes include complex redistributions between the nuclear and cytoplasmic compartments that are achieved by changes in both total abundance and redistribution (Supplementary Figure S-9). For example, RAB18 shows strong SAME decrease in nuclear abundance, while RAB5B and RAB7A show OPPOSITE increase/decrease in nuclear abundance for OAC/OXS respectively. Similarly complex patterns were observed for many other
Table 5. 401-set Proteins Annotated to Small GTPase Mediated Signal Transduction and/or to GTPase Activity ${ }^{1,2}$

\begin{tabular}{|c|c|c|c|}
\hline genes & protein names & CLASS & MAGNITUDE $^{3}$ \\
\hline \multicolumn{4}{|c|}{ RAB proteins: small GTPase mediated signal transduction \& GTPase activity } \\
\hline RAB11B & Ras-related protein Rab-11B & MIXED & MODERATE \\
\hline RAB14 & Ras-related protein Rab-14 & OXS & STRINGENT \\
\hline RAB18 & Ras-related protein Rab-18 & MIXED & STRINGENT \\
\hline RAB1A & Ras-related protein Rab-1A & OXS & STRICT \\
\hline RAB2A & Ras-related protein Rab-2A & oxs & STRINGENT \\
\hline RAB5A & Ras-related protein Rab-5A & OXS & STRINGENT \\
\hline RAB5B & Ras-related protein Rab-5B & MIXED & STRINGENT \\
\hline RAB5C & Ras-related protein Rab-5C & oxs & STRINGENT \\
\hline RAB7A & Ras-related protein Rab-7a & MIXED & STRINGENT \\
\hline \multicolumn{4}{|c|}{ other proteins: small GTPase mediated signal transduction \& GTPase activity } \\
\hline ARF4 & ADP-ribosylation factor 4 & MIXED & MODERATE \\
\hline ARL8A & ADP-ribosylation factor-like protein $8 \mathrm{~A}$ & SAME & MODERATE \\
\hline ARL8B & ADP-ribosylation factor-like protein $8 \mathrm{~B}$ & SAME & STRINGENT \\
\hline CDC42 & Cell division control protein 42 homolog & MIXED & MODERATE \\
\hline RALA & Ras-related protein Ral-A & OXS & MODERATE \\
\hline RAP2B & Ras-related protein Rap-2b & OAC & MODERATE \\
\hline RND3 & Rho-related GTP-binding protein RhoE & OPPOSITE & STRINGENT \\
\hline RRAS2 & Ras-related protein R-Ras2 & MIXED & STRINGENT \\
\hline \multicolumn{4}{|c|}{ small GTPase mediated signal transduction } \\
\hline CHP1 & Calcineurin B homologous protein 1 & MIXED & MODERATE \\
\hline COL1A2 & Collagen alpha-2(I) chain & MIXED & STRINGENT \\
\hline FARP1 & $\begin{array}{l}\text { FERM, RhoGEF and pleckstrin domain- } \\
\text { containing protein } 1\end{array}$ & OXS & STRINGENT \\
\hline G3BP1 & Ras GTPase-activating protein-binding protein 1 & OXS & STRINGENT \\
\hline G3BP2 & Ras GTPase-activating protein-binding protein 2 & SAME & STRICT \\
\hline IQGAP1 & Ras GTPase-activating-like protein IQGAP1 & MIXED & STRINGENT \\
\hline RAB1B & Ras-related protein Rab-1B & OXS & STRINGENT \\
\hline RAB34 & Ras-related protein Rab-34 & MIXED & STRINGENT \\
\hline RAB8A & Ras-related protein Rab-8A & OXS & MODERATE \\
\hline SQSTM1 & Sequestosome-1 & MIXED & STRINGENT \\
\hline \multicolumn{4}{|c|}{ GTPase activity } \\
\hline GNB2 & $\begin{array}{l}\text { Guanine nucleotide-binding protein subunit } \\
\text { beta-2 }\end{array}$ & OPPOSITE & MODERATE \\
\hline GNB2L1 & $\begin{array}{l}\text { Guanine nucleotide-binding protein subunit } \\
\text { beta-2-like } 1\end{array}$ & MIXED & STRINGENT \\
\hline RAP1A & Ras-related protein Rap-1A & OXS & STRINGENT \\
\hline SAR1A & GTP-binding protein SAR1a & OPPOSITE & STRINGENT \\
\hline TUFM & Elongation factor $\mathrm{Tu}$, mitochondrial & MIXED & STRINGENT \\
\hline
\end{tabular}

Supplementary Text). 
signalling proteins (Supplementary Figure S-9) and constitute further evidence for strong intertwining/cross-talk between OAC and OXS.

\section{3.d. Conclusions regarding transport processes.}

The 49-set included 18 proteins involved in subcellular transport with strong changes for both OXS and OAC. Some of these (KPNA2, KPNB1) are "classical" nuclear import/export proteins. Other proteins are "classical" vesicle-mediated transport proteins (AP2 and AP3 adaptor complex proteins, COPI coatomer proteins, various RAB proteins) that may have roles in dynamic nuclear redistribution of proteins that are more important than is currently generally appreciated. Still other proteins (HMOX1, FTH1, FTL, TIMP1, SERPINE1, SDCBP) are all included in cytoplasmic vesicles and many of these seem to equilibrate facilely between the nuclear and cytoplasmic compartments. For example, HMOX1, FTH1 and FTL show large SAME increases in total abundance that in the context of OXS seem to be equilibrated between the nuclear/cytoplasmic compartments in the four hours following the TBP challenge. These might represent "balancers" for general levels of vesicle-mediated transport, with the disposition and consequences of such transport influenced by the many proteins classified as MIXED or OPPOSITE (Tables 4,5, Fig. 7C, Supplementary Figure S-9). Overall, the data suggests that many of the proteins annotated to specific subcellular transport processes may be selectively or transiently involved with individual processes depending on functional context and that any specific transport process may be substantially altered by changes in abundance or spatial distribution of a small number of key proteins.

\subsection{Plasma Membrane/Extracellular Matrix - Nucleus Communication.}

The observation of significant changes for substantial numbers of proteins involved in endocytosis, exocytosis or vesicle-mediated trafficking suggests that many membrane-bounded organelles may be changed by OAC/OXS. We have previously shown that in IMR90 cells there are at least 371 proteins present in the nucleus that are annotated by GO to mitochondria. Of these, 39 were found to show significant changes in response to OXS. ${ }^{11}$ Here we take the plasma membrane as an example. GO annotates 5136 proteins to the plasma membrane and 4557 to the extracellular region, with 1403 proteins annotated to both. Not all of these will be expressed in all cell types. We monitored 1667 proteins annotated to either location, of which $243 / 34$ were included in the 401-set/49-set. The 401-set included significant changes in the nucleus for 125 proteins $\left(S_{n}\right)$ and in the cytoplasm for 82 proteins $\left(S_{c}\right)$. The 49 -set included significant changes in the nucleus for 21 proteins $\left(S_{n}\right)$ and in the cytoplasm for 23 proteins $\left(S_{c}\right)$. The data thus contains strong indications that among the proteins that distribute to the nucleus and the plasma membrane/extracellular region, changes in compartmental abundance of proteins can cause changes in plasma membrane processes, that these changes are communicated to the nucleus and that correlated changes in the nucleus and in/at the cell membrane contribute to cross-talk between OAC/OXS.

\section{4.a. Caveolae.}

A specific example is provided by the plasma membrane caveolar invaginations that are common in epithelial cells (Fig. 8A). Functions involving caveolae have been proposed to include mechano-sensing-protective roles, regulation of lipid transport, scaffolding for signaling events, and endocytotic vesicles. ${ }^{47-50}$ We monitored 15 caveolae-related proteins for which their GO annotations include experimental evidence (Fig. 8A). Recent work indicates that caveolins form plasma membrane complexes with Polymerase I and transcript release factor (PTRF, cavin 1), Serum deprivation-response protein (SDPR, cavin 2) and Protein kinase 
C delta-binding protein (PRKCDBP, cavin 3). ${ }^{47,51} \mathrm{We}$ observed specific changes in compartmental abundance of these proteins (Fig 8A). For example, for caveolin-1 (CAV1), but not CAV2, and only for OXS, C $\rightarrow \mathrm{N}$ redistribution led to substantial decrease in cytoplasmic abundance. For cavins 1 and 3, SAME $\mathrm{C} \rightarrow \mathrm{N}$ redistribution was observed to strongly decrease cytoplasmic abundance with little change in total abundance and moderate increase in nuclear abundance. For cavin 2, there were indications of substantial increases in nuclear and total abundance for OXS, albeit with smaller numbers of SILAC ratio counts (Supplementary Table 1). The ATPase EHD2 shows OPPOSITE behaviour with appreciable increase/decrease in total, nuclear and cytoplasmic abundance for OAC/OXS respectively. Plasma membrane calciumtransporting ATPase 4 (ATP2B4) showed strong increase in cytoplasmic abundance for OAC and appreciable decrease in nuclear abundance for OXS, dominated by increase in total abundance for $\mathrm{OAC}$ and by $\mathrm{N} \rightarrow \mathrm{C}$ redistribution for OXS (Fig. 8A). GO includes inferred annotations to caveolae for two other proteins that showed strong changes in our experiments (HMOX1, MYOF).

Overall these results suggest that functional processes involving caveolae are intimately linked to high level cellular processes such as DNA replication/cell cycle or oxidative control and that changes in both total

abundance and subcellular distribution of individual components of caveolar systems, including in the nucleus, are essential features of the associated plasma membrane processes. In fact, as indicated by their names, the cavins were originally identified as modulators of transcriptional and serum deprivation response activities. Although the changes in CAV1 may reflect vesicle trafficking/endocytotic processes, the differential behaviour of CAV1 and cavins1-3 suggests that in the context of OAC/OXS the dominant plasma membrane features may involve coupled changes in total abundance and compartmental location of these proteins rather than vesicle trafficking per se. Given recent evidence that cavin1-cavin2 and cavin1-cavin3 form different subcomplexes $^{51}$ and given the different response of cavins2,3 to OAC/OXS (Fig. 8A), this suggests that competition for formation of different coat complexes may be important for modulating caveolar function in the plasma membrane. Recent reports linking cavin 3 in the plasma membrane to balancing of ERK and Akt signalling ${ }^{52}$ as well as links of cavin 3 to 
circadian rhythms and the clock proteins PER/CRY ${ }^{53}$ suggest complex roles associated with subcellular redistribution of caveolar components.

\section{4.b. Extracellular Matrix Related Proteins.}

Although functionally important, the significant changes observed for the caveolae-related proteins are mostly in the 401-set. Only PTRF (cavin 1) and PRKCDBP (cavin 3) were included in the 49-set. A number of other proteins in the 49-set (Table 1, Fig. 8B) are related to collagens (COL1A1, COL1A2), integrins (ITGA5), matrix metalloproteinases (MMP14), receptor endocytosis (TFRC, GNB2L1), cell adhesion (SDCBP) and proteins induced by transforming growth factor beta (TGFBI). We used an $r=2$ overlap matrix of the CORUM complexes to look for relationships amongst these proteins and identified 252 related proteins, of which 135 were monitored and 28 included in the 401-set.

The four 49-set proteins (COL1A1, MIXED; COL1A2, MIXED; ITGA5, SAME; MMP14, SAME) show a complex pattern of distribution over many different extracellular matrix complexes, variable but strong changes in total/compartmental abundance (Fig 8B), as well as interactions with at least 90 other proteins. Matrix metalloproteinase 14 (MMP14, also known as MT1-MMP) has long been known to promote tumor cell invasion and metastasis ${ }^{54}$ by ECM remodeling, but there is also increasing evidence for a variety of other roles in cellular signaling systems ${ }^{55}$ Construction of a $r=2$ overlap matrix (Supplementary Figure S-10) for their CORUM complexes identified connections of these four proteins to a number of other 401-set proteins including integrins ITGA1 (SAME) and ITGB1 (OXS), Basigin (BSG, also known as CD147, EMPPRIN; OXS), tetraspanins CD9 and CD63 (OAC), TIMP1 (SAME), RAP1A (OXS) and catenins CTNNA1, CTNNB1, and CTNND1 (OXS). A variety of apparently previously unreported changes were observed, e.g. strong decreases in nuclear abundance for OXS of BSG, ITGB1 and RAP1A (Supplementary Figure S-10). There are other "matricellular" proteins ${ }^{56}$ such as SPARC that show appreciable nuclear/cytoplasmic changes for OAC/OXS. Their nuclear functions remain poorly defined, although SPARC has been connected with the cell cycle. ${ }^{57}$ Evidence was obtained that is suggestive of extensive SNAREbased vesicle-mediated transport between the nuclear compartment and the cytoplasmic compartment involving SNAP23, VAMP3, STX7, and STX12 as well as numerous RAB proteins (RAB1A, RAB2A, RAB5A, RAB5C, RAB6A, RAB8A, RAB11B, RAB14). This system potentially transports proteins such as ITGB1, BSG, LGAL1, LMAN1 and UTRN that have roles in the plasma membrane/extracellular matrix, but it may also be related to increasing evidence for endosomal vesicle involvement in early stages of mitosis (see Supplementary Figure S-10). Changes in 33 proteins related to TGF $\beta$ signalling were detected.

\section{4.c. Other Proteins.}

For TGFBI, SDCBP, GNB2L1, and TFRC, CORUM contained a single complex. Overlap matrices for the proteins in each of these complexes indicate that these four proteins have intimate involvement with many cellular processes. These include various signalling systems (GNB2L1: RAS, MEK, ERK, SRC), receptor trafficking (TFRC: SNX internalization, retromer trafficking, IGF2R retrieval), catenin-related signalling (SDCBP: S-phase cell cycle) and nuclear processes (TGFBI: transcription, mRNA processing, DNA repair, proteasomes). The distribution over these processes might be partly based on competition for different crucial components of the processes in a manner similar to the PCNA core complexes.

\section{4.d. Conclusions regarding plasma membrane/ECM - nucleus communication.}


Overall the data suggests that substantial remodelling of extracellular matrix and plasma membrane interactions at the cell surface involving collagen-integrin and other interactions is an integral part of both the OXS and OAC responses, that this is accompanied by nuclear changes, and that some aspects of such remodelling are shared by OXS/OAC while other aspects are unique to OXS or OAC.

There has long been evidence for the involvement of other endocytotic proteins ${ }^{58,59}$ and growth factors $^{60}$ in the nucleus. In fact our data suggests there are also distribution processes that connect many other subcellular locations with the nucleus. Based on these results we suggest that dynamic rebalancing of extracellular matrix/plasma membrane complexes involving integrins (ITGA1, ITGA5, ITGB1), collagens (COL1A1, COL1A2), tetraspanins (CD9 and CD63), catenins (CTNNA1, CTNNB1, CTNND1), related proteins such as PTRF, PRKCDBP, MMP14, TFRC, GNB2L1, SDCBP, TGFBI, BSG and various signalling systems may constitute another dynamic control axis in which changes in compartmental abundance influence distribution between different functional complexes, trafficking with the nucleus and hence functional response.

\subsection{The Protein Interaction Network.}

The previously described results emphasize that a large number of cellular processes at diverse subcellular locations can be changed by the OAC/OXS perturbations, that changes in both total protein abundance and subcellular distribution are crucial, and that there is complex cross-talk between OAC/OXS. Many other sub-networks, which are too numerous to include here, are apparent. Much of presently available information on these processes has been obtained by focussed studies of the individual processes/locations with limited attention to the possibility of high level, coordinated processes that are spatially integrated over many cellular locations. At the same time, attempts to record information that would allow construction of electronic models of cells have recently tended to concentrate on two types of data: (1) Changes in total abundance of proteins (and other entities such as miRNAs), whether measured by proteomics or transcriptomics; and, (2) local interactions of molecules, especially the physical proteinprotein interactions in complexes that are essentially invisible to the genomic methods.

To see to what extent presently available information of these types might be adequate to identify more global, higher level, spatially dispersed processes, we used CytoScape ${ }^{21,22}$ to visualize properties of the OXS/OAC interaction networks. We chose to conservatively use only experimentally verified, well-curated human binary protein interactions from CORUM, STRING and REACTOME in this analysis. Larger sets of binary interactions are available from diverse sources, but these may be of less certain quality and reliability, and their association with specific functions is often more ambiguous. We chose to use the latter only as secondary information for further exploration of specific features of the global interaction network (see below). In the present work one of our main goals was to estimate to what extent subcellular trafficking of proteins is a decisive part of cellular function and hence requires collection of data on such trafficking to obtain comprehensive pictures of cellular function. In this context, the next section provides an overview of global features of the interaction network. In section 3.5.b. we look at the quantitative contributions of co-expression and protein-protein binding to the network. We analyse in more detail several local aspects of the global interaction network in the following three sections. Section 3.5.c. illustrates how redistribution of a few key proteins can lead to complex control axes in the nucleus. Section 3.5.d. illustrates how the data can be used to explore possible functional roles of less well-studied proteins. Section 3.5.e. 
outlines possible global mechanisms of mitochondrial/nucleus interaction that may be important in a wide variety of disease states.

\section{5.a. Global properties of the functional interaction network.}

The overall interaction network contains 134,850 binary interaction pairs between the 4048 proteins and is shown in Supplementary Figure S-11. The 49-set and 401-set proteins with significant changes are widely distributed throughout the network. A general characteristic of the full interaction network is that for many of the proteins no significant changes in total or compartmental abundance were detected. This suggests that a relatively small number of proteins control spatial/functional response even though the overall network is enormously complex. We therefore concentrated on networks for the 49-set and the 401-set. The unchanged 4048-set proteins are included at a second stage to provide functional context and interpretation. For example, the putative dynamic distribution of PCNA over different nuclear complexes is recognized by including unchanged proteins.

STRING, REACTOME and CORUM contained 3472 binary interactions that included 382 of the 401-set proteins (Supplementary Table 6). Clustering of the interaction network identified seven large clusters of related proteins with 30 to 76 proteins (Table 6A: combined data set). The identities of the proteins in each cluster, including the clusters calculated using only co-expression and/or binding interactions (Table 6A), are shown in Supplementary Figure S-12. Each cluster in the combined interaction set contains groups of proteins with strong enrichment of specific GO biological process terms, each cluster corresponds to recognizable functional classes (Table 6B), and the clusters have recognizable spatial associations, e.g. cluster $\{76\}$ involves nuclear processes. Figure 9 shows the interaction network for these proteins. Many of the interactions appear to involve messenger and promiscuous proteins. For example, the 2218 intra-cluster interactions reduce to 1142 at the level of "supernodes" (Fig. 9A).
Table 6. Structure of the 401-set Interaction Network

\begin{tabular}{|c|c|c|c|}
\hline \multicolumn{4}{|c|}{ A. Clustering for Subsets of the Binary Interactions ${ }^{1}$} \\
\hline data set & $\begin{array}{r}\text { binary } \\
\text { pairs }\end{array}$ & $\begin{array}{c}\text { unique } \\
\text { genes }\end{array}$ & number of proteins in sub-network clusters \\
\hline co-expression & 906 & 148 & $\{41\}\{39\}\{32\}\{14\}\{6\}\{4\} 2 \times\{3\} 3 \times\{2\} 253 x\{1\}$ \\
\hline binding & 1627 & 305 & $\begin{array}{l}\{57\}\{42\}\{41\}\{33\}\{23\}\{22\} 2 \times\{21\}\{12\}\{9\}\{6\} \\
\{5\}\{3\} 5 \times\{2\} 96 \times\{1\}\end{array}$ \\
\hline $\begin{array}{l}\text { co-expression } \\
\& \text { binding }\end{array}$ & 1964 & 313 & $\begin{array}{l}\{69\}\{51\}\{42\}\{34\}\{31\}\{22\} 2 \times\{21\}\{6\}\{4\} \\
6 \times\{2\} 88 \times\{1\}\end{array}$ \\
\hline combined & 3472 & 382 & $\begin{array}{l}\{76\}\{68\}\{59\}\{54\}\{53\}\{35\}\{30\}\{5\}\{2\} \\
19 x\{1\}\end{array}$ \\
\hline
\end{tabular}

\begin{tabular}{|c|c|c|c|}
\hline \multicolumn{4}{|c|}{ B. GO Term Enrichment for Clusters of the Combined Data Set ${ }^{2}$} \\
\hline cluster & p-value & GO ID & GO biological process term \\
\hline \multirow{5}{*}{76} & $1.86 \mathrm{E}-09$ & GO:0000723 & telomere maintenance \\
\hline & 5.31E-09 & GO:0006260 & DNA replication \\
\hline & $5.26 \mathrm{E}-09$ & GO:0006323 & DNA packaging \\
\hline & $7.29 \mathrm{E}-06$ & GO:0070934 & CRD-mediated mRNA stabilization \\
\hline & $5.34 \mathrm{E}-15$ & GO:0071103 & DNA conformation change \\
\hline \multirow{4}{*}{68} & $6.00 \mathrm{E}-06$ & GO:0010810 & regulation of cell-substrate adhesion \\
\hline & $2.08 \mathrm{E}-14$ & GO:0030198 & extracellular matrix organization \\
\hline & $2.46 \mathrm{E}-08$ & GO:0032963 & collagen metabolic process \\
\hline & $1.13 \mathrm{E}-07$ & GO:0034330 & cell junction organization \\
\hline \multirow{6}{*}{59} & $2.60 \mathrm{E}-15$ & GO:0006091 & generation of precursor $\mathrm{me}$ \\
\hline & $2.32 \mathrm{E}-12$ & GO:0006099 & tricarboxylic acid cycle \\
\hline & $6.39 \mathrm{E}-06$ & GO:0009084 & glutamine family amino acid biosynthetic process \\
\hline & 2.61E-06 & GO:0019395 & fatty acid oxidation \\
\hline & $4.89 \mathrm{E}-14$ & GO:0033572 & transferrin transport \\
\hline & $2.34 \mathrm{E}-06$ & GO:0055129 & L-proline biosynthetic process \\
\hline \multirow{6}{*}{54} & $9.51 \mathrm{E}-07$ & GO:0006826 & iron ion transport \\
\hline & $2.47 \mathrm{E}-10$ & GO:0006892 & post-Golgi vesicle-mediated transport \\
\hline & $5.22 \mathrm{E}-09$ & GO:0006906 & vesicle fusion \\
\hline & 4.12E-14 & GO:0016197 & endosomal transport \\
\hline & $1.14 \mathrm{E}-27$ & GO:0048193 & Golgi vesicle transport \\
\hline & $3.14 \mathrm{E}-12$ & GO:0051650 & establishment of vesicle localization \\
\hline \multirow{3}{*}{53} & $1.08 \mathrm{E}-50$ & GO:0006412 & translation \\
\hline & $1.85 \mathrm{E}-23$ & GO:0070125 & mitochondrial translational elongation \\
\hline & $6.24 \mathrm{E}-24$ & GO:0072594 & establishment of protein localization to organelle \\
\hline \multirow{4}{*}{35} & $2.42 \mathrm{E}-20$ & GO:0006457 & protein folding \\
\hline & $1.47 \mathrm{E}-14$ & GO:0007339 & binding of sperm to zona pellucida \\
\hline & $3.06 \mathrm{E}-07$ & GO:0042026 & protein refolding \\
\hline & $3.76 \mathrm{E}-05$ & GO:0044743 & intracellular protein transmembrane import \\
\hline \multirow{4}{*}{30} & $2.68 \mathrm{E}-33$ & GO:0006977 & $\begin{array}{l}\text { DNA damage response, signal transduction by p53 clas } \\
\text { mediator resulting in cell cycle arrest }\end{array}$ \\
\hline & 2.91E-09 & GO:0010388 & cullin deneddylation \\
\hline & $2.00 \mathrm{E}-23$ & GO:0043161 & $\begin{array}{l}\text { proteasome-mediated ubiquitin-dependent protein } \\
\text { catabolic process }\end{array}$ \\
\hline & $1.01 \mathrm{E}-32$ & GO:0051437 & $\begin{array}{l}\text { positive regulation of ubiquitin-protein ligase activity } \\
\text { involved in regulation of mitotic cell cycle transition }\end{array}$ \\
\hline
\end{tabular}

${ }^{1}$ Calculated with the Clust\&See T-fit algorithm of Cytoscape. For STRING only medium confidence interactions (score > 400) were included. Combined includes co-expression, experimental, text mining, binding, database, etc. from STRING. For REACTOME direct and indirect complexes were included in binding and all interactions in combined. For CORUM binding pairs were constructed for all proteins included in the same complex. The sub-networks with their number of included proteins $\{\mathrm{n}\}$ are shown schematically. The identities of the $\{\mathrm{n}\}$ proteins in each cluster are shown in Supplementary Figure 12 and Supplementary Table 6. Proteins with no pair interactions in the data set correspond to $\{1\}$. Two proteins (POLDIP2 and SEC22B) had no binary pairs and 17 proteins only had interactions with STRING combined score $<400$. The p-values are Bonferroni corrected.

${ }^{2}$ Calculated with the ClueGO plugin for Cytoscape. Sub-networks with $>5$ proteins are shown. 
That is, specific subunits of complexes such as PSME3/proteasome have functional roles as messengers. Although the GO biological processes have highly significant p-values (Table $6 \mathrm{~B})$, there are also very substantial numbers of binary interactions between proteins in different clusters (Fig. 9A, Supplementary Figure S-12). Since the 1252 inter-cluster interactions reduce to 793 at the supernode level, these interactions also seem to involve a limited number of key messenger and promiscuous proteins. Because they connect different functional classes or molecular machines, the inter-cluster interactions may be particularly important to spatial control. For example, NUDT21, which was identified as an one of four outliers of the spliceosome (Fig. 4), has 11 intra-cluster-\{76\}-\{76\} interactions, 2 inter-cluster- $\{76\}-\{53\}$ interactions to the RPL and RPS supernodes and 1 inter-cluster- $\{76\}-\{30\}$ interaction to PABPC1, which is another spliceosome outlier. The interactions in the nuclear and cytoplasmic compartments are substantially different (thumbnails in Fig. 9B). This reflects a strong influence for subcellular redistribution in compartmental interactions. Separation of the interaction network according to $S_{n}, S_{c}, S_{t}$ and $S_{n} / S_{\mathrm{c}}$ (Supplementary Figure S-13) shows similarities and differences for OXS/OAC that are suggestive of phase changes. Overall, these features are consistent with the involvement of the 401-set proteins in coordination of different processes at various subcellular locations.
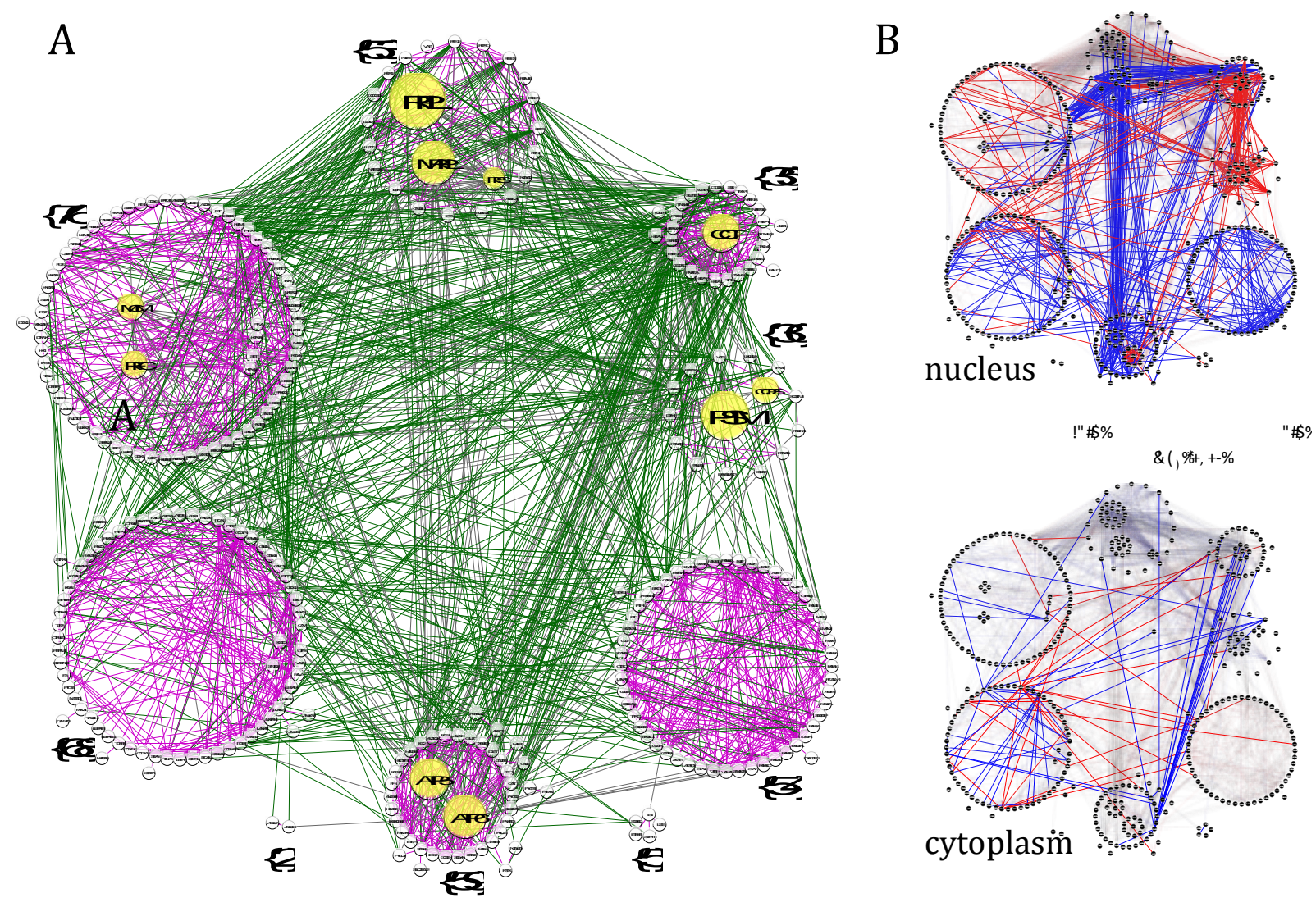

Fig. 9. Interaction network for the 382 proteins of the 401 -set corresponding to the 3472 binary interactions identified in STRING, REACTOME and CORUM. (A) The indicated clusters were obtained with the T-fit algorithm of the Clust\&See module of CytoScape. To simplify visualization, constituents of large protein complexes with moderate average changes, e.g. ribosomes and proteasomes (Fig. 4), are shown as "supernodes" with grey edges. Outliers were retained as individual nodes. Intra- and inter-cluster interactions are indicated by magenta/green edges. (B) Nucleus and cytoplasm "thumbnails" for OXS illustrating the differential behaviour of the interaction network in the nuclear and cytoplasmic compartments. The edges joining two proteins (A and $\mathrm{B}$ ) are color-coded according to the scale by the interaction potentials $\log _{i}\left(S_{i i}^{A}+S_{\eta}^{5}\right)$ and $\log _{2}\left(S_{i}^{A}+S_{i}^{5}\right)$. A full set of all eight thumbnails is shown in Supplementary Figure S-13.

More sophisticated modelling is in principle possible with data sets of the present type. For all 
binary pairs in the present interaction network, Supplementary Table 6 provides spatially resolved quantitative measures of compartmental changes in pair interaction potentials $\left(S^{*} S\right)$ for the nucleus and cytoplasmic compartments, as well as for the changes in total abundance and redistribution that produce the compartmental changes.

\section{5.b. Contributions of Gene Co-expression and Protein-Protein Binding.}

STRING provides several types of scores (co-expression, binding, experimental, text mining, etc.) for each binary interaction. We used these to look at the contribution of different kinds of interactions to the functional network. Of the proteins in the 49-set, 47 had direct interactions with other proteins in the 49-set in the STRING database (Fig 10A, upper off-diagonal region). That is, our data captured interactions that are consistent with previous information. STRING records substantial co-expression for three groups of 49-set proteins (lower off-diagonal region in Fig. 10A): \{RPS2; RPS10; GNB2L1\}, \{SET; PRMT1\} and \{HSPA9; GRPEL1\}. These are a small minority of all substantial direct interactions (Fig. 10A) and only a minority of the 401set proteins exhibited co-expression (Table 6A). This suggests that gene co-expression is not the dominant contributor to the strongest cross-talk responses between OAC and OXS. Many of the substantial direct interactions for the 49-set were in fact captured in STRING from conventional low-throughput experimental studies and/or text mining, suggesting that there may be many functional relationships that are not captured efficiently by gene co-expression data.

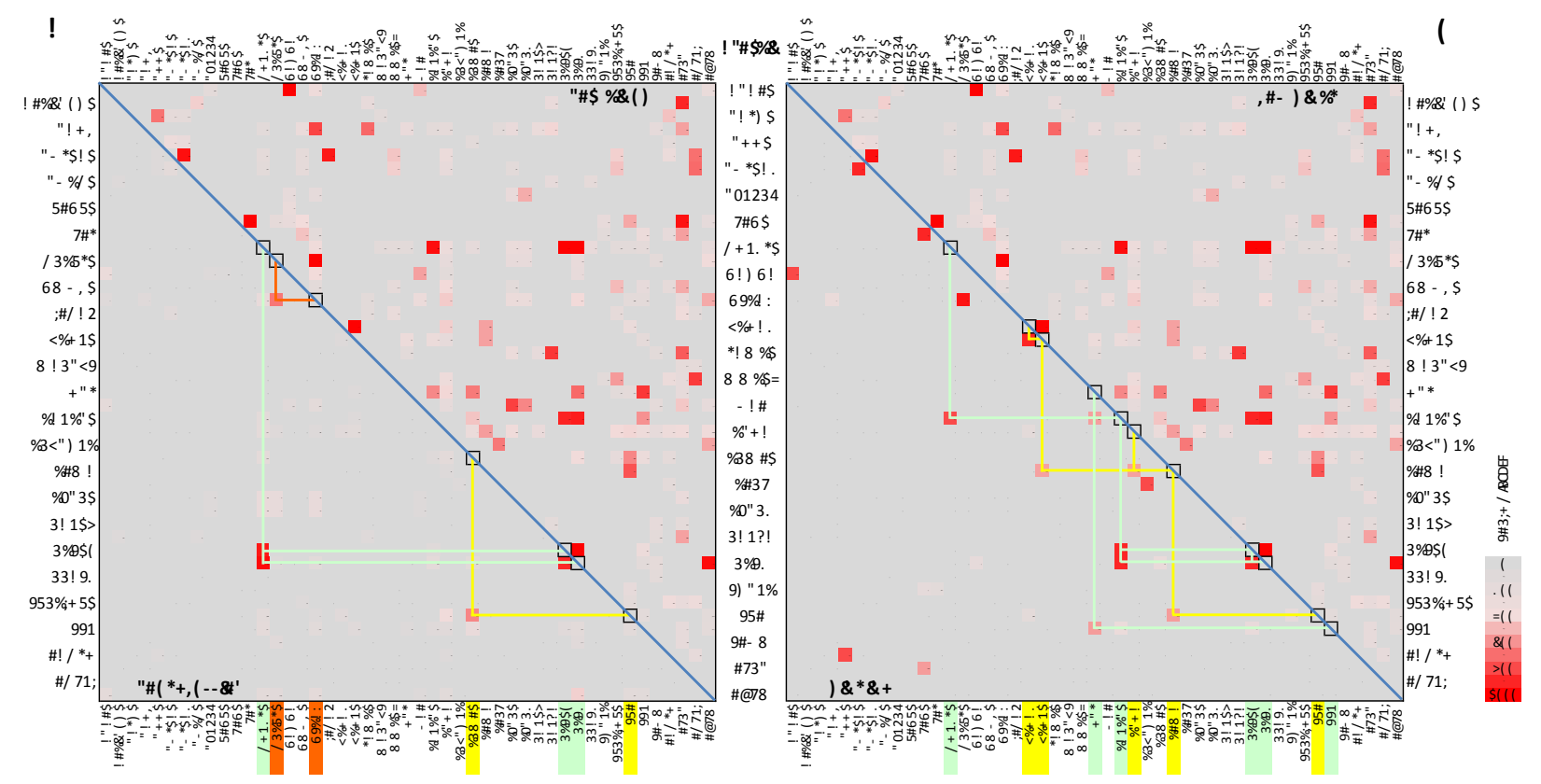

Fig. 10. STRING combined scores (upper off-diagonal region), co-expression scores (lower off-diagonal region, panel A) and binding scores (lower off-diagonal region, panel B) for pairs of proteins included in the 49 -set. The proteins are ordered alphabetically by gene name. The magnitude of the scores is indicated by the legend at lower right. Medium confidence levels are defined by scores $\geq 400$. For co-expression, in the experimental data $\{$ RPS2, RPS10, GNB2L1\} were characterized by modest changes in $S_{t}$ and were included in the 49set on the basis of increases in nuclear abundance associated with $\mathrm{C} \rightarrow \mathrm{N}$ redistribution. \{SET, PRMT1\} showed SAME increases in $S_{t}$, but changes in the nuclear/cytoplasmic compartments were dominated by $\mathrm{N} \leftrightarrow \mathrm{C}$ redistribution (Supplementary Table 2). For \{HSPA9, GRPEL1\}, changes in $S_{t}$ did not appear to be correlated and compartmental changes in abundance were dominated by $\mathrm{N} \leftrightarrow \mathrm{C}$ redistribution (see Section $\mathrm{J}$ below). For binding, the $\{$ KPNA2, KPNB1, PCNA, PTMA, SET $\}$ group is further analysed in section $\mathrm{H}$. The experimental changes for the \{GNB2L1, NCL, PABPC1, RPS10, RPS2, SSB $\}$ group are shown in Supplementary Table 2. 
A similar analysis of the full 401-set (Table 6: co-expression data set, Supplementary Figure S12B) suggests that for cross-talk between OAC and OXS measurements of correlations in gene co-expression predominantly capture information about (moderate) correlated changes in total abundance of core cellular complexes such as ribosomes, proteasomes, ATP5, ATP6, etc.

A similar analysis was carried out for the contribution of known protein-protein binding interactions to cross-talk between OXS/OAC (Fig. 10B). Notable is that there are only a few pairs of 49-set proteins with direct binding interactions and only two sets of proteins that are interconnected by substantial binding interactions: \{KPNA2, KPNB1, PCNA, PTMA, SET \} and \{GNB2L1, NCL, PABPC1, RPS10, RPS2, SSB $\}$. These results suggest that many of the 49-set proteins are isolated from each other and predominantly distributed over quite different sets of local interaction partners as these are currently known. This is in concert with the dispersion of the 49-set proteins in the overall global network for the 4048-set (Supplementary Figure S-11) and could be consistent with inclusion of the proteins in different functions as a consequence of transfer between different subcellular locations. The analogous analysis for the full 401-set (Table 6A: binding data set, Supplementary Figure S-12C) suggests that high throughput binding data is also only capturing efficiently a limited subset of previously identified interactions.

As a further test of whether present data on binding interactions (inclusion in complexes) and on gene co-expression can account for the experimental interaction network, we compared the connectivity of the 401-set interaction network when only the binding or the gene coexpression binary interactions were included (Table 6A, Supplementary Figure S-12). In general the network was substantially fragmented, some of the network clusters were either not identified or included far fewer proteins, and substantial numbers of proteins had no connections to clusters. Connectivity improved using the union of co-expression and binding data, but remained fragmented (Table 6A, Supplementary Figure S-12).

These results suggests that interactions that are dominant in the context of cross-talk between OAX and OXS have been captured by forms of correlation (conventional experimental data, text mining, etc.) that go beyond the known direct binding interactions or gene co-expression captured in high throughput experiments. We suggest that subcellular transport of proteins is a major contributor (see below).

Much more sophisticated modelling is in principle possible with data sets of the present type. For all binary pairs in the present interaction network, Supplementary Table 6 provides spatially resolved quantitative measures of compartmental changes in pair interaction potentials $\left(S^{*} S\right)$ for the nucleus and cytoplasmic compartments, as well as for the changes in total abundance and redistribution that produce the compartmental changes.

\section{5.c. An extended PCNA / SET / PTMA / HMOX1 nuclear control axis.}

The 49-set of proteins with the strongest response for both OXS and OAC include two further proteins with strong binary interactions with PCNA: SET and PTMA. These three proteins were used to construct a local interaction matrix for OXS in which the binary interactions are differentiated according to co-expression, binding and other interactions and the experimental changes are mapped to those binary pairs that have at least medium confidence (Fig. 11). For PCNA, the interaction matrix largely reproduces the properties deduced from the analysis of CORUM complexes (section 3.2.d). For example, the strong $\mathrm{N} \rightarrow \mathrm{C}$ redistribution for PCNA results in strongly reduced amplitudes for the binding interaction pairs in the nucleus of the three branch points previously identified. As shown in Figs. 6 and 11, these branch point 
proteins (DNMT1, RFC2-5, XRCC5,6) connect with only a few other proteins involving strong pairwise changes, i.e. the interaction matrix is consistent with PCNA having transient, redistributable interactions with multiple core functional complexes. However, the
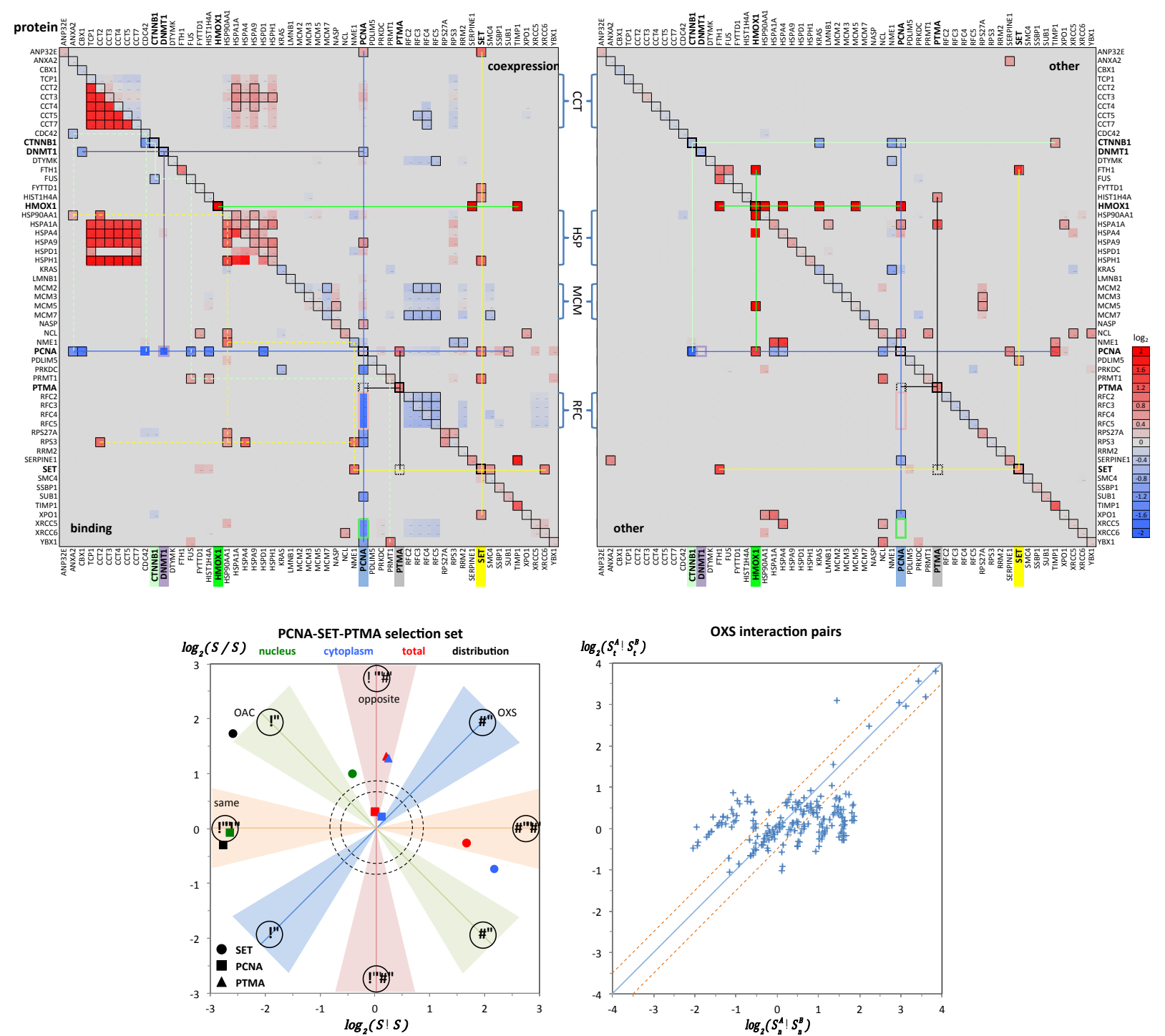

Fig. 11. The local STRING-based interaction network for OXS around the 49-set proteins PCNA, PTMA and SET. A set of 287 binary pair interactions was constructed by identifying a set of 54 additional 401-set proteins with direct interactions with the three 49-set seed proteins ( $r=1$, STRING combined score $>400)$. KPNA2 and KPNB1 were analysed separately (Fig. 10). To facilitate comparison with the spatially resolved experimental data, the STRING interaction pairs were classified into three types as shown in the upper portion of the figure: (a) co-expression, (b) binding, and (c) other interaction pairs, the latter without (a) or (b) and many of which are largely based on text-mining or other experimental correlations. The experimental $S_{t}$ data for each pair A-B was then mapped to the STRING co-expression pairs $\left(S_{t}^{A} \bullet S_{\mathrm{t}}^{\mathrm{E}}\right\rangle$, upper off diagonal region) while the experimental $S_{n}$ data was mapped to the STRING binding pairs $\left(S_{\mathrm{K}}^{A}+S_{11}^{\mathrm{B}}\right.$, lower off diagonal region). The mechanism(s) underlying the correlation of the other pairs is often ambiguous and these pairs were therefore included symmetrically with mapping to $S_{t}^{A}+S_{t}^{\mathbf{b}}$ (upper off-diagonal region) and to $S_{\mathrm{K}}^{A}+S_{\|}^{\mathrm{E}}$ (lower off-diagonal region). Changes in total abundance for individual proteins $\left(S_{t}\right)$ were mapped to the diagonal. The off-diagonal interaction pairs with $\left|\log _{2}\left\langle S^{A}+5^{6}\right\rangle\right| \geq 0.4$ are indicated by light black outlining. The three branch points of the PCNA control axis identified in section D are indicated by the heavily outlined purple, pink and green binding/nuclear interaction pairs. Horizontal/vertical solid lines though the diagonal identify direct interaction partners for PCNA, PTMA, SET, DNMT1, CTNNB1 and HMOX1. Short walks on the nuclear binding matrix ( $\mathrm{r} \leq 3$, dashed lines) are shown for SET and CTNNB1 (see text). The lower left plot shows the joint spatial razor plot for PCNA (SAME class), PTMA (OPPOSITE) and SET (MIXED). The lower right plot shows the correlation 
experimental data is also consistent with binding interactions between PCNA and a substantial number of other proteins detected in the nucleus including ANXA2, CBX1, CDC42, FUS, HIST1H4A, HSPD1, PRKDC, RPS3, SUB1 and YBX1. The strongest co-expression interactions are observed for PTMA and SET, while the other interactions include possible binding with catenin $\beta 1$ (CTNNB1) and HMOX1 as well as co-expression with TIMP1. An $r=$ 2,3 walk on the nuclear binding matrix for CTNNB1 crosses with PCNA at several points and includes CDC42, ANXA2 and FUS. In short, PCNA shows a multitude of interactions that suggest its strong $\mathrm{N} \rightarrow \mathrm{C}$ redistribution is a crucial aspect of response to OXS and also to OAC (see below).

SET also appears to be a critical component of response to OXS, with nuclear binding interactions to FTH1, NME1 and XPO1 as well as indications for co-expression interactions with ANP32E, FTH1, HSPH1, PCNA, PRMT1 and XRCC6. The $r=2,3$ walk for SET on the nuclear binding matrix suggests that changes in the nuclear abundance of SET can interplay with a variety of other proteins including CCT2, HSP90AA1, HSPA4, HSPH1 and RSP3. The connections to heat shock proteins and the CCT complex may be crucial (see below).

A third crucial protein seems to be HMOX1. It shows co-expression interactions with SERPINE1 and TIMP1. The other interactions suggest possible nuclear binding interactions with FTH1, HSP90A1, HSPA4, MCM5 and PCNA and possibly co-expression with these proteins as well as KRAS. The connection to MCM5 is of interest because suppression of the CDC7 kinase (for OAC) induces cell cycle arrest at the origin activation checkpoint for DNA replication by reducing phosphorylation of the MCM complex. ${ }^{8,10}$

The data contains clear evidence that analyses based only on changes in total abundance of proteins may miss important functional relationships. For example, of the 287 STRING binary pairs, 228 correspond to cases where both $S_{n}$ and $S_{t}$ were measured for both proteins in both experiments. Comparison of the magnitudes for the co-expression $\left(S_{i}^{A}: S_{t}^{b}\right)$ and nuclear binding $\left(S_{n}^{A}: S_{n}^{B}\right)$ pairwise interactions (lower right panel, Fig. 11) indicates that changes in total abundance do not adequately reflect the potential changes in nuclear binding interactions. For example, only $101(44 \%)$ of the pair interactions show a ratio $\left|\log _{2}\left(S_{t}^{A} \times S_{i}^{b}\right) /\left(S_{n}^{A} \times S_{n}^{b}\right)\right| \leq 0.5$, i.e. $0.71 \leq\left(S_{i}^{A} * S_{\mathrm{t}}^{b}\right) /\left(S_{n}^{A} * S_{12}^{b}\right) \leq 1.41$. There are variations in the ratio $\left(S_{i}^{A} * S_{i}^{B}\right) /\left(S_{n}^{A} * S_{n}^{B}\right)$ of up to 4-fold and $56(25 \%)$ of the binary interactions show variations greater than 2.5 -fold.

Many crucial nuclear binding interactions are clearly susceptible to strong modulation via nuclear-cytoplasmic redistribution of key proteins. Although the exemplary $r=2,3$ walks on the nuclear binding matrix suggest strong functional intertwining, there are few short pathways between SET and PCNA (SET-NME1-RPS3-PCNA over binding interactions and SET-FTH1HMOX1-PCNA over other pairs). SET and PCNA show moderate co-expression interaction

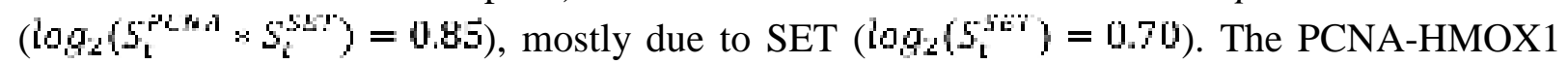

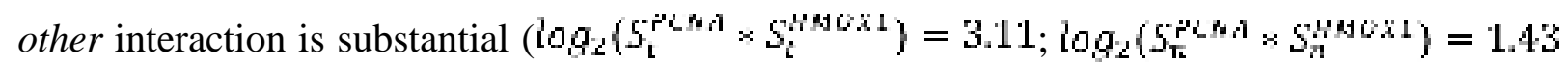
for co-expression/binding respectively) and the other pathway SET-FTH1-HMOX1 is also substantial (Fig. 11), both mainly as a consequence of the very strong increase in HMOX1 abundance $\left(\log _{2}\left(S_{\mathrm{t}}^{\text {iixox }}{ }^{1}\right)=2.96\right)$. There are ambiguities in the role of the PCNA-PTMASET pathway (see below).

The joint spatial razor plot suggests that there are two major distinguishing differences between OXS and OAC among PCNA, SET and PTMA. First, SET shows substantial increases in total 
and cytoplasmic abundance for both $\mathrm{OAC}$ and $\mathrm{OXS}$, but strong $\mathrm{N} \rightarrow \mathrm{C}$ redistribution that substantially reduces its nuclear abundance only for OAC. This difference is associated with major changes in the interaction network (Fig. 12). Note that the trend for change in total abundance of SET is similar for OAC and OXS as are the co-expression interactions with FTH1, HSPH1, PCNA, PRMT1 and XRCC6. The same is true for co-expression interactions involving HMOX1 with SERPINE1 and TIMP1. In contrast, the strong decrease in the nuclear abundance of SET has very strong effects on the nuclear binding interaction network. Conversely, many of the co-expression, binding and other interactions for PCNA and HMOX1 show much more moderate changes in magnitude between OXS and OAC. Changes for the MCM and RFC complexes and other proteins such as RRM2 and SMC4 are perhaps not surprising in the context of suppression of DNA replication by suppression of CDC7 kinase and may be associated with nuclear envelope changes of emerin complexes (section 3.2.b). More unexpected are the striking nuclear differences for the CCT complex and numerous heat shock proteins, which are reminiscent of the systematic changes in subcellular protein transport systems such as AP complexes and RAB proteins (section 3.3.a).

The second major distinguishing difference between OXS and OAC amongst PCNA, SET and PTMA is the opposite behaviour of PTMA total/cytoplasmic abundance (Fig. 11). The present experimental data leaves some ambiguity regarding the possibility that PTMA connects the PCNA and SET subsystems. For OAC, the decrease in total/nuclear abundance of PTMA $\left(S_{t}, S_{n}\right.$ $=0.68,0.55)$ is correlated with co-expression interactions with PCNA and with other interactions with HIST1H4A and HSPA1A. The potentials for nuclear binding interactions of PTMA involving PCNA and SET are substantially decreased and those involving HIST1H4A and HSPA1A are more moderately decreased. For OXS, PTMA showed an opposite, substantial increase in total/cytoplasmic abundance $\left(S_{t}, S_{c}=1.70\right)$, which is reflected in the coexpression and other interactions with PCNA, HIST1H4A and HSPA1A. All of this is consistent with an important role for PTMA in connecting the PCNA and SET subsystems. The ambiguity arises because PTMA was not detected in the nucleus for OXS. Although an artefact of the MS sampling cannot be fully excluded, the increased total abundance of PTMA for OXS suggests this might reflect strong $\mathrm{N} \rightarrow \mathrm{C}$ redistribution that depletes nuclear PTMA and directs PTMA to cytoplasmic anti-apoptotic functions (see discussion). On the other hand, note that 


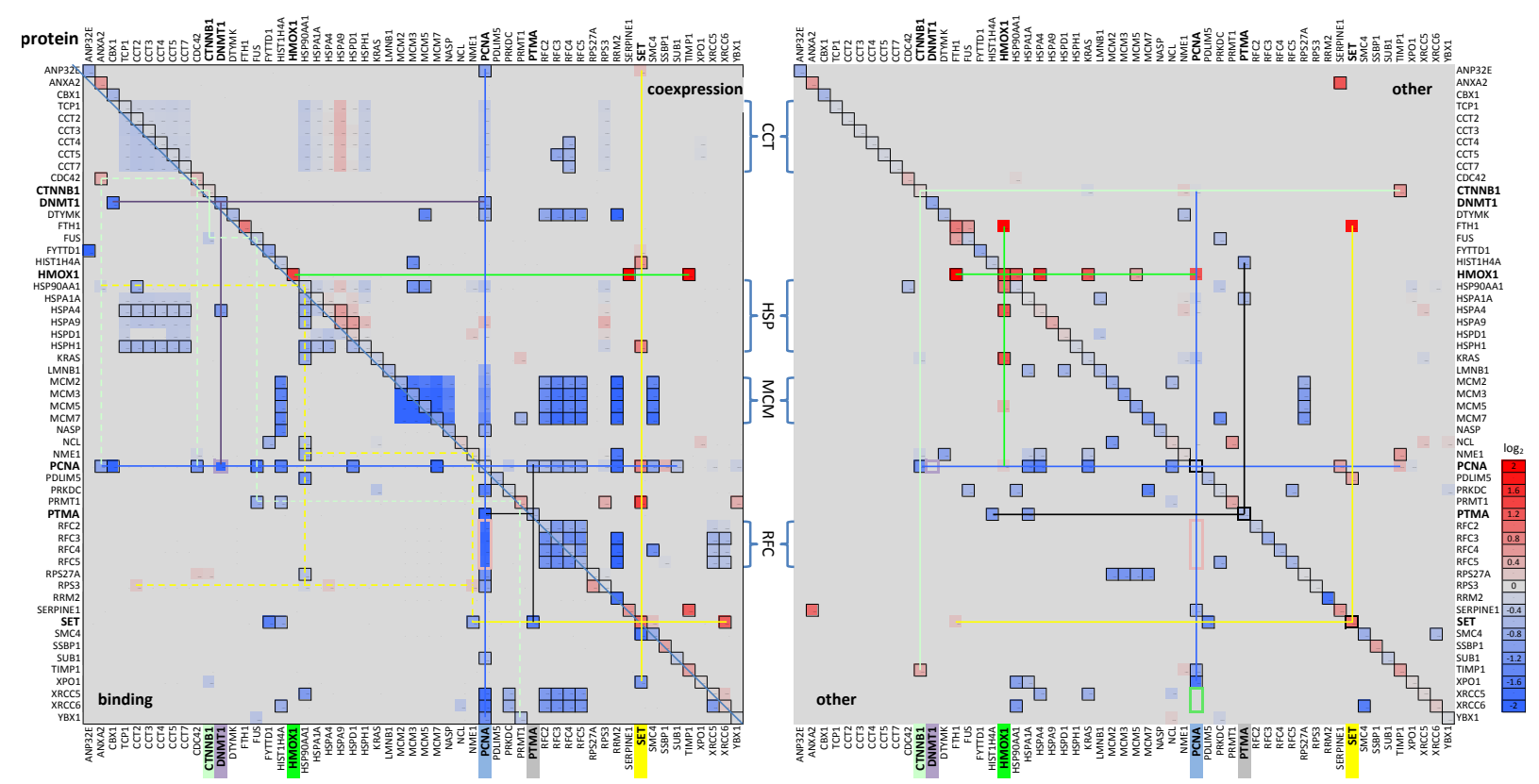

Figure 12. The local STRING-based interaction network for OAC around the 49-set proteins PCNA, PTMA and SET. The same set of 287 binary pair interactions as in Fig. 11 is shown. See the caption to Fig. 11 for explanation of the coding of the interactions.

PTMA seems to be an important connection of PCNA and SET to the nuclear transport karyopherins KPNA2 and KPNB1 (Fig. 10). Overall the set of proteins \{KPNA2, KPNB1, PCNA, PTMA, SET $\}$ and their interactions appear to constitute a "spatial switch" in which compartmental rebalancing of key proteins potentially modulates many core nuclear processes. The nuclear-cytoplasmic trafficking of these proteins connects to many processes at other subcellular locations (see discussion). There is clearly a strong connection to HMOX1 and FTH1, but the mechanism(s) are ambiguous and appear not to involve KPNA2 and KPNB1.

\section{5.d. An "orphan" protein - POLDIP2 and Oxidative Stress.}

There are many other local networks contained in the overall interaction network (see discussion). The extent to which these can be interpreted in terms of specific mechanisms is dependent on the coverage of the binary interactions available for the subset of proteins. As we have noted previously, ${ }^{9,11}$ this is often limited by lack of information about the nuclear roles of proteins with known functions in mitochondria, the plasma membrane, etc. Conversely, the local networks often suggest specific groups of proteins for which further investigation would be profitable. We illustrate this feature with an analysis of Polymerase delta interacting protein 2 (POLDIP2), a protein that has been under investigated, but which has indications for a crucial role in balancing oxidative stress responses in the nucleus, mitochondria and the plasma membrane and changes in DNA metabolism in the nucleus and mitochondria. ${ }^{11}$ STRING, REACTOME and CORUM do not contain human binary interactions for POLDIP2. STRING contains a small number of binary interactions for mouse and rat POLDIP2. Because POLDIP2 has been little investigated, these are mostly co-expression interactions of quite moderate magnitude. BioGrid ${ }^{20}$ contains a small number of binding interactions for human POLDIP2 gleaned mostly from low throughput experiments. These interactions identified five proteins (ICT1, PCNA, SHMT2, TRAP1, TUFM) that were included in our experimental 401-set (Fig. 13, selection set). We used these five proteins and their interactions within the joint human STRING, REACTOME and CORUM interactions to identify 42 further proteins in the 401-set that had interactions with at least two of the selection set proteins (Fig. 13, analysis set). This is effectively a constrained $r=2$ walk on the interaction matrix starting at POLDIP2. 

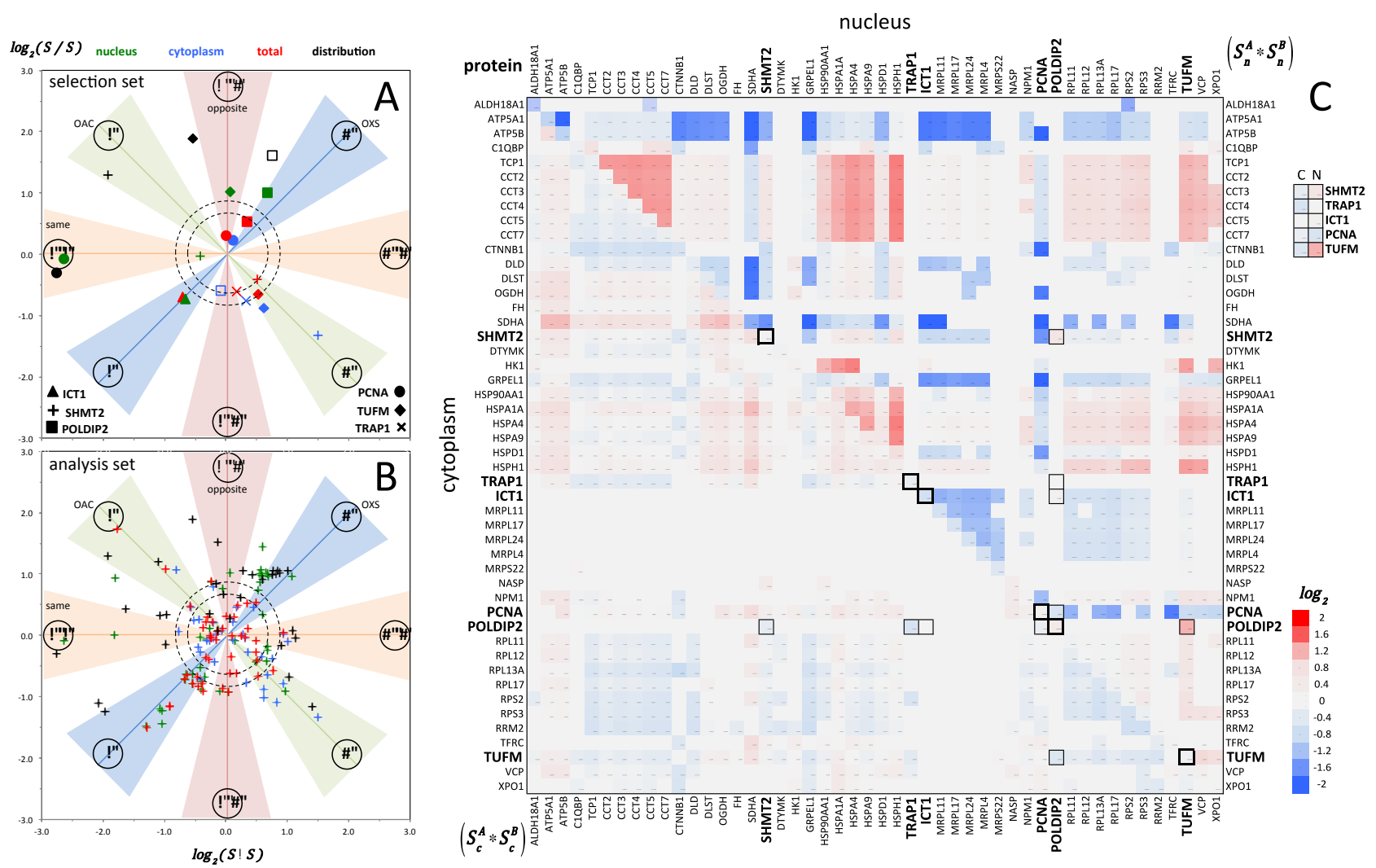

Fig. 13. Analysis of proteins related to POLDIP2. (A) Joint spatial razor plot for POLDIP2 and the 5 proteins used as a selection set. (B) Joint spatial razor plot for 48 proteins of the 401-set with human STRING interactions to at least two of the selection set proteins. (C) STRING combined score interaction network for OXS for the nuclear (upper off diagonal) and cytoplasmic (lower off diagonal) compartments. For the five proteins in the selection set, the insert at upper right shows a side-by-side comparison of their off diagonal intersections with POLDIP2 for the nuclear (N) and cytoplasmic (C) compartments.

For this set of 47 proteins that are potentially related to POLDIP2, the resulting interaction matrices in the nuclear and cytoplasmic compartments for OXS reveals a number of interesting features (Fig. 13). Although nominally "mitochondrial" proteins are predominant in the selection set (ICT1, SHMT2, TRAP1, TUFM), the large changes in binary interaction potentials are predominantly in the nuclear compartment. The pairwise changes for interaction of these selection proteins with POLDIP2 are modest, but for all four proteins the nuclear interactions are maintained/increased at the expense of cytoplasmic interactions. The PCNA/POLDIP2 binary interaction shows a modest reverse behavior. Conversely, PCNA is again a protein with strong changes in nuclear binary interaction potentials with many other proteins, amongst which "mitochondrial" proteins such as ATP5A1, ATP5B, SDHA and the mitochondrial import system protein GRPEL1 are prominent and several other mitochondrial proteins are included. This local perspective of the overall response to OXS suggests that mitochondria/nucleus retrograde signalling is important in response to OXS. Interestingly there is also a strong local nuclear interaction pathway involving SDHA and Transferrin receptor protein 1 (TFRC) with PCNA. The frataxin complex \{AFG3L2, ATP5L, FXN, HSPA9, HSPD1, LYRM4, SDHA\}, which is involved in iron storage and mitochondria (Table 1), includes four proteins with significant nuclear changes in our experiments. These interactions suggest nuclear connections to the important changes in iron/heme proteins, including HMOX1, FTH1 and FTL, that we have previously described for OXS. ${ }^{11}$ However, the crucial $\operatorname{link}(\mathrm{s})$ to the PCNA-SET-PTMA-HMOX1 axis remains to be characterized. POLDIP2 has recently been shown to be connected to the cell cycle, ${ }^{61}$ but the present data suggests that this may be indirect and involve POLDIP2-PCNA interactions. One plausible link is 
cooperation/competition between PCNA and POLDIP2 in binding to POLD and other DNA polymerases. ${ }^{62-64}$ There is further literature implicating POLDIP2 in interactions with the plasma membrane proteins CEACAM, NOX4 and EFGR, ${ }^{65-67}$ the mitochondrial proteins LONP1 and TUFM ${ }^{68,69}$ and to a possible role linking POLDIP2 to reactive oxygen species and balancing of nuclear, plasma membrane and mitochondrial response to oxidative stress. ${ }^{11}$ Further investigation of the role(s) of this protein in responses to oxidative stress is warranted.

\section{5.e. Chaperones and Retrograde Mitochondria to Nucleus Signalling.}

Many chaperones as well as the CCT complex that is involved in both de novo protein folding and membrane fusion events, have strong interactions in the 401-set (e.g., Figs. 11-13). In this section we illustrate the potentially crucial importance of such proteins in the context of mitochondrial import and of the retrograde mitochondria to nucleus signalling that is critical to many cellular functions. ${ }^{70}$

In addition to those proteins mentioned above, we have previously shown that substantial numbers of other mitochondrial proteins are present in the nucleus of IMR90 cells and that a small proportion of these mitochondrial proteins show nuclear responses to OXS or OAC. ${ }^{9,11}$ The joint analysis of the two data sets reveals complex cross-talk between the two perturbations that tends to be dominated by $\mathrm{N} \leftrightarrow \mathrm{C}$ redistribution rather than changes in total protein abundance (Fig. 14A). The changes for some proteins are primarily for one or the other perturbation, e.g. C1QBP/MDH2 (OAC) or LONP1/ALDH18A1 (OXS). Other proteins show clear cross-talk, e.g. EFTA (OPPOSITE) or PYCR1/HADHA (MIXED). As we have described previously, proteins of the proline regulatory axis (GLS, GLUD1, ALDH18A1, ALDH4A1, OAT, PYCR1,2) show systematic changes in compartmental abundance for OXS that correlate with major, opposite changes in collagen abundance and distribution. ${ }^{11}$ This system connects proline/arginine metabolism with glutamine metabolism, is coupled to NADH usage/production and has been proposed to play a major role in cancer metabolism. ${ }^{71}$ The redistribution mechanisms and the extent to which nuclear functions of mitochondrial proteins such as ALDH18A1 and PYCR1 are involved in the proline regulatory axis are subjects of on-going investigations.

Import of proteins into mitochondria has been extensively studied and mechanisms are known that direct proteins to the inner/outer mitochondrial membrane, the inter-membrane space or the mitochondrial matrix. ${ }^{72}$ Much less is known about partitioning of mitochondrial proteins to the nucleus or about their disposition to the nucleoplasm or nuclear envelope. Some prototypes for changes in the partitioning of proteins between the mitochondria and the nucleus in connection with the mitochondrial unfolded protein response are known, ${ }^{73}$ although the location/function(s) of such proteins in the nucleus are often unknown. REACTOME describes a key complex in systems for import of mitochondrial proteins from the cytoplasm \{HSPA9, GRPEL1, TIMM44, GRPEL2, PAM16, DNAJC19\} (REACT_120135.1), in which HSPA9 constitutes the ATP-motor for translocation of proteins into the mitochondrial matrix. ${ }^{74}$ This complex interacts with the TIMM complex \{TIMM17A, TIMM17B, TIMM21, TIMM23, TIMM50\} (REACT_119853.1) in mitochondrial matrix protein import. The mitochondrial proteases PMPCA, PMPCB and PITRM1 are involved in processing of import pre-sequences.

For OXS/OAC particularly pronounced experimental changes were observed for GRPEL1, HSPA9, and TIMM44. Other mitochondrial import proteins in these complexes were in the 4048-set of proteins with little change (DNAJC19, TIMM17A, TIMM21, TIMM50) or were not detected (GRPEL2, PAM16, TIMM17B). For IMR90 cells, the major changes in DNAJ 
chaperones were for highly abundant DNAJA1 and for DNAJC9. A striking feature is the redistribution of GRPEL1 and HSPA9 (Fig. 14B). GRPEL1 is classified as SAME and is similar to PCNA, i.e. a major decrease in nuclear abundance with limited change in total or cytoplasmic abundance as a consequence of strong $\mathrm{N} \rightarrow \mathrm{C}$ redistribution for both $\mathrm{OXS}$ and OAC. In contrast HSPA9 shows MIXED behaviour with strong increase in total abundance for OXS/OAC, but strong opposite redistribution. The consequence is a strong increase in nuclear abundance of HSPA9 for OXS, but strong increase in cytoplasmic abundance for OAC.

To assess possible functional significance, we constructed local STRING-based interaction networks for DNAJA1, GRPEL1, HSPA9 and TIMM44 (Fig 14C). The interaction networks suggest that the potential for mitochondrial import of many proteins can be substantially altered by changes in their total abundance in coordination with the abundance and distribution of GRPEL1, HSPA9 and TIMM44 (upper off-diagonal region). Even proteins that are not imported to mitochondria could influence this potential by competition for available GRPEL1, HSPA9 and TIMM44. These potentials change in ways that differ appreciably between response to OXS and OAC and seem to be consistent with substantial differences in protein import to mitochondria in response to OXS/OAC. There are also strong changes in the total abundances of the PMPCA, PMPCB and PITRM1 proteases (Supplementary Table 2). 

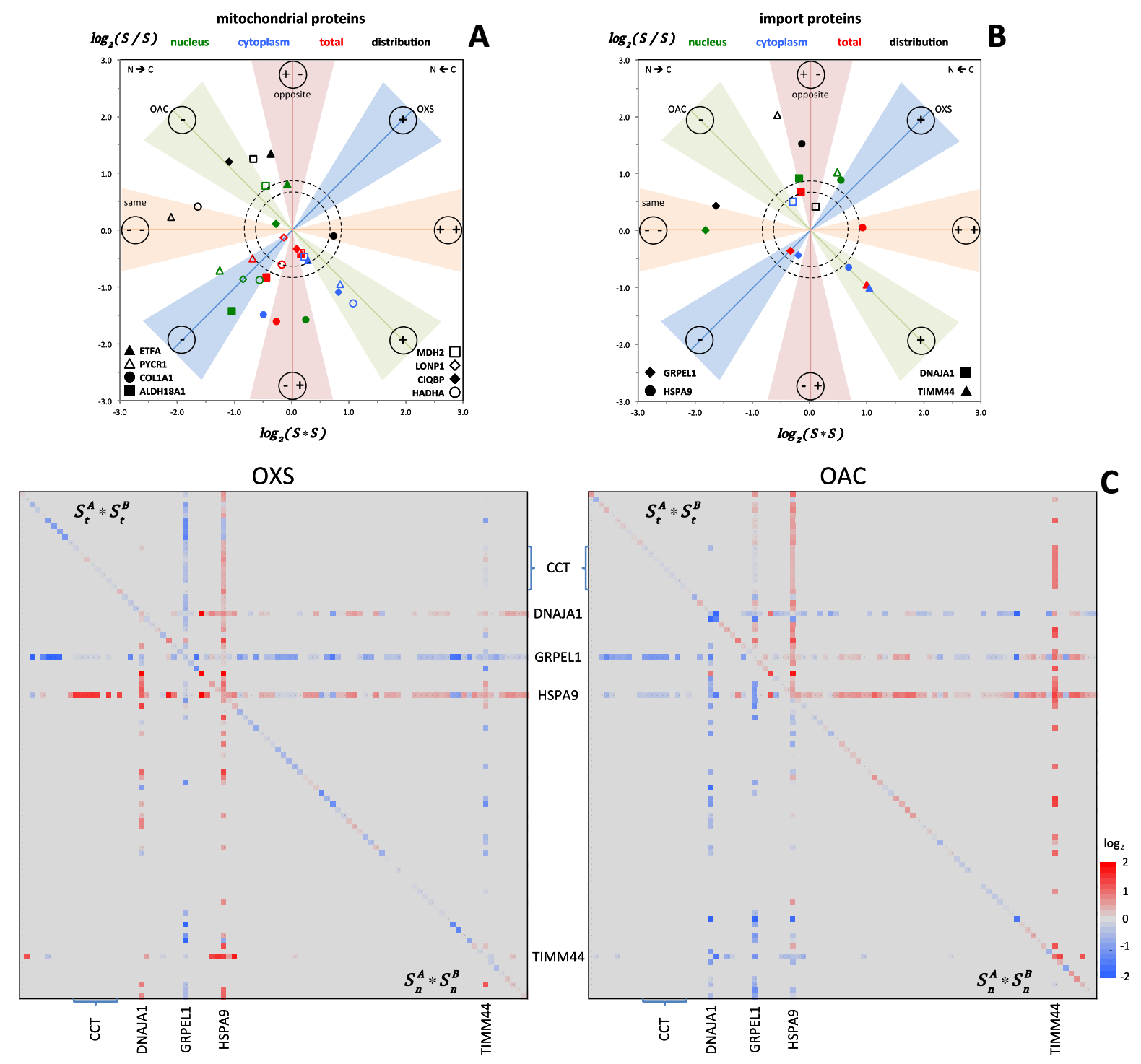

Figure 14. (A) Joint spatial razor plot for selected mitochondrial proteins and collagen. (B) Joint spatial razor plot for proteins involved in import of proteins to mitochondria and for DNAJA1. The open symbols correspond to proteins with small numbers of SILAC ratio counts in one compartment, i.e., cytoplasm for DNAJA1 and nucleus for TIMM44. (C) The local STRING-based interaction networks for OXS/OAC around the proteins DNAJA1, GRPEL1, HSPA9 and TIMM44. A set of 317 binary pair interactions was constructed by identifying a set of 89 additional 401-set proteins with interactions with at least two of the four seed proteins. Changes in total abundance for individual proteins $\left(S_{t}\right)$ were mapped to the diagonal. The experimental $S_{t}$ data for each STRING interaction pair A-B was mapped to the upper off diagonal region $\left(S_{\tilde{t}}^{A}+S_{\mathrm{t}}^{\mathbf{b}}\right)$, while the experimental $S_{n}$ data was mapped to the lower off diagonal region $\left(S_{\mathrm{K}}^{A}+S_{11}^{\mathbf{B}}\right)$. Supplementary Figure S-14 shows the identities for all 93 proteins and the separation of the interactions into coexpression, binding and other interactions.

A striking result in our data is that these same proteins are present in the nucleus and show complex nuclear changes for OXS/OAC (Fig. 14B). Interestingly, concurrent changes in compartmental distribution result in different apparent binding interaction potentials in the nucleus (Fig 14C). HSPA9 is distributed to and has many crucial functions in other locations besides mitochondria and the nucleus, including in exocytosis, endocytosis and cytoplasmic sequestering of $\mathrm{p} 53,{ }^{75}$ but $47 / 93$ proteins included in the interaction network and detected in the nucleus are annotated by GO to mitochondria. This includes a number of metabolic enzymes such as ALDH18A1, ATP5A1, DLD, DLST, GLUD1, ETFA, IDH3A, MDH2, SDHA, SDHB, and SHMT2 (Supplementary Figure S-14). HSPA9 is known to exist in the nucleus. For example, HSPA9 and ATP5A1 have been detected as components of the COPS nuclear 
signalosome ${ }^{76}$ and nuclear HSPA9 also interacts with the retinoic acid receptor to promote neuronal differentiation. ${ }^{77}$ There has been much recent progress regarding metabolic coupling between the nucleus and mitochondria in cellular function, e.g. in the context of cancer. ${ }^{78-80}$ However, although many proteins such as p53, prohibitin, various cyclins, nuclear hormone receptors, etc. also exist in both locations, study of dynamic, global partitioning of proteins to both organelles remains a topic ripe for exploitation. Although speculative, we hypothesize that complex changes in the abundance and subcellular location of key proteins such as GRPEL1 and HSPA9 could provide a basis for coordination of nuclear/mitochondrial response to perturbations such as OXS and OAC. It is unlikely and probably functionally counterproductive that nuclei would have an import system identical to mitochondria. However, such strong changes can certainly have influences on mitochondrial import that could alter subcellular partitioning of many proteins. This includes p53, which binds to HSPA9 and partitions not only to the cytoplasm and nucleus but also to mitochondria. ${ }^{81-83}$ Other chaperones such as DNAJA1, DNAJC9 and DNAJC19, as well as the various other heat shock proteins in the 401-set may also be involved in nuclear import/retention and might depend on compartment or cell type. What is also increasingly clear is that the nuclear envelope is not simply a passive barrier, but is actively involved in many cellular responses. ${ }^{84-87}$

\section{5.f. Conclusions regarding functional networks.}

The interaction network for the 4048-set of proteins is exceedingly complex and contains over 134,000 binary interactions. However, the present quantitative results identify 3472 strongly intertwined interactions for the 401-set that dominate both OXS and OAC responses. The changes in abundance/distribution are clustered in fundamental cellular processes such as DNA replication, extracellular matrix and cell-cell interactions, metabolic and energetic processes, translation, intracellular protein transport, and proteasomal degradation of proteins. The primary spatial associations of each process and their joint involvement emphasizes that response to OXS/OAC is spatially dispersed across cells. 2218 intra-cluster interactions that are partially the same for OXS/OAC modulate these subsystem functions. 1242 specific binary pairs dominate cross-process interactions. The changes of the interaction networks in the nuclear and cytoplasmic compartments are different and are suggestive of phase changes. Protein co-expression and protein-protein binding interactions do not adequately account for the changes, indicating a major role for subcellular protein transport. Local "hotspots" in the overall interaction network can be identified. For example, correlated changes in promiscuous proteins such as PCNA, PTMA and SET seem to use a KPNA2, KPNB1 nuclear import/export system in a control axis that changes numerous nuclear processes. The proteins GNB2L1, NCL, PABPC1, RPS10, RPS2, SSB may constitute a similar promiscuous control axis. The interaction network provides a means to identify functional relationships for orphan, littlestudied proteins such as POLDIP2 that for OXS may have spatially dispersed roles in the nucleus, plasma membrane and mitochondria. The network also suggests that proteins such as HSPA9 and GRPEL1 that are critical components of mitochondrial import systems also have a major role in retrograde mitochondrial to nucleus communication.

\section{DISCUSSION.}

At the molecular level living cells are exquisitely interconnected complex adaptive systems in which intertwined genomic, transcriptomic, proteomic and metabolic networks all play a crucial role. At the same time, cells are spatially heterogeneous systems in which subcellular compartmentalization of different functions is ubiquitous and requires efficient cross- 
compartmental communication. The present results indicate that data on the dynamic spatial reorganization of proteins provides an essential complement to studies of cellular function based on high throughput measurements of total abundance or of differential expression. They suggest that dynamic, coordinated redistribution of multitudinous proteins to different subcellular locations in response to cellular functional state is at least as important as overall changes in the abundance of proteins or other molecules such as miRNAs. In this context we consider three topics in the following. (1) We suggest that information on dynamic spatial redistribution of proteins is essential to obtain comprehensive pictures of cellular function. (2) We describe how spatial data of the type presented here can provide priorities for further investigation of crucial features of spatial coordination. (3) We suggest that the present data is related to increasing indications that much of subcellular protein transport is constitutive and that perturbation of these constitutive transport processes may be related to cancer and other diseases.

\subsection{Spatial Switching of Cellular Function.}

The present data contains indications that there are aspects of cellular function that are not captured efficiently by measurements of gene expression, whether measured by abundance of RNA transcripts or of proteins. Despite vast numbers of measurements aggregated by databases such as STRING, gene co-expression scores only identified about $37 \%$ of the proteins and $26 \%$ of the binary interactions for the 401-set (Table 6). Although measurements of direct proteinprotein binding are presently less extensive, these identified a greater proportion of proteins (76\%) as interactors. This proportion did not increase much $(78 \%)$ with the union of coexpression and binding interactions, suggesting that a plateau in the usefulness of gene coexpression measurements may have been reached. More extensive direct high-throughput measurements of global protein-protein binding may still increase the proportion of proteins identified as interactors, but we suspect that for a variety of reasons these will also reach a plateau in their usefulness: (1) transient binding interactions may be difficult to capture, (2) distribution of the same protein over multiple functional roles may be difficult to identify, (3) strong non-linearity in cellular function means that only a small proportion of a given protein may be involved in a specific function, i.e. there may be dynamic range difficulties for individual proteins, (4) the available methodologies are not optimal for very high throughput application to wide ranges of functional contexts and cell types, etc. Direct binding only detected $47 \%$ of the interaction pairs and even the union of binding and co-expression only detected 56\% (Table 6). Much more sophisticated mathematical modelling of data of the present type is possible and will eventually be necessary to construct electronic models of cells, but even this simple analysis suggests there are important contributions that are not being captured. Both of these types of global measurements largely ignore features long known from more conventional cell biology approaches: cells are functionally and spatially inhomogeneous, such heterogeneity is an essential characteristic of cellular function, proteins move and any given protein can only carry out a specific function if it is in the right spatial location.

The present study provides extensive evidence that subcellular distribution and translocation of proteins is a crucial missing link in systems biology analysis of cellular function. As we have described in more detail previously, ${ }^{11,88-90}$ this has long been implicit in the data on subcellular location aggregated by databases such as GO. For example, at a high level of description of cellular location (nucleus, cytoplasm, plasma membrane, extracellular region), the 401-set proteins generally have wide distribution over different locations (Fig. 15). Of the 185 proteins annotated to the nucleus by GO, 90/41/160 are also annotated to the extracellular region, 
plasma membrane and cytoplasm respectively. There are very few proteins annotated uniquely to nucleus (21 proteins), plasma membrane (2) or extracellular region (3). About $35 \%$ of the 401-set proteins are annotated to three or more high level locations. Of the 70 proteins annotated uniquely to cytoplasm, many have annotations to multiple cytoplasmic organelles at a more detailed level (Fig. 15). In short, there are large amounts of independent data that are consistent with substantial subcellular dispersion/mobility of the proteins in the 401set. In fact, as with other cell types, ${ }^{90}$ the GO annotations seem to underestimate the dispersion of proteins over multiple locations in IMR90 cells. For example, whereas GO annotates $185 / 401$ proteins to the nucleus, we quantitated 313/401 in the nucleus for both OXS/OAC and 265 showed significant changes in $S_{n}$ for OXS and/or OAC. The dispersion of the 401-set proteins over many subcellular locations is consistent with their involvement in high-level spatial coordination of cellular function. For proteins such as PCNA, SET, KPNA2, KPNB1, etc. that have been intensively studied in the nucleus, functional mechanisms and networks that are
Distribution of GO CC Annotation for 401-set Proteins

\begin{tabular}{rrrrrrrrrrr}
\hline LOCATION & Ex & \multicolumn{1}{c}{$\mathrm{N}$} & \multicolumn{1}{c}{$\mathrm{P}$} & \multicolumn{1}{c}{$\mathrm{C}$} & \multicolumn{1}{c}{$\mathrm{S}$} & $\mathrm{Er}$ & $\mathrm{En}$ & $\mathrm{G}$ & \multicolumn{1}{c}{$\mathrm{L}$} & $\mathrm{M}$ \\
\hline extracellular region & 203 & 90 & 76 & 193 & 90 & 34 & 28 & 29 & 31 & 49 \\
nucleus & 185 & 41 & 160 & 89 & 17 & 8 & 13 & 9 & 34 \\
plasma membrane & & & 115 & 110 & 53 & 22 & 25 & 21 & 20 & 22 \\
cytoplasm & & & 364 & 153 & 59 & 36 & 51 & 37 & 109 \\
\cline { 4 - 10 } cytosol & & & 153 & 20 & 16 & 19 & 11 & 24 \\
endoplasmic reticulum & & & & & 59 & 7 & 21 & 6 & 13 \\
endosome & & & & & & 36 & 12 & 17 & 6 \\
Golgi apparatus & & & & & & & 51 & 9 & 6 \\
lysosome & & & & & & & & 37 & 4 \\
mitochondrion & & & & & & & & & 109 \\
\hline
\end{tabular}

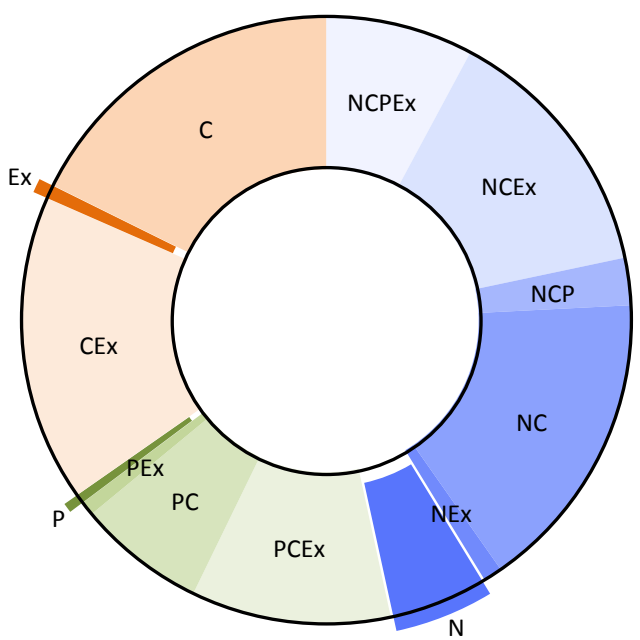

Fig. $15 \mathrm{GO}$ annotation of the spatial distribution of proteins in the 401-set. Table. Number of proteins annotated to high level spatial descriptors (diagonal, Ex, N, P, C) or jointly to two high level descriptors (off-diagonal). For proteins annotated to cytoplasm, more detailed cytoplasmic locations are shown. Doughnut. Proportion of proteins assigned to 1-4 of the high level spatial descriptors. coupled with trafficking can be identified. We expect that many of the newly identified proteins will lead to novel mechanisms and networks with further investigation of their nuclear roles. Indeed, we suggest that the local compartmental changes in abundance are the real basis for modulation of cellular function and that comprehensive pictures of function will require identification of the transported proteins and elucidation of the local processes in which these proteins participate. Recent work on human dermal fibroblasts, which proliferate continuously without being cancer cells, indicates that numerous enzymes involved in central carbon metabolism (the TCA cycle and glycolysis) influence entry to S-phase and DNA replication. ${ }^{91}$ We detected changes in the nucleus for a number of these enzymes, which suggests complex, spatially dependent, inter-compartmental feedback loops. Much as the original dogma of genomics [one gene $\Rightarrow$ one mRNA $\Rightarrow$ one protein] has had to be extensively modified, so the often unconsciously assumed corollary [one protein $\Rightarrow$ one location $\Rightarrow$ one function] also requires revision. Furthermore, the very substantial intertwining of different, complex functional networks and the transfer of proteins between different local spatial/functional networks requires quantitative monitoring of whole networks rather than of a few individual proteins to distinguish direct, dominant mechanisms from indirect, propagated effects. The magnitude of the responses in highly intertwined networks that cover diverse spatial locations are crucial since propagation and/or alternative, non-monitored functions at other locations may 
well lead to detectable, but secondary effects of some magnitude at some observed location for induced perturbation of many single proteins.

\subsection{Prioritizing Discovery of High Level Spatial Integration.}

Current wisdom often implies that the most desirable way to examine dynamic cellular properties are experimental time series of the responses to a single type of perturbation. In fact, the limitations of this approach have already been discussed in papers that justify the need for theoretical prediction of fluxes and protein "mislocation" in disease models ${ }^{156}$ - the approach leads to an almost infinite set of possible experiments. We feel that a more productive strategy is to drive cells into different (semi)-stable regions of a response landscape (phase changes) and identify the major differences between two such states. By using the checkpoints of the cell cycle we were able to induce cell cycle arrest with two completely different cellular perturbations, neither of which involves direct manipulation of cyclins. The resulting characterization of the responses that are the SAME, OPPOSITE, MIXED or UNIQUE to one of the two perturbations provides a profound view into the complex, spatially distributed interrelationships that are involved in cellular proliferation. This approach provides unbiased "hot spot" characterizations of an exceedingly complex overall network that provide focus for further investigations and that should already be of major interest to many researchers.

The present experiments indicate that for strong perturbations such as oxidative stress or suppression of DNA replication/cell cycle progression, there are large numbers of proteins that show no or modest changes in compartmental abundance and distribution, but only a limited subset of proteins that show substantial changes. These latter proteins seem to be functionally strongly intertwined with only a minority of the proteins more specific to OXS or OAC (Fig. 3). Their extensive distribution over many subcellular locations recorded in databases such as GO suggests that proteins of the 49-set and 401-set may be important contributors to high order spatio-functional organization across the cell. Conversely, the changes are not dominated by very large changes in a few proteins, but rather by more limited changes for substantial numbers of proteins. This type of coordinated network behaviour is reminiscent of very extensive gene expression measurements and is probably what should be expected for the stable networks of complex adaptive systems. ${ }^{92}$ Greater depth in global detection of proteins is always desirable and there are some lower abundance proteins for which significant changes were only adequately quantified in one of the two present experimental data sets (Supplementary Table 1). However, the present experiments provide a very significant prioritization of the most relevant proteins and the quantitative, spatially resolved interaction network (Supplementary Table 6) provides a very rich context for further investigations. We estimate from the present data that greater depth in the spatial analysis of OXS, OAC and their crosstalk would be adequately covered by collection of more extensive data for about 500 proteins using MS-based selected reaction monitoring. ${ }^{93}$ Apart from increased spatial resolution of "cytoplasm" and more extensive coverage of lower abundance proteins, this should also include more complete coverage of protein sequence to detect variation in transcriptional/translational isoforms and post-translational modifications. For example, we note that isoform 2 of SET was the consensus sequence in our experiments, but that the available peptides do not exclude the co-presence of isoform 1. In general, the observation that a large majority of proteins show limited change suggests that methods for detailed, parallel coverage of roughly 100-500 prioritized proteins may provide a more productive strategy for in-depth elucidation of cellular function than attempts to achieve global monitoring of 10,000+ proteins with much more limited data for the individual proteins. We have addressed technical 
issues regarding collection of suitable proteomics data for elucidation of spatial features of function elsewhere ${ }^{9,11,88}$ and note here that the use of a conservation of mass test provides a strong framework to select the most reliable changes.

The set of proteins $\{$ KPNA2, KPNB1, PCNA, PTMA, SET $\}$ provides an instructive example of a putative spatial switch, with the concurrent changes described here offering new perspectives that intersect with many nuclear processes (Figs. 6,11,12). We note that in our experiments the bulk of PCNA was in the cytoplasm (Fig. 5). This is in concert with other very recent studies that identify cytosolic complexes of PCNA with many proteins involved in MAPK and PI3K/Akt signaling pathways and in TLR-mediated cytokine secretion. ${ }^{94}$ This suggests PCNA will also have many cytoplasmic activities and provides starting points for further investigation of control of PCNA nucleo-cytoplasmic transport. Post-translational modifications modulate nuclear activities of $\mathrm{PCNA}^{95,96}$ and the integration of cytoplasmic signaling systems with nuclear trafficking may provide mechanisms that influence the distribution of PCNA over the suggested nuclear functional branches (Fig. 6).

SET has also long been known to be a multi-faceted protein with various roles in the nucleus, including regulation of histone acetylation and transcriptional repression, ${ }^{97}$ CTL-mediated apoptosis in combination with NME1, ${ }^{98}$ and repression of p53 activity. ${ }^{99}$ Its nuclear import has been connected to phosphorylation and to karyopherins such as KPNB1. ${ }^{100}$ That SET binds to p53 and prevents its acetylation by EP300- and PCAF-mediated processes, thereby inhibiting p53-mediated cell cycle arrest and apoptosis, ${ }^{99}$ and that PCNA also binds to EP300 $0^{101}$ is possibly a nuclear interaction that could have wide-ranging effects. In the cytoplasm SET is an inhibitor of phosphatase (PP2A) activity and this is closely related to processes such as hematologic malignancies ${ }^{102}$ or hyperphosphorylation of tau in neuronal cells and Alzheimer's patients. ${ }^{103}$ SET has also been shown to form a plasma membrane complex with RAC1 that stimulates cell migration, ${ }^{104}$ to regulate VE-cadherin in mammalian cells ${ }^{105}$ and to be recruited to the G-protein-coupled adrenergic receptor complex. ${ }^{106}$ Its distribution between the nucleus, cytoplasm and plasma membrane appears to toggle inhibition or promotion of axon growth and regeneration. ${ }^{107}$ In the endoplasmic reticulum SET has been identified as part of a complex with three DNAses (NME1, APE1 and TREX1) that traffics with the nucleus and facilitates HIV-1 infection by preventing suicidal autointegration. ${ }^{108}$ NME1 is included in the 401-set and its potential nuclear interactions with SET were monitored in our experiments (Figs. 11,12). However, in the context of OAC/OXS changes in nuclear/cytoplasmic abundance of SET and NME1 were not correlated (Supplementary Table 2), i.e. are not dominated by the trafficking of their complex with APE1 and TREX1. The diversity of its many functions suggests that SET, like PCNA, may also be distributed over many functional branches in the nucleus. In contrast to PCNA, the nuclear-cytoplasmic trafficking of SET is already known to have functional consequences at numerous other subcellular spatial locations. It may also be noted that a closely related protein (SETSIP, with a 10 amino acid extension at the amino terminus of SET) has been implicated in reprogramming of fibroblasts into endothelial cells. ${ }^{109}$

In addition to the interactions with PCNA and SET noted above, prothymosin alpha (PTMA) has nuclear interactions with linker $\mathrm{H} 1$ histones that may be important for chromatin decondensation and replication. ${ }^{10,111}$ It enhances transcription of estrogen receptor, ${ }^{112}$ physically interacts with CREB-binding protein to stimulate AP1- and NF- $\kappa B$-dependent transcription, ${ }^{113}$ and potentiates 553 transcription. ${ }^{14}$ Expression of PTMA is positively regulated by estrogen receptor alpha ${ }^{115}$ and $\mathrm{c}-\mathrm{myc}^{116}$ and negatively regulated by $\mathrm{p} 53 .{ }^{117} \mathrm{~A}$ potentially decisive connection with oxidative stress is that PTMA can bind to KEAP1 and 
influence NRF2 availability in the nucleus, ${ }^{118,119}$ which may have profound effects on transcription of proteins related to oxidative stress. The binding between PTMA and KEAP1 has been confirmed by a crystal structure ${ }^{120}$ and in vitro biophysical studies. ${ }^{121}$ In the cytoplasm PTMA has a defined activity as a suppressor of apoptosis by hindering assembly of the apoptosome $^{122,123}$ and its translation is controlled by the ubiquitous member HuR of the $\mathrm{Hu} / \mathrm{ELAV}$ family of mRNA binding proteins that are strongly involved in translational control. ${ }^{124}$ The strong nuclear import sequence of PTMA has been reported to be involved in translocation of STAT3 to the nucleus in response to interferon. ${ }^{125}$ PTMA was originally characterized as a protein with strong immune-modulatory activity and recent results suggest that PTMA has extracellular roles in cytokine-like functions that stimulate type I interferon via Toll-like receptor $4 .^{126,127}$

Vigilin (HDLBP, high density lipoprotein binding protein) was also included as a peripheral part of the PCNA control axis (Fig. 6). After original identification as a plasma membrane protein that was estrogen-inducible and sensitive to cholesterol, this role was little investigated further. As a protein highly conserved from yeast to mammals that contains $14 \mathrm{KH}$ domains involved in nucleotide binding, research instead concentrated on putative roles in chromatin silencing together with PRKDC/XRCC5,6 $6^{42,128,129}$ and on translational control via mRNA interactions. ${ }^{130-132}$ It is known to partition between the nucleus and the cytoplasm. Recently HDLBP has been shown to function as a receptor for a potential anti-cancer agent in plasma membrane lipid rafts, ${ }^{133}$ to interact with CCCTC-binding factor (CTCF) involved in CTCFdependent regulation of the imprinted genes IGF2 and $\mathrm{H} 19,{ }^{134}$ and as a candidate tumor suppressor deleted at 2q37.3 in tumor cells generated from many tissue types with insertional mutagenesis screens. ${ }^{135}$ Our data, which shows appreciable OPPOSITE change in cytoplasmic abundance (Supplementary Table 2), seems to be the first report connecting vigilin to oxidative stress and DNA replication. In fact, for OAC the dominant changes for vigilin and the associated nuclear proteins (PRKDC, XRCC5,6) are $\mathrm{N} \rightarrow \mathrm{C}$ increases in cytoplasmic abundance (Supplementary Table 2), suggesting that vigilin might sequester PRKDC/XRCC5,6 to the cytoplasm in the context of OAC.

Spatial redistribution of key proteins is an important characteristic of the proposed \{KPNA2, KPNB1, PCNA, PTMA, SET \} switch, with nuclear-cytoplasmic trafficking connecting these proteins to alternate functional activities in diverse subcellular locations. For OXS there are diverse interactions via PTMA/KEAP1, IQGAP1/NRF2 ${ }^{136}$ and HMOX1/NRF2 ${ }^{137}$ that may operate in parallel to the better-known KEAP1/NRF2 system. OAC response is intertwined with the OXS changes and the present data suggests priorities for further investigations. There are many indications in the present data for similar trafficking effects in other systems. For example, another protein in the 401-set is HMGB1 (OPPOSITE, Supplementary Table 2), which in addition to nuclear roles in DNA replication/repair has intricate involvement in autophagy, phagocytosis, and oxidative stress as a cytosolic/extracellular protein. ${ }^{138,139}$ Similarly, \{GRPEL1, HSPA9\} may be an important spatial switch for mitochondrial/nuclear communication (section 3.5.e). In general, the present data suggests that there may be correlated subcellular trafficking of specific networks of proteins and that understanding of the functional relationships for individual proteins will require embedding them in these transport networks.

There are many more local features of interest in the present OXS/OAC interaction network than can be presented here. For each of these there is often a substantial literature that requires very appreciable effort to find and digest. We suggest that a symbiosis between global 
proteomics data of the type reported here and the many experts in specific subsystems is needed to fully exploit the information. We included numerous subsystems in the analyses to motivate such symbiosis. Ideally this would involve collaborative efforts to define the salient spatial integration of core cellular processes. For example, the present data identifies >100 proteins with known functional roles in non-nuclear locations that are present in the nucleus and responsive to OXS/OAC, but whose functional role(s) in the nucleus are ambiguous or unknown. To provide some entry points to the present data, Supplementary Table 2 contains several pre-selected groups of proteins that appeared interesting to us. For example, the 401-set includes five proteins related to insulin-like growth factors: Insulin-like growth factor-binding proteins (IGFBP5, IGFBP7), insulin-like growth factor receptor 2 (IGF2R), and Insulin-like growth factor 2 mRNA-binding proteins (IGF2BP1, IGF2BP3). With a smaller number of ratio counts, IGF2BP2 shows similar behaviour to IGF2BP1,3 for OXS (Supplementary Table 1). This system is crucial to prenatal development and prominent in cancer cells. ${ }^{140}$ IGF2BP2 has recently been related to mitochondrial OxPhos proteins in cancer stem cells ${ }^{141}$ and IGF2R to response to oxidative stress involving mitochondria. ${ }^{142}$ IGF2R may have functional endoplasmic reticulum connections to two other mannose receptors included in the 401-set (M6PR, MRC2) and/or to proteins involved in stress granules (G3BP1, G3BP2, YBX1), ${ }^{143}$ all three of which tend to show increased nuclear abundance for OXS (Supplementary Table 2). Both IGF2BP3 and YBX1 are involved in spliceosomes (Fig. 4). These features, the modulation of c-myc by IGF2BP2 $2^{144}$ and the involvement of c-myc in crucial aspects of response to oxidative stress ${ }^{145}$ suggest that there may be large networks that connect many aspects of the responses to OXS/OAC via spatial redistribution of key proteins.

Other pre-selected groups in Supplementary Table 2 include heme/iron proteins, proteins related to $\mathrm{Ca}^{2+}$, redox proteins that use NAD/NADH, the EGFR pathway, etc. The clusters in Fig. 9 and Supplementary Figure S-12 and the interactions that connect different clusters (Fig. 9, Supplementary Table 6) provide other entry points. No doubt there are other proteins and groups of proteins that may be of interest in specific contexts and for which information on their response to OXS/OAC may be useful. We would encourage readers to look for their favourite proteins/systems in the joint spatial razor plots and data in Supplementary Tables 1 and 2, in the complexes in Supplementary Table 3, in the subcellular transport annotation in Supplementary Tables 4 and 5 and in the spatially resolved interaction network in Supplementary Table 6. We anticipate that the present information should aid in setting priorities for experiments aimed at a crucial but somewhat neglected area: high level spatial integration of function over diverse subcellular locations.

We also note that the present interaction network and the outlined strategy for exploring possible functional relationships of less studied proteins (POLDIP2, section 3.5.d) can in principle also be applied to other proteins that may not have been detected in our experiments. If your favorite protein was not reported in our listings, look for sets of related proteins and construct a network by adding interactions with your favorite protein from STRING or elsewhere. We used this approach to identify 401-set proteins with interactions to TGF $\beta$ signalling (Supplementary Figure S-10).

\subsection{Dynamic Spatial Integration and Disease.}

Dynamic changes in the abundance, form and distribution of proteins are essential for cellular function. At least part of distribution is constitutive. For example, large proportions of the constituent proteins of mitochondria or the plasma membrane are known to be directed to the 
organelle by protein transport/import systems and to be recycled from such organelles by processes such as autophagy. Recent evidence suggests that even organelles such as mitochondria may have constitutive export of proteins. ${ }^{146,147}$ Oscillatory circadian rhythms, ${ }^{148}$ oscillations of response to oxidative state, ${ }^{149-151}$ superoxide bursts in mitochondria, ${ }^{128,152}$ and $\mathrm{pH}$ bursts in endosomes ${ }^{153}$ are among the many other instances of dynamic behaviour. Treadmilling of cadherins in the maintenance of cellular polarity and the possible involvement of this and other endocytotic processes in epithelial-to-mesenchymal transitions is another example. ${ }^{154}$ The present data suggests that many such dynamic processes will be reciprocally coupled to processes such as DNA replication or oxidative state, e.g., that the responsiveness of cells to external signals is intricately coupled to oxidative or cell cycle status.

At the same time, there is increasing evidence that "mislocated" proteins, which presumably reflect defects in subcellular transport, are a characteristic of many diseases. ${ }^{155}$ Global, systematic analysis of the subcellular spatial dynamics of proteins has recently been initiated, but proteome-wide data is still sparse. This has led to attempts to couple predictions of the subcellular location of proteins with functional network analysis to predict "mislocated" proteins in diseases such as cancer, for example in brain glioma cells. ${ }^{156}$ Many proteins (157) were predicted to be candidate "mislocated" proteins and experimental confirmations of "anomalous" locations/distributions were obtained for 15 proteins. ${ }^{156}$ Some of these proteins are in the 401-set in the present experiments. For example, Lee et al. predicted that the "mislocations" endoplasmic reticulum $\rightarrow$ nucleus (FTL, PTCD1) and cytosol $\rightarrow$ nucleus (SSB) are associated with glioma. ${ }^{156} \mathrm{We}$ observe all three of these proteins in the nucleus in unperturbed IMR90 fibroblasts with strong changes in nuclear abundance upon perturbation (FTL, SAME; PTCD1, OXS; SSB, OPPOSITE; Supplementary Table 2). This suggests that the predictive methods may be identifying normal, spatially distributed cellular responses related to oxidative state and DNA replication/proliferation rather than cancer per se. Further characterization of the spatially dispersed "trademarks" for basic processes such as oxidative stress and DNA replication (Fig. 3) in various cell types would aid in classifying such features. On the other hand, for MCF7 breast cancer cells there is direct experimental evidence that large numbers of proteins do indeed show anomalous subcellular distributions, that massive numbers of proteins undergo nuclear-cytoplasmic redistribution when the cells are exposed to estrogen and that in this context subcellular redistribution of proteins is much more prominent than changes in their total abundance. ${ }^{88,90,157}$

We suggest that focussing on the requirement for efficient cross-compartmental subcellular communication in a spatially heterogeneous system offers a powerful, but so far underexploited paradigm to characterize cellular function, especially for defining spatial integration of function over many locations. Oblique recognition of the need for such approaches is beginning to appear in the form of databases that catalogue "moonlighting" proteins that are known to have multiple functions at different locations ${ }^{17,158}$ or that catalogue protein-protein binding interactions according to specific locations/organelles. ${ }^{159}$ The rapidly increasing number of examples of moonlighting proteins has led to suggestions that new paradigms are needed in cell biology. ${ }^{16,160}$ The present results suggest that there may be sets of limited numbers of proteins that have a dominant role in spatial coordination of function. We would further suggest that more extensive understanding of the integrated protein transport processes in normal cells is crucial to making sense of the large numbers of "anomalous" proteins that are being identified as correlated with a plethora of different diseases. It may be the failure to correctly transport a protein(s) that contributes to dysfunction. 


\section{ACKNOWLEDGEMENTS}

This study has been supported by the Wellcome Trust grant 081879/z/06/z (JGZ), King Abdullah Al Saud Foreign Scholarship Program and the Saudi Ministry of Higher Education (NB).

\section{SUPPLEMENTARY MATERIALS}

1. Supplementary Figures 1-14 and Supplementary References.

Figure S-1. Network and joint spatial razor plot for 18 enzymes of glycolysis and the pentose phosphate shunt.

Figure S-2. Correlation of SILAC ratios between OXS and OAC for proteins assigned to the SAME class.

Figure S-3. Overlap matrix $(r=1)$ for groups of CORUM complexes containing 19 proteins of the 49-set.

Figure S-4. Joint spatial razor plots for the Nop56p complex and FIB-associated complex involved in ribosome biogenesis.

Figure S-5. Analysis of the response of emerin nuclear envelope complexes to OXS and OAC.

Figure S-6. Joint spatial razor plots for the CCT protein folding complex, ATP synthase and V-Type ATPase.

Figure S-7. Joint spatial razor plots showing changes in subcellular abundance and compartmental distribution for proteins annotated by GO to nucleocytoplasmic transport (GO:0006913).

Figure S-8. Joint spatial razor plots showing changes in subcellular abundance and compartmental distribution for proteins annotated to endocytosis (GO:0006897).

Figure S-9. Joint spatial razor plots for 401-set proteins annotated by GO to small GTPase mediated signal transduction (GO:0007264) and/or GTPase activity (GO:0003924).

Figure S-10. Overlap matrix with radius $=2$ and joint spatial razor plots for integrins, collagens and related proteins contained in the CORUM database.

Figure S-11. The overall set of 134,850 binary interaction pairs for the 4048 -set of proteins.

Figure S-12. Interaction network for 401-set proteins clustered with the ClustNSee T-fit algorithm.

Figure S-13. Experimental weighted interaction network for the 401-set proteins for the clusters of the combined data set.

Figure S-14. The local STRING-based interaction networks for OXS/OAC around the proteins DNAJA1, GRPEL1, HSPA9 and TIMM44.

Supplementary References.

2. Supplementary Text. Methods used for selection of significant proteins.

3. Supplementary Tables

Supplementary Table 1. MS data for 4048-set of proteins.

Supplementary Table 2. Summary of MS data for 401-set of significant proteins.

Supplementary Table 3. CORUM complexes for 401-set proteins.

Supplementary Table 4. Nuclear import-export annotation for 401-set proteins.

Supplementary Table 5. Vesicle trafficking annotation for 401-set proteins.

Supplementary Table 6 . Binary interaction data for 401-set proteins. 


\section{REFERENCES}

(1) Burhans, W. C.; Heintz, N. H. Free Radical Biology and Medicine 2009, 47, 1282.

(2) Chiu, J.; Dawes, I. W. Trends in cell biology 2012, 22, 592.

(3) Menon, S. G.; Goswami, P. C. Oncogene 2006, 26, 1101.

(4) Robey, R. B.; Weisz, J.; Kuemmerle, N. B.; Salzberg, A. C.; Berg, A.; Brown, D. G.; Kubik, L.; Palorini, R.; Al-Mulla, F.; Al-Temaimi, R.; Colacci, A.; Mondello, C.; Raju, J.; Woodrick, J.; Scovassi, A. I.; Singh, N.; Vaccari, M.; Roy, R.; Forte, S.; Memeo, L.; Salem, H. K.; Amedei, A.; Hamid, R. A.; Williams, G. P.; Lowe, L.; Meyer, J.; Martin, F. L.; Bisson, W. H.; Chiaradonna, F.; Ryan, E. P. Carcinogenesis 2015, 36 Suppl 1, S203.

(5) Rosa M. Sainz, F. L., and Juan C 2012, 4, 442.

(6) Sarsour, E. H.; Kumar, M. G.; Chaudhuri, L.; Kalen, A. L.; Goswami, P. C. Antioxidants \& redox signaling 2009, 11, 2985.

(7) Ong, S. E.; Blagoev, B.; Kratchmarova, I.; Kristensen, D. B.; Steen, H.; Pandey, A.; Mann, M. Molecular \& cellular proteomics : MCP 2002, 1, 376.

(8) Mulvey, C.; Tudzarova, S.; Crawford, M.; Williams, G. H.; Stoeber, K.; GodovacZimmermann, J. Journal of proteome research 2010, 9, 5445.

(9) Mulvey, C. M.; Tudzarova, S.; Crawford, M.; Williams, G. H.; Stoeber, K.; GodovacZimmermann, J. Journal of proteome research 2013, 12, 1436.

(10) Tudzarova, S.; Trotter, M. W.; Wollenschlaeger, A.; Mulvey, C.; GodovacZimmermann, J.; Williams, G. H.; Stoeber, K. The EMBO journal 2010, 29, 3381.

(11) Baqader, N. O.; Radulovic, M.; Crawford, M.; Stoeber, K.; Godovac-Zimmermann, J. Journal of proteome research 2014, 13, 4398.

(12) Carbon, S.; Ireland, A.; Mungall, C. J.; Shu, S.; Marshall, B.; Lewis, S. Bioinformatics 2009, 25, 288.

(13) Szklarczyk, D.; Franceschini, A.; Wyder, S.; Forslund, K.; Heller, D.; Huerta-Cepas, J.; Simonovic, M.; Roth, A.; Santos, A.; Tsafou, K. P.; Kuhn, M.; Bork, P.; Jensen, L. J.; von Mering, C. Nucleic acids research 2015, 43, D447.

(14) Croft, D.; Mundo, A. F.; Haw, R.; Milacic, M.; Weiser, J.; Wu, G.; Caudy, M.; Garapati, P.; Gillespie, M.; Kamdar, M. R.; Jassal, B.; Jupe, S.; Matthews, L.; May, B.; Palatnik, S.; Rothfels, K.; Shamovsky, V.; Song, H.; Williams, M.; Birney, E.; Hermjakob, H.; Stein, L.; D'Eustachio, P. Nucleic acids research 2014, 42, D472.

(15) Ruepp, A.; Waegele, B.; Lechner, M.; Brauner, B.; Dunger-Kaltenbach, I.; Fobo, G.; Frishman, G.; Montrone, C.; Mewes, H. W. Nucleic acids research 2010, 38, D497.

(16) Copley, S. D. Bioessays 2012, 34, 578.

(17) Mani, M.; Chen, C.; Amblee, V.; Liu, H. P.; Mathur, T.; Zwicke, G.; Zabad, S.; Patel, B.; Thakkar, J.; Jeffery, C. J. Nucleic acids research 2015, 43, D277.

(18) Cox, J.; Mann, M. Nature biotechnology 2008, 26, 1367.

(19) Cox, J.; Matic, I.; Hilger, M.; Nagaraj, N.; Selbach, M.; Olsen, J. V.; Mann, M. Nature protocols 2009, 4, 698 .

(20) Stark, C.; Breitkreutz, B. J.; Reguly, T.; Boucher, L.; Breitkreutz, A.; Tyers, M. Nucleic acids research 2006, 34, D535.

(21) Shannon, P.; Markiel, A.; Ozier, O.; Baliga, N. S.; Wang, J. T.; Ramage, D.; Amin, N.; Schwikowski, B.; Ideker, T. Genome Research 2003, 13, 2498.

(22) Smoot, M. E.; Ono, K.; Ruscheinski, J.; Wang, P. L.; Ideker, T. Bioinformatics 2011, 27, 431.

(23) Spinelli, L.; Gambette, P.; Chapple, C. E.; Robisson, B.; Baudot, A.; Garreta, H.; Tichit, L.; Guenoche, A.; Brun, C. Biosystems 2013, 113, 91.

(24) Shackelford, R. E.; Kaufmann, W. K.; Paules, R. S. Free radical biology \& medicine 2000, 28, 1387.

(25) Lehtinen, S.; Lees, J.; Bahler, J.; Shawe-Taylor, J.; Orengo, C. PloS one 2015, 10, e0134668. 
(26) Pavlidis, P.; Gillis, J. F1000Research 2012, 1, 14.

(27) Pavlidis, P.; Gillis, J. F1000Research 2013, 2, 230.

(28) Piro, R. M.; Di Cunto, F. Febs Journal 2012, 279, 678.

(29) Sun, X. X.; DeVine, T.; Challagundla, K. B.; Dai, M. S. Journal of Biological Chemistry 2011, 286, 22730.

(30) Han, X. J.; Lee, M. J.; Yu, G. R.; Lee, Z. W.; Bae, J. Y.; Bae, Y. C.; Kang, S. H.; Kim, D. G. Cell death \& disease 2012, 3, e255.

(31) Bursac, S.; Brdovcak, M. C.; Donati, G.; Volarevic, S. Biochimica Et Biophysica ActaMolecular Basis of Disease 2014, 1842, 817.

(32) Zhou, X.; Liao, W. J.; Liao, J. M.; Liao, P.; Lu, H. Journal of molecular cell biology 2015, 7, 92 .

(33) James, A.; Wang, Y. B.; Raje, H.; Rosby, R.; DiMario, P. Nucleus 2014, 5, 402.

(34) Tafforeau, L.; Zorbas, C.; Langhendries, J. L.; Mullineux, S. T.; Stamatopoulou, V.; Mullier, R.; Wacheul, L.; Lafontaine, D. L. Molecular cell 2013, 51, 539.

(35) Sloan, K. E.; Leisegang, M. S.; Doebele, C.; Ramirez, A. S.; Simm, S.; Safferthal, C.; Kretschmer, J.; Schorge, T.; Markoutsa, S.; Haag, S.; Karas, M.; Ebersberger, I.; Schleiff, E.; Watkins, N. J.; Bohnsack, M. T. Nucleic acids research 2015, 43, 553.

(36) Kubota, T.; Nishimura, K.; Kanemaki, M. T.; Donaldson, A. D. Molecular cell 2013, 50, 273.

(37) Majka, J.; Burgers, P. M. Progress in nucleic acid research and molecular biology 2004, 78, 227.

(38) Osborn, A. J.; Elledge, S. J.; Zou, L. Trends in cell biology 2002, 12, 509.

(39) Esteve, P. O.; Chin, H. G.; Smallwood, A.; Feehery, G. R.; Gangisetty, O.; Karpf, A. R.; Carey, M. F.; Pradhan, S. Genes \& Development 2006, 20, 3089.

(40) Balajee, A. S.; Geard, C. R. Nucleic Acids Research 2001, 29, 1341.

(41) Goodwin, J. F.; Knudsen, K. E. Cancer Discov 2014, 4, 1126.

(42) Wang, Q. Q.; Zhang, Z.; Blackwell, K.; Carmichael, G. G. Current Biology 2005, 15, 384.

(43) Newell-Litwa, K.; Seong, E.; Burmeister, M.; Faundez, V. Journal of Cell Science 2007, 120, 531.

(44) Boucrot, E.; Saffarian, S.; Zhang, R. Y.; Kirchhausen, T. PloS one 2010, 5.

(45) Kirchhausen, T.; Owen, D.; Harrison, S. C. Cold Spring Harbor Perspectives in Biology 2014, 6 .

(46) Orci, L.; Stamnes, M.; Ravazzola, M.; Amherdt, M.; Perrelet, A.; Sollner, T. H.; Rothman, J. E. Cell 1997, 90, 335.

(47) Ludwig, A.; Howard, G.; Mendoza-Topaz, C.; Deerinck, T.; Mackey, M.; Sandin, S.; Ellisman, M. H.; Nichols, B. J. Plos Biology 2013, 11.

(48) Parton, R. G.; del Pozo, M. A. Nature Reviews Molecular Cell Biology 2013, 14, 98.

(49) Parton, R. G.; Howes, M. T. Journal of Cell Biology 2010, 191, 439.

(50) Shvets, E.; Ludwig, A.; Nichols, B. J. Current Opinion in Cell Biology 2014, 29, 99.

(51) Gambin, Y.; Ariotti, N.; McMahon, K. A.; Bastiani, M.; Sierecki, E.; Kovtun, O.; Polinkovsky, M. E.; Magenau, A.; Jung, W.; Okano, S.; Zhou, Y.; Leneva, N.; Mureev, S.; Johnston, W.; Gaus, K.; Hancock, J. F.; Collins, B. M.; Alexandrov, K.; Parton, R. G. Elife 2014, 3 .

(52) Hernandez, V. J.; Weng, J.; Ly, P.; Pompey, S.; Dong, H. Y.; Mishra, L.; Schwarz, M.; Anderson, R. G. W.; Michaely, P. Elife 2013, 2.

(53) Schneider, K.; Kocher, T.; Andersin, T.; Kurzchalia, T.; Schibler, U.; Gatfield, D. Embo Reports 2012, 13, 1138.

(54) Sabeh, F.; Ota, I.; Holmbeck, K.; Birkedal-Hansen, H.; Soloway, P.; Balbin, M.; LopezOtin, C.; Shapiro, S.; Inada, M.; Krane, S.; Allen, E.; Chung, D.; Weiss, S. J. J Cell Biol 2004, 167, 769.

(55) Valacca, C.; Tassone, E.; Mignatti, P. PLoS One 2015, 10, e0136797.

(56) Murphy-Ullrich, J. E.; Sage, E. H. Matrix Biology 2014, 37, 1. 
(57) Gooden, M. D.; Vernon, R. B.; Bassuk, J. A.; Sage, E. H. Journal of Cellular Biochemistry 1999, 74, 152.

(58) Pilecka, I.; Banach-Orlowska, M.; Miaczynska, M. European Journal of Cell Biology 2007, 86, 533.

(59) Pyrzynska, B.; Pilecka, I.; Miaczynska, M. Molecular Oncology 2009, 3, 321.

(60) Wang, Y. N.; Yamaguchi, H.; Hsu, J. M.; Hung, M. C. Oncogene 2010, 29, 3997.

(61) Brown, D. I.; Lassegue, B.; Lee, M.; Zafari, R.; Long, J. S.; Saavedra, H. I.; Griendling, K. K. PloS one 2014, 9.

(62) Liu, L.; Rodriguez-Belmonte, E. M.; Mazloum, N.; Xie, B.; Lee, M. Y. W. T. Journal of Biological Chemistry 2003, 278, 10041.

(63) Maga, G.; Crespan, E.; Markkanen, E.; Imhof, R.; Furrer, A.; Villani, G.; Hubscher, U.; van Loon, B. Proceedings of the National Academy of Sciences of the United States of America 2013, 110, 18850.

(64) Tissier, A.; Janel-Bintz, R.; Coulon, S.; Klaile, E.; Kannouche, P.; Fuchs, R. P.; Cordonnier, A. M. DNA Repair 2010, 9, 922.

(65) Klaile, E.; Muller, M. M.; Kannicht, C.; Otto, W.; Singer, B. B.; Reutter, W.; Obrink, B.; Lucka, L. Journal of Biological Chemistry 2007, 282.

(66) Lyle, A. N.; Deshpande, N. N.; Taniyama, Y.; Seidel-Rogol, B.; Pounkova, L.; Du, P. F.; Papaharalambus, C.; Lassegue, B.; Griendling, K. K. Circulation Research 2009, $105,249$.

(67) Tong, J. F.; Taylor, P.; Moran, M. F. Molecular \& Cellular Proteomics 2014, 13, 1644.

(68) Cheng, X. L.; Kanki, T.; Fukuoh, A.; Ohgaki, K.; Takeya, R.; Aoki, Y.; Hamasaki, N.; Kang, D. C. Journal of Biochemistry 2005, 138, 673.

(69) Xie, B.; Li, H.; Wang, Q.; Xie, S. Q.; Rahmeh, A.; Dai, W.; Lee, M. Y. W. T. Journal of Biological Chemistry 2005, 280, 22375.

(70) Kotiadis, V. N.; Duchen, M. R.; Osellame, L. D. Biochimica Et Biophysica ActaGeneral Subjects 2014, 1840, 1254.

(71) Phang, J. M.; Liu, W.; Hancock, C.; Christian, K. J. Frontiers in oncology 2012, 2, 60.

(72) Harbauer, A. B.; Zahedi, R. P.; Sickmann, A.; Pfanner, N.; Meisinger, C. Cell Metab 2014, 19, 357.

(73) Nargund, A. M.; Pellegrino, M. W.; Fiorese, C. J.; Baker, B. M.; Haynes, C. M. Science 2012, 337, 587.

(74) van der Laan, M.; Hutu, D. P.; Rehling, P. Biochimica Et Biophysica Acta-Molecular Cell Research 2010, 1803, 732.

(75) Flachbartova, Z.; Kovacech, B. Acta Virologica 2013, 57, 2.

(76) Fang, L.; Wang, X.; Yamoah, K.; Chen, P. L.; Pan, Z. Q.; Huang, L. Journal of proteome research $\mathbf{2 0 0 8 ,}$ 7, 4914.

(77) Shih, Y. Y.; Lee, H.; Nakagawara, A.; Juan, H. F.; Jeng, Y. M.; Tsay, Y. G.; Lin, D. T.; Hsieh, F. J.; Pan, C. Y.; Hsu, W. M.; Liao, Y. F. PloS one 2011, 6, e26236.

(78) Boland, M. L.; Chourasia, A. H.; Macleod, K. F. Frontiers in oncology 2013, 3, 292.

(79) Opalinska, M.; Meisinger, C. Current Opinion in Cell Biology 2015, 33, 42.

(80) Yizhak, K.; Chaneton, B.; Gottlieb, E.; Ruppin, E. Mol Syst Biol 2015, 11, 817.

(81) Leu, J. I. J.; Dumont, P.; Hafey, M.; Murphy, M. E.; George, D. L. Nature Cell Biology 2004, 6, 443.

(82) Mihara, M.; Erster, S.; Zaika, A.; Petrenko, O.; Chittenden, T.; Pancoska, P.; Moll, U. M. Molecular cell 2003, 11, 577.

(83) Perfettini, J. L.; Kroemer, R. T.; Kroemer, G. Nature Cell Biology 2004, 6, 386.

(84) Al-Mehdi, A. B.; Pastukh, V. M.; Swiger, B. M.; Reed, D. J.; Patel, M. R.; Bardwell, G. C.; Pastukh, V. V.; Alexeyev, M. F.; Gillespie, M. N. Science Signaling 2012, 5.

(85) Malhas, A.; Goulbourne, C.; Vaux, D. J. Trends in cell biology 2011, 21, 362.

(86) Talamas, J. A.; Capelson, M. Frontiers in genetics 2015, 6, 95.

(87) Wu, J.; Bakerink, K. J.; Evangelista, M. E.; Thomas, G. H. PloS one 2014, 9.

(88) Pinto, G.; Alhaiek, A. A.; Amadi, S.; Qattan, A. T.; Crawford, M.; Radulovic, M.; Godovac-Zimmermann, J. Journal of proteome research 2014, 13, 1112. 
(89) Qattan, A. T.; Mulvey, C.; Crawford, M.; Natale, D. A.; Godovac-Zimmermann, J. Journal of proteome research 2010, 9, 495.

(90) Qattan, A. T.; Radulovic, M.; Crawford, M.; Godovac-Zimmermann, J. Journal of proteome research 2012, 11, 6080.

(91) Konieczna, A.; Szczepanska, A.; Sawiuk, K.; Wegrzyn, G.; Lyzen, R. BMC Cell Biol 2015, 16, 16.

(92) Whitacre, J. M.; Bender, A. Theoretical Biology and Medical Modelling 2010, 7.

(93) Picotti, P.; Aebersold, R. Nat Methods 2012, 9, 555.

(94) Olaisen, C.; Muller, R.; Nedal, A.; Otter, M. Cellular Signalling 2015, 27, 1478.

(95) Mailand, N.; Gibbs-Seymour, I.; Bekker-Jensen, S. Nature Reviews Molecular Cell Biology 2013, 14, 269.

(96) Yin, L.; Xie, Y.; Yin, S.; Lv, X.; Zhang, J.; Gu, Z.; Sun, H.; Liu, S. Plos One 2015, 10, e0117546.

(97) Seo, S. B.; McNamara, P.; Heo, S.; Turner, A.; Lane, W. S.; Chakravarti, D. Cell 2001, 104, 119.

(98) Fan, Z.; Beresford, P. J.; Oh, D. Y.; Zhang, D.; Lieberman, J. Cell 2003, 115.

(99) Kim, J. Y.; Lee, K. S.; Seol, J. E.; Yu, K.; Chakravarti, D.; Seo, S. B. Nucleic acids research 2012, 40, 75 .

(100) Qu, D.; Zhang, Y.; Ma, J.; Guo, K.; Li, R.; Yin, Y.; Cao, X.; Park, D. S. Journal of neurochemistry 2007, 103, 408.

(101) Vieyra, D.; Loewith, R.; Scott, M.; Bonnefin, P.; Boisvert, F. M.; Cheema, P.; Pastyryeva, S.; Meijer, M.; Johnston, R. N.; Bazett-Jones, D. P.; McMahon, S.; Cole, M. D.; Young, D.; Riabowol, K. The Journal of biological chemistry 2002, 277, 29832.

(102) Haesen, D.; Sents, W.; Lemaire, K.; Hoorne, Y.; Janssens, V. Frontiers in oncology 2014, 4, 347.

(103) Chasseigneaux, S.; Clamagirand, C.; Huguet, L.; Gorisse-Hussonnois, L.; Rose, C.; Allinquant, B. Bmc Neuroscience 2014, 15.

(104) ten Klooster, J. P.; von Leeuwen, I.; Scheres, N.; Anthony, E. C.; Hordijk, P. L. Embo Journal 2007, 26, 336.

(105) Le Guelte, A.; Galan-Moya, E. M.; Dwyer, J.; Treps, L.; Kettler, G.; Hebda, J. K.; Dubois, S.; Auffray, C.; Chneiweiss, H.; Bidere, N.; Gavard, J. Journal of cell science 2012, 125, 4137.

(106) Vasudevan, N. T.; Mohan, M. L.; Goswami, S. K.; Naga Prasad, S. V. Cell cycle 2011, 10,3684 .

(107) Trakhtenberg, E. F.; Wang, Y.; Morkin, M. I.; Fernandez, S. G.; Mlacker, G. M.; Shechter, J. M.; Liu, X. F.; Patel, K. H.; Lapins, A.; Yang, S.; Dombrowski, S. M.; Goldberg, J. L. Journal of Neuroscience 2014, 34, 7361.

(108) Yan, N.; Cherepanov, P.; Daigle, J. E.; Engelman, A.; Lieberman, J. Plos Pathogens 2009, 5 .

(109) Margariti, A.; Winkler, B.; Karamariti, E.; Zampetaki, A.; Tsai, T. N.; Baban, D.; Ragoussis, J.; Huang, Y.; Han, J. D. J.; Zeng, L. F.; Hu, Y. H.; Xu, Q. B. Proceedings of the National Academy of Sciences of the United States of America 2012, 109, 13793.

(110) George, E. M.; Brown, D. T. Febs Letters 2010, 584, 2833.

(111) Karetsou, Z.; Martic, G.; Tavoulari, S.; Christoforidis, S.; Wilm, M.; Gruss, C.; Papamarcaki, T. FEBS Lett 2004, 577, 496.

(112) Martini, P. G.; Delage-Mourroux, R.; Kraichely, D. M.; Katzenellenbogen, B. S. Molecular and cellular biology 2000, 20, 6224.

(113) Karetsou, Z.; Kretsovali, A.; Murphy, C.; Tsolas, O.; Papamarcaki, T. Embo Reports 2002, 3, 361 .

(114) Kobayashi, T.; Wang, T.; Maezawa, M.; Kobayashi, M.; Ohnishi, S.; Hatanaka, K.; Hige, S.; Shimizu, Y.; Kato, M.; Asaka, M.; Tanaka, J.; Imamura, M.; Hasegawa, K.; Tanaka, Y.; Brachmann, R. K. Cancer Research 2006, 66, 3137.

(115) Bianco, N. R.; Montano, M. M. Oncogene 2002, 21, 5233.

(116) Gaubatz, S.; Meichle, A.; Eilers, M. Molecular and cellular biology 1994, 14, 3853. 
(117) Zhao, R.; Gish, K.; Murphy, M.; Yin, Y.; Notterman, D.; Hoffman, W. H.; Tom, E.; Mack, D. H.; Levine, A. J. Cold Spring Harbor symposia on quantitative biology 2000, $65,475$.

(118) Karapetian, R. N.; Evstafieva, A. G.; Abaeva, I. S.; Chichkova, N. V.; Filonov, G. S.; Rubtsov, Y. P.; Sukhacheva, E. A.; Melnikov, S. V.; Schneider, U.; Wanker, E. E.; Vartapetian, A. B. Molecular and cellular biology 2005, 25, 1089.

(119) Sun, Z.; Zhang, S.; Chan, J. Y.; Zhang, D. D. Mol Cell Biol 2007, 27, 6334.

(120) Padmanabhan, B.; Nakamura, Y.; Yokoyama, S. Structural analysis of the complex of Keap1 with a prothymosin $\alpha$ peptide. Acta Cryst. 2008, F64, 233-238.

(121) Khan, H.; Cino, E. A.; Brickenden, A.; Fan, J. S.; Yang, D. W.; Choy, W. Y. Journal of Molecular Biology 2013, 425, 1011.

(122) Jiang, X. J.; Kim, H. E.; Shu, H. J.; Zhao, Y. M.; Zhang, H. C.; Kofron, J.; Donnelly, J.; Burns, D.; Ng, S. C.; Rosenberg, S.; Wang, X. D. Science 2003, 299, 223.

(123) Lin, Y. T.; Lu, H. P.; Chao, C. C. K. Biochemical Pharmacology 2015, 93, 110.

(124) Lal, A.; Kawai, T.; Yang, X. L.; Mazan-Mamczarz, K.; Gorospe, M. Embo Journal 2005, 24, 1852.

(125) Yang, C. H.; Murti, A.; Baker, S. J.; Frangou-Lazaridis, M.; Vartapetian, A. B.; Murti, K. G.; Pfeffer, L. M. Experimental Cell Research 2004, 298, 197.

(126) Mosoian, A. Future medicinal chemistry 2011, 3, 1199.

(127) Mosoian, A.; Teixeira, A.; Burns, C. S.; Sander, L. E.; Gusella, G. L.; He, C. J.; Blander, J. M.; Klotman, P.; Klotman, M. E. Proceedings of the National Academy of Sciences of the United States of America 2010, 107, 10178.

(128) Wang, W.; Fang, H. Q.; Groom, L.; Cheng, A. W.; Zhang, W. R.; Liu, J.; Wang, X. H.; Li, K. T.; Han, P. D.; Zheng, M.; Yin, J. H.; Wang, W. D.; Mattson, M. P.; Kao, J. P. Y.; Lakatta, E. G.; Sheu, S. S.; Ouyang, K. F.; Chen, J.; Dirksen, R. T.; Cheng, H. P. Cell 2008, 134, 279.

(129) Wei, L.; Xie, X.; Li, J.; Li, R.; Shen, W.; Duan, S.; Zhao, R.; Yang, W.; Liu, Q.; Fu, Q.; Qin, Y. Cell Biol Int 2015.

(130) Cunningham, K. S.; Dodson, R. E.; Nagel, M. A.; Shapiro, D. J.; Schoenberg, D. R. Proc Natl Acad Sci U S A 2000, 97, 12498.

(131) Hirschmann, W. D.; Westendorf, H.; Mayer, A.; Cannarozzi, G.; Cramer, P.; Jansen, R. P. Nucleic Acids Res 2014, 42, 4043.

(132) Woo, H. H.; Yi, X.; Lamb, T.; Menzl, I.; Baker, T.; Shapiro, D. J.; Chambers, S. K. Mol Cell Biol 2011, 31, 215.

(133) Otsuka, H.; Gotoh, Y.; Komeno, T.; Ono, T.; Kawasaki, Y.; Iida, N.; Shibagaki, Y.; Hattori, S.; Tomatsu, M.; Akiyama, H.; Tashiro, F. Biochem Biophys Res Commun 2014, 453, 117.

(134) Liu, Q.; Yang, B.; Xie, X.; Wei, L.; Liu, W.; Yang, W.; Ge, Y.; Zhu, Q.; Zhang, J.; Jiang, L.; Yu, X.; Shen, W.; Li, R.; Shi, X.; Li, B.; Qin, Y. FEBS J 2014, 281, 2713.

(135) Molyneux, S. D.; Waterhouse, P. D.; Shelton, D.; Shao, Y. W.; Watling, C. M.; Tang, Q. L.; Harris, I. S.; Dickson, B. C.; Tharmapalan, P.; Sandve, G. K.; Zhang, X.; Bailey, S. D.; Berman, H.; Wunder, J. S.; Izsvak, Z.; Lupien, M.; Mak, T. W.; Khokha, R. Nat Genet 2014, 46, 964.

(136) Cheung, K. L.; Lee, J. H.; Shu, L.; Kim, J. H.; Sacks, D. B.; Kong, A. N. T. Journal of Biological Chemistry 2013, 288, 22378.

(137) Biswas, C.; Shah, N.; Muthu, M.; La, P.; Fernando, A. P.; Sengupta, S.; Yang, G.; Dennery, P. A. Journal of Biological Chemistry 2014, 289, 26882.

(138) Vernon, P. J.; Tang, D. L. Antioxidants \& redox signaling 2013, 18, 677.

(139) Yu, Y.; Tang, D. L.; Kang, R. Frontiers in Physiology 2015, 6.

(140) Bell, J. L.; Wachter, K.; Muleck, B.; Pazaitis, N.; Kohn, M.; Lederer, M.; Huttelmaier, S. Cellular and Molecular Life Sciences 2013, 70, 2657.

(141) Janiszewska, M.; Suva, M. L.; Riggi, N.; Houtkooper, R. H.; Auwerx, J.; ClementSchatlo, V.; Radovanovic, I.; Rheinbay, E.; Provero, P.; Stamenkovic, I. Genes \& Development 2012, 26, 1926. 
(142) Martin-Montanez, E.; Pavia, J.; Santin, L. J.; Boraldi, F.; Estivill-Torrus, G.; Aguirre, J. A.; Garcia-Fernandez, M. Biochimica Et Biophysica Acta-Molecular Basis of Disease 2014, 1842, 1041.

(143) Bley, N.; Lederer, M.; Pfalz, B.; Reinke, C.; Fuchs, T.; Glass, M.; Moller, B.; Huttelmaier, S. Nucleic acids research 2015, 43.

(144) Weidensdorfer, D.; Stohr, N.; Baude, A.; Lederer, M.; Kohn, M.; Schierhorn, A.; Buchmeier, S.; Wahle, E.; Huttelmaier, S. RNA 2009, 15, 104.

(145) Egler, R. A.; Fernandes, E.; Rothermund, K.; Sereika, S.; de Souza-Pinto, N.; Jaruga, P.; Dizdaroglu, M.; Prochownik, E. V. Oncogene 2005, 24, 8038.

(146) Mohanty, A.; McBride, H. M. Frontiers in Physiology 2013, 4.

(147) Soubannier, V.; McLelland, G. L.; Zunino, R.; Braschi, E.; Rippstein, P.; Fon, E. A.; McBride, H. M. Current Biology 2012, 22, 135.

(148) Aguilar-Arnal, L.; Sassone-Corsi, P. Proceedings of the National Academy of Sciences of the United States of America 2015, 112, 6863.

(149) Causton, H. C.; Feeney, K. A.; Ziegler, C. A.; O'Neill, J. S. Current Biology 2015, 25, 1056.

(150) Hoyle, N. P.; O'Neill, J. S. Biochemistry 2015, 54, 184.

(151) Pekovic-Vaughan, V.; Gibbs, J.; Yoshitane, H.; Yang, N.; Pathiranage, D.; Guo, B.; Sagami, A.; Taguchi, K.; Bechtold, D.; Loudon, A.; Yamamoto, M.; Chan, J.; van der Horst, G. T.; Fukada, Y.; Meng, Q. J. Genes \& Development 2014, 28, 548.

(152) Xu, J. M.; Hao, Z. M.; Gou, X. B.; Tian, W.; Jin, Y. L.; Cui, S. X.; Guo, J.; Sun, Y. J.; Wang, Y.; Xu, Z. L. Microscopy Research and Technique 2013, 76, 612.

(153) Lamb, F. S.; Moreland, J. G.; Miller, F. J., Jr. Antioxid Redox Signal 2009, 11, 1335.

(154) Corallino, S.; Malabarba, M. G.; Zobel, M.; Di Fiore, P. P.; Scita, G. Frontiers in oncology 2015, 5, 45.

(155) Hung, M. C.; Link, W. J Cell Sci 2011, 124, 3381.

(156) Lee, K.; Byun, K.; Hong, W.; Chuang, H. Y.; Pack, C. G.; Bayarsaikhan, E.; Paek, S. H.; Kim, H.; Shin, H. Y.; Ideker, T.; Lee, B. Genome Research 2013, 23, 1283.

(157) Pinto, G.; Alhaiek, A. A.; Godovac-Zimmermann, J. Expert Rev Proteomics 2015, 12, 61.

(158) Hernandez, S.; Ferragut, G.; Amela, I.; Perez-Pons, J.; Pinol, J.; Mozo-Villarias, A.; Cedano, J.; Querol, E. Nucleic acids research 2014, 42, D517.

(159) Veres, D. V.; Gyurko, D. M.; Thaler, B.; Szalay, K. Z.; Fazekas, D.; Korcsmaros, T.; Csermely, P. Nucleic acids research 2015, 43, D485.

(160) Henderson, B.; Martin, A.C. Protein moonlighting: a new factor in biology and medicine. Biochem Soc Trans. 2014, 42, 1671-8. 


\section{Supplementary Text.}

The following text describes the methods used for joint analysis/visualization of the experimental SILAC data sets for human IMR90 fibroblasts for tert-butyl hydrogen peroxide oxidative stress (OXS) and for CDC7-depletion-induced cell cycle arrest at the origin activation checkpoint for DNA replication (OAC).

Section A. Introduces the "joint spatial razor" plot as a formulation for concurrent visualization of the changes in total abundance $\left(S_{t}\right)$, nuclear/cytoplasmic compartmental abundance $\left(S_{n}\right.$ or $\left.S_{c}\right)$ and compartmental redistribution $\left(S_{n} / S_{c}\right)$ in a common framework.

Section B. Describes the methods used to select SILAC pairs representing significant changes in abundance or distribution and the assignment of these pairs to one of four SELECTION classes: OXSOAC-RADIAL, OAC-RADIAL, OXS-RADIAL, RADIAL.

Section C. Describes the criteria for identification of proteins that represent "trademarks" with significant changes in compartmental abundance, or in the mechanisms used to achieve the compartmental abundances, dominantly for OXS or dominantly for OAC.

Section $D$. Includes some comments regarding selection of significant proteins when the basal abundance of different proteins may vary by a thousand-fold or more.

\section{A. Joint Spatial Razor Plots for OXS and OAC.}

With the limits of at least 2 peptides and 3 ratio counts, the three replicates for each of the OAC and OXS experiments gave a total of 48001 SILAC ratios and their associated Significance B score outlier values (SigB hereafter) for analysis of the 4048 proteins. The unions over the replicates contained 6099 "SILAC pairs" (instances with measurement of the same SILAC ratio in both experiments) for one or more of $S_{c}, S_{n}, S_{t}$ and $S_{n} / S_{c}$ for the same protein in both the OAC and OXS data sets. As described in more detail in the main text for the 401-set (section A), the maximum number of possible SILAC pairs is constrained by the fact that some proteins are only present in one compartment. Others have very strong skewing of their basal abundances in unstimulated cells and may not be adequately quantified in both experiments according to our conservative selection criteria.

To jointly analyze the data sets for similarities and differences in cellular response, to include proteins which were quantified in only one of the subcellular compartments and to handle all four types of comparisons $\left(S_{c}, S_{n}, S_{t}, S_{n} / S_{c}\right)$ equivalently, we plotted $S^{O X S} / S^{O A C}$ versus $S^{O X S} \bullet S^{O A C}$ for each of the four types of SILAC pairs. In this "joint spatial razor" plot the 6099 data points cluster around the origin, that is, only a minority of proteins show major changes in their SILAC ratios in either experiment (Fig. $1 \mathrm{~A}, \mathrm{~B})$. The radial distance from the origin for the data points gave very similar distributions for each of the four types of comparison, as shown for $S_{n}$ and the union over $\left(S_{c}, S_{n}, S_{t}, S_{n} / S_{c}\right)$ in Fig. 1C.

The "joint spatial razor" plot classifies the SILAC pairs into regions such that the cellular response can be analyzed for dominance of one stimulation, for similarity in both responses or for opposite response to the two stimulations (see the labels of the colored radial slices in Fig. 1D). This is very helpful for visualizing the nature of any correlation in the changes for OXS and OAC. By selecting proteins that correspond to specific functional processes, e.g. glycolysis (Fig. 1D), the interplay between functional processes, changes in abundance and in subcellular location can begin to be visualized. For example, 10 proteins of the glycolysis/gluconeogenesis enzymatic cascade were monitored in both the cytoplasm and nucleus in both experiments. For OXS, hexokinase 1 (HK1) showed appreciable change: $\mathrm{N} \leftarrow \mathrm{C}$ redistribution without much change in total abundance that led to strongly increased nuclear abundance (Fig. 1D), whereas only minor changes were observed for OAC. In contrast, although hexokinase 2 was not detected in the nucleus, for OAC HK2 showed appreciable change: decrease in total and cytoplasmic abundance, with only very minor changes for OXS. These are known effects that are 
related to the metabolic fate of glucose and to metabolism in cancer cells (see Supplementary Figure 1). None of the other nine glycolytic enzymes (TPI1, ALDOA, ENO1, GAPDH, LDHA, LDHB, PKFP, PKM2, PGAM1, TPI1) showed strong changes in either experiment.

\section{B. Selection of joint sets of significant changes in abundance for OXS and OAC.}

Our goal in the present study was to look for possible cross talk between TBP-induced oxidative stress and CDC7-depletion-induced cell cycle arrest at the DNA replication origin activation checkpoint. Conventional outlier analysis such as the Significance B score used in MaxQuant can be used to select

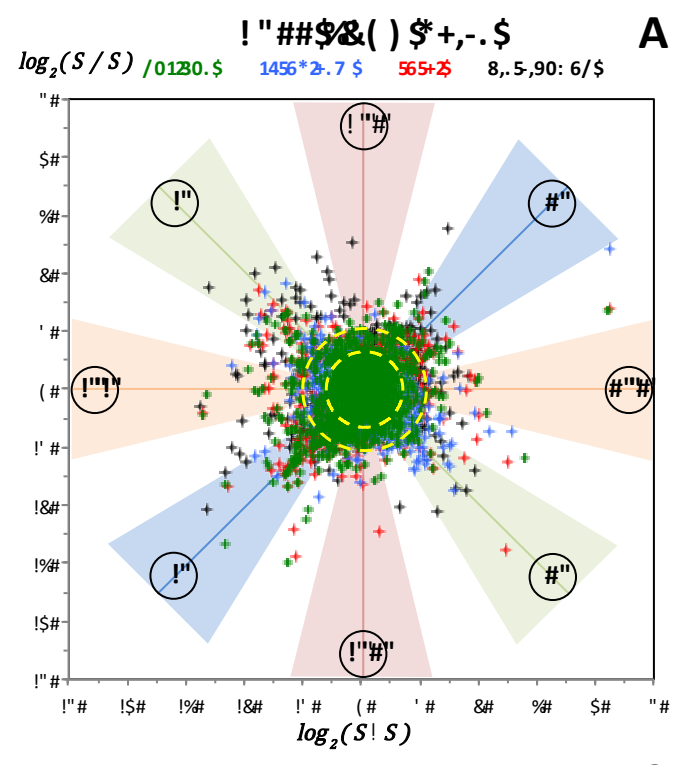

A

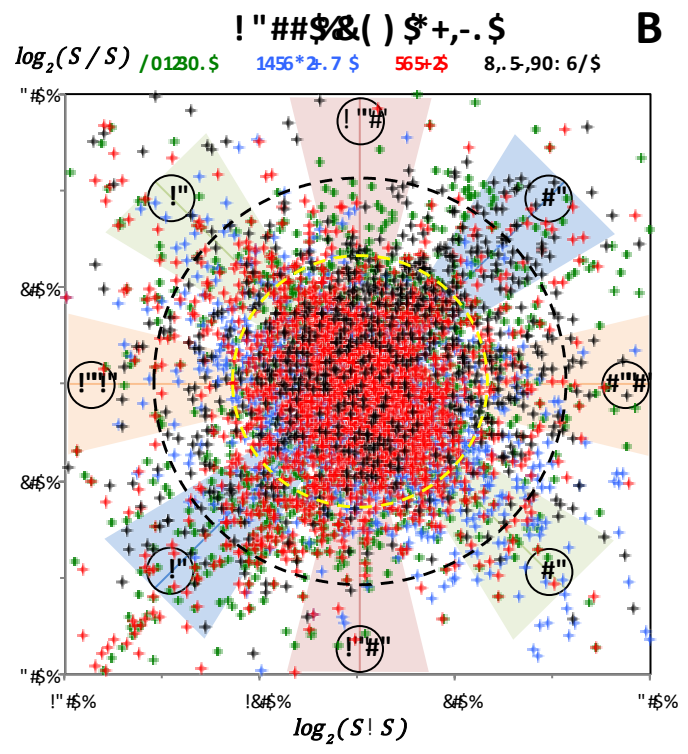

C

! "\#\$\%\#\&\&

D
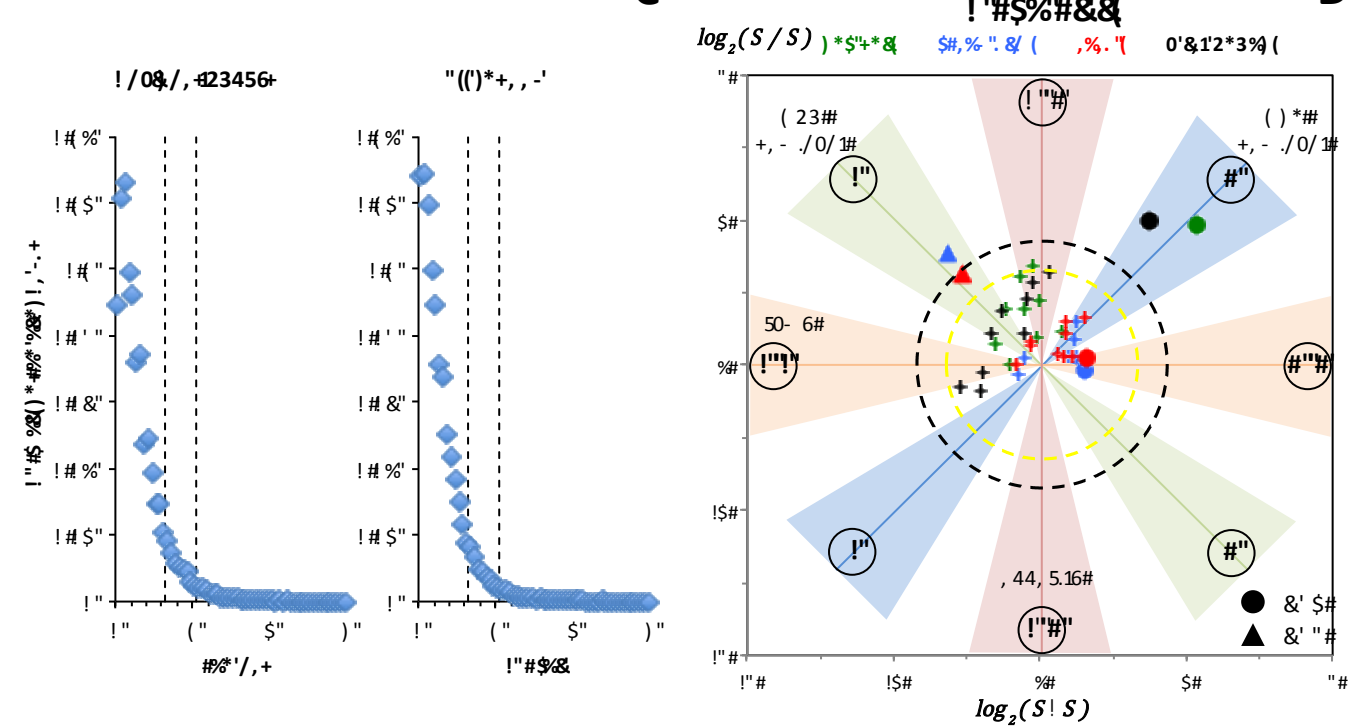

Figure 1. Joint spatial razor plot of the OXS and OAC data sets. (A) Plots of $\log _{2}\left(S^{O X S} / S^{O A C}\right)$ vs $\log _{2}\left(S^{O X S} \cdot S^{O A C}\right)$ for $S_{n} / S_{c}, S_{t}, S_{c}, S_{n}$, (back to front). The four types of comparisons are color coded according to the legend at the top. (B) Expansion of the central region of panel (A) with reverse back to front order. (C) Radial distribution of the data points in (A) for the union over all 6099 data points and for the 1705 nuclear data points. Normalized radial density is the number of data points in a radial annulus divided by the area of the annulus and normalized to a summed density $=1$. (D) Response for 11 enzymes of the glycolytic enzymatic cascade. The dashed circles in (A) and (B) correspond to the radii indicated in (C) of 0.65 (radial exclusion limit, see next sections) and 1.05 (stringent radial selection). The dashed circles in (D) correspond to the radial exclusion limit (inner circle) and radius $=0.85$, which was used for selection of significant proteins according to moderate radial selection (see next section). The colored radial slices represent angular regions where the dominant response is for OAC (green), for OXS (blue), SAME for OXS/OAC (orange) or OPPOSITE for OXS/OAC. (red. see section C. for more nrecise definitions). The circled + and - svmbols denote significant proteins in the individual experiments. ${ }^{1,2}$ However, although a protein may not be in the most significant set for either individual experiment (depending on the selection cutoffs used, see below), strong differences/similarities in the behavior of a protein between the two stimulations can result in the inclusion of a protein in the significant set for the joint radial analysis of both data sets. For example, for 
a pair of SILAC ratios $S^{O X S}=1.30, S^{O A C}=0.65$ the pair ratio $S^{O X S} / S^{O A C}=2.0$ may be selected as radially significant even though $S^{O A C}$ and $S^{O A C}$ are not selected as significant in the two individual experiments (see below).

Conversely, radial comparison requires sufficient ratio counts/MS intensity for the same protein in two different experiments, which may not be always achieved for both experiments because of the large range of total protein abundances and because the basal distribution between the nucleus/cytoplasm in non-stimulated cells is strongly skewed for some of the proteins. We therefore combined conventional SigB analysis of the individual experiments with joint radial analysis of both experiments to select significant proteins and used the presence/absence of the protein in both significant sets as a flag to further identify/verify less well quantified proteins. As described previously, ${ }^{1-3}$ the SigB analysis takes into account the total MS intensity recorded for each protein in evaluating the significance of SILAC ratios. This amounts to exclusion of less abundant proteins that may nominally show substantial changes in a SILAC ratio, but are less reliable due to limited experimental MS intensity.

Method 1. Each experiment (OXS or OAC) was analyzed independently for significant changes in total protein abundance $\left(S_{t}\right)$, nuclear protein abundance $\left(S_{n}\right)$, cytoplasmic protein abundance $\left(S_{c}\right)$ or redistribution between the nuclear and cytoplasmic compartments $\left(S_{n} / S_{c}\right)$. This procedure has previously been described in detail. ${ }^{3,4}$ For the present data sets, a minimum of 3 ratio counts in a single replicate was required for inclusion of a SILAC ratio in the analysis (Table 1). For selection of a SILAC ratio as significant, the union over the three replicates and at least two replicates were required to satisfy the corresponding ratio count limits and the SigB cutoff limits shown in Table 1. As described previously, the inclusion of reproducibility over the replicates tended to select more abundant proteins with considerable numbers of ratio counts. ${ }^{3,4}$

The SigB cutoff limit can be regarded as a variable parameter that determines the number of proteins accepted as significant and included in search sets for functional analysis. For example, for a range of possible SigB cutoffs for Method 1 (stringent, strict, moderate, relaxed, minimum; see Table 1) and with the requirement of at least two replicates per protein, the number of proteins classified as showing significant change in at least one of $S_{n}, S_{c}, S_{t}$ and $S_{n} / S_{c}$ varied by more than two-fold (224 to 574) in the present data (Table 1, Method 1). At all SigB cutoffs, approximately equal numbers of proteins were selected from OXS and OAC. Over the set of significant proteins there was an average of about 16 SILAC ratios (8-9 significant) per protein, and about 6-9\% of these proteins were common to both OXS and OAC (Table 1, Method 1). That is, although the number of included proteins increases, neither the overall balance between the two experiments nor the average amount of data available for individual proteins varies strongly with the SigB cutoff. With the weakest limits on SigB (minimal cutoffs) about $10 \%$ of all measured SILAC ratios were classified as significant. 
Method 2. Significant proteins were selected using ratio count limits and radii in the joint spatial razor plot format (Table 1). This allows for selection of additional proteins that show substantial similarity or difference in the two experiments. To provide compatibility with the conventional Method 1 procedure

Table 1. Methods and Criteria for selection of significant proteins

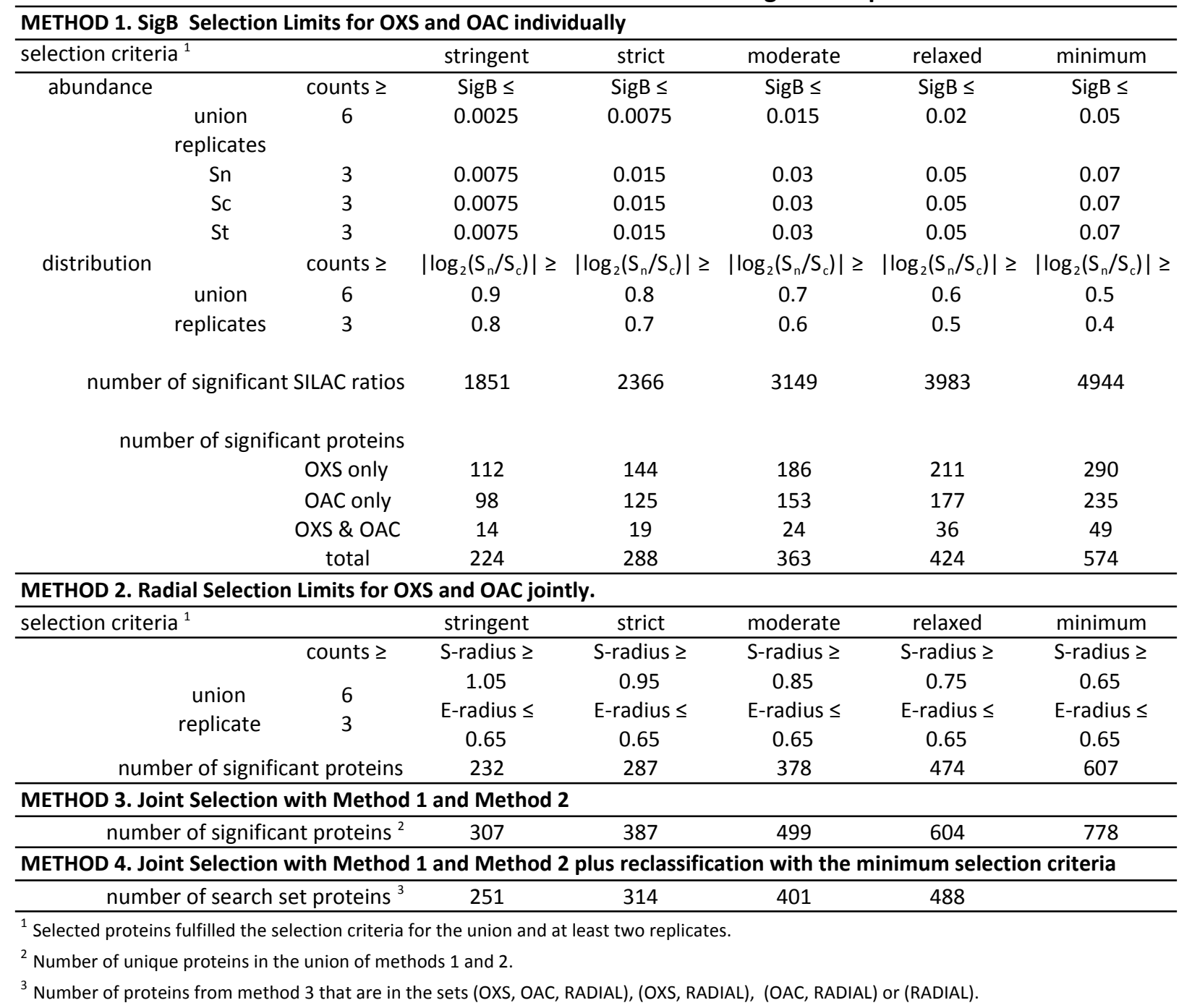

for estimation of significance and to balance the two methods, we determined a radial exclusion limit (E-radius $=0.65$ ). When proteins which only had SILAC ratio pairs with radius less than this exclusion radius were omitted, Method 2 selected about equal numbers of significant proteins as the SigB limit (0.05) used for the minimum selection set in Method 1 (607, 574 proteins respectively, Table 1). We then defined a significance limit (S-radius) such that only proteins with at least one SILAC pair with radius $>$ S-radius were considered significant. Values of this S-radius for relaxed, moderate, strict and stringent protein sets were chosen so that roughly equal numbers of significant proteins were obtained as for the corresponding proteins sets with Method 1 (Table 1, Method 2).

Method 3. The union of proteins that satisfied the criteria of either Method 1 or Method 2 led to somewhat larger sets of significant proteins (Table 1, Method 3) at any given cutoffs, i.e. the sets of proteins selected with Methods 1 and 2 were only partially identical. This seemed to be for the coverage reasons noted above, e.g., a protein only satisfied the count limits in one of OXS or OAC, as well as due to the (artificial) consequences of the use of discrete cutoffs, e.g., a protein is just inside or outside of a cutoff, or due to the selection of some radial SILAC pairs that were not selected in the individual experiments. We used the fact that the sets of proteins were not identical with the two methods to review the acceptance of some proteins (method 4). This is exemplified with the 307 proteins of the "stringent" Method 3 set (Table 2, leftmost columns). 
Table 2. Number of proteins selected for network search sets ${ }^{1}$

\begin{tabular}{|c|c|c|c|c|c|c|c|}
\hline \multicolumn{2}{|c|}{ STRINGENT } & \multicolumn{2}{|l|}{ STRICT } & \multicolumn{2}{|c|}{ MODERATE } & \multicolumn{2}{|c|}{ RELAXED } \\
\hline \multicolumn{8}{|c|}{ METHOD 3. Joint selection with SigB and radial selection. } \\
\hline \multicolumn{2}{|c|}{ Evaluated stringent criteria } & \multicolumn{2}{|c|}{ Evaluated strict criteria } & \multicolumn{2}{|c|}{ Evaluated moderate criteria } & \multicolumn{2}{|c|}{ Evaluated relaxed criteria } \\
\hline selection by & number & selection by & number & selection by & number & selection by & number \\
\hline OXS, OAC, RADIAL & 14 & OXS, OAC, RADIAL & 18 & OXS, OAC, RADIAL & 23 & OXS, OAC, RADIAL & 36 \\
\hline OXS, OAC & 0 & OXS, OAC & 1 & OXS, OAC & 1 & OXS, OAC & 0 \\
\hline OXS, RADIAL & 79 & OXS, RADIAL & 97 & OXS, RADIAL & 132 & OXS, RADIAL & 152 \\
\hline OAC, RADIAL & 56 & OAC, RADIAL & 73 & OAC, RADIAL & 89 & OAC, RADIAL & 106 \\
\hline OXS & 33 & OXS & 47 & OXS & 55 & OXS & 59 \\
\hline OAC & 42 & OAC & 52 & OAC & 64 & OAC & 71 \\
\hline RADIAL & 83 & RADIAL & 99 & RADIAL & 135 & RADIAL & 180 \\
\hline total & 307 & total & 387 & total & 499 & total & 604 \\
\hline search set & 232 & search set & 287 & search set & 379 & search set & 474 \\
\hline
\end{tabular}

\begin{tabular}{|c|c|c|c|c|c|c|c|}
\hline \multicolumn{2}{|c|}{ Reclassified minimum criteria } & \multicolumn{2}{|c|}{ Reclassified minimum criteria } & \multicolumn{2}{|c|}{ Reclassified minimum criteria } & \multicolumn{2}{|c|}{ Reclassified minimum criteria } \\
\hline selection by & number & selection by & number & selection by & number & selection by & number \\
\hline OXS, OAC, RADIAL & 46 & $\overline{O X S}$, OAC, RADIAL & 48 & $\overline{O X S}$, OAC, RADIAL & 49 & $\overline{O X S}$, OAC, RADIAL & 49 \\
\hline OXS, OAC & 0 & OXS, OAC & 0 & OXS, OAC & 0 & OXS, OAC & 0 \\
\hline OXS, RADIAL & 113 & OXS, RADIAL & 141 & OXS, RADIAL & 173 & OXS, RADIAL & 192 \\
\hline OAC, RADIAL & 83 & OAC, RADIAL & 105 & OAC, RADIAL & 130 & OAC, RADIAL & 146 \\
\hline OXS & 25 & OXS & 34 & OXS & 46 & OXS & 53 \\
\hline OAC & 31 & OAC & 39 & OAC & 52 & OAC & 63 \\
\hline RADIAL & 9 & RADIAL & 20 & RADIAL & 49 & RADIAL & 101 \\
\hline total & 307 & total & 387 & total & 499 & total & 604 \\
\hline search set & 251 & search set & 314 & search set & 401 & search set & 488 \\
\hline
\end{tabular}

${ }^{1}$ For both methods 3 and 4 , each protein in the search set has at least one parameter $S_{n}, S_{c}, S_{t}, S_{n} / S_{c}$ that satisfies the respective stringent, strict, moderate or relaxed selection criteria in Table 1. The search set includes proteins classified as (OXS, OAC, RADIAL), (OXS, RADIAL), (OAC, RADIAL) OR (RADIAL).

Method 4. The stringent set of 307 proteins from method 3 were re-evaluated against the minimum selection criteria and re-assigned to a SELECTION type according to whether they were then selected by SigB (OXS and OAC individually, Method 1) and/or S-radius (RADIAL, OXS and OAC jointly, Method 2). After reevaluation against the minimum selection criteria (Table 2), 251/307 proteins in the stringent set for Method 3 had at least one feature selected by the stringent selection criteria and were also detected by both Method 1 and Method 2 with the minimum selection criteria. An enlarged set of proteins that showed significant changes in both experiments (46 proteins) was obtained. These were proteins initially selected by the cutoff S-radius $>1.05$, but for which the changes for the proteins in one of the two individual experiments fell in the range $0.0025<\mathrm{SigB}<0.05$, i.e. they show appreciable similarities or differences in the two experiments and the changes are significant in both experiments at less stringent cutoffs. This is mainly influenced by a very stringent cutoff for significance in Method 1 (SigB $<0.0025)$. There were 9 RADIAL proteins that showed strongly similar or different changes for OXS/OAC. There were 56 proteins that were only selected by Method 1 (OXS, OAX sets in Table 2, Method 4). Manual review of these proteins indicated that many were detected in both experiments, but corresponded to less abundant proteins that satisfied the count/replicate limits for one or more of $S_{n}, S_{c}$, $S_{t}$ or $S_{n} / S_{c}$ in only one of the two experiments. Since our goal was to identify cross talk between OXS and OAC, we did not include these proteins in the network search sets. The remaining set of 251 proteins was considered the highest-confidence search set for the network analyses. We stress that all of these 251 proteins had at least one SILAC ratio (Method 1) or one pair of SILAC ratios (Method 2) that satisfied the stringent selection criteria for the magnitude of the changes (Table 1) and all were adequately quantified in both experiments. The minimal selection criteria were only used in assigning the proteins to a selection class. As shown in Fig. 2, this procedure essentially corresponds to a kind of fuzzy filtering for the SELECTION class assignments.

The joint use of Method 1 and Method 2 (as Method 3) together with re-evaluation against the minimum selection criteria to better define the selection class (Method 4) had several attractive features. Method 4 identified a high-confidence set of proteins without user intervention, ensured that the protein was adequately quantified in both experiments, established clearly the selection criteria (OXS-RADIAL, OAC-RADIAL, OXS-OAC-RADIAL, or RADIAL), flagged a limited set of proteins (56/4048) for manual review, and ameliorated to a certain extent the ambiguities caused by the use of discrete significance cutoffs. To obtain search sets with larger numbers of proteins and to partially classify the 

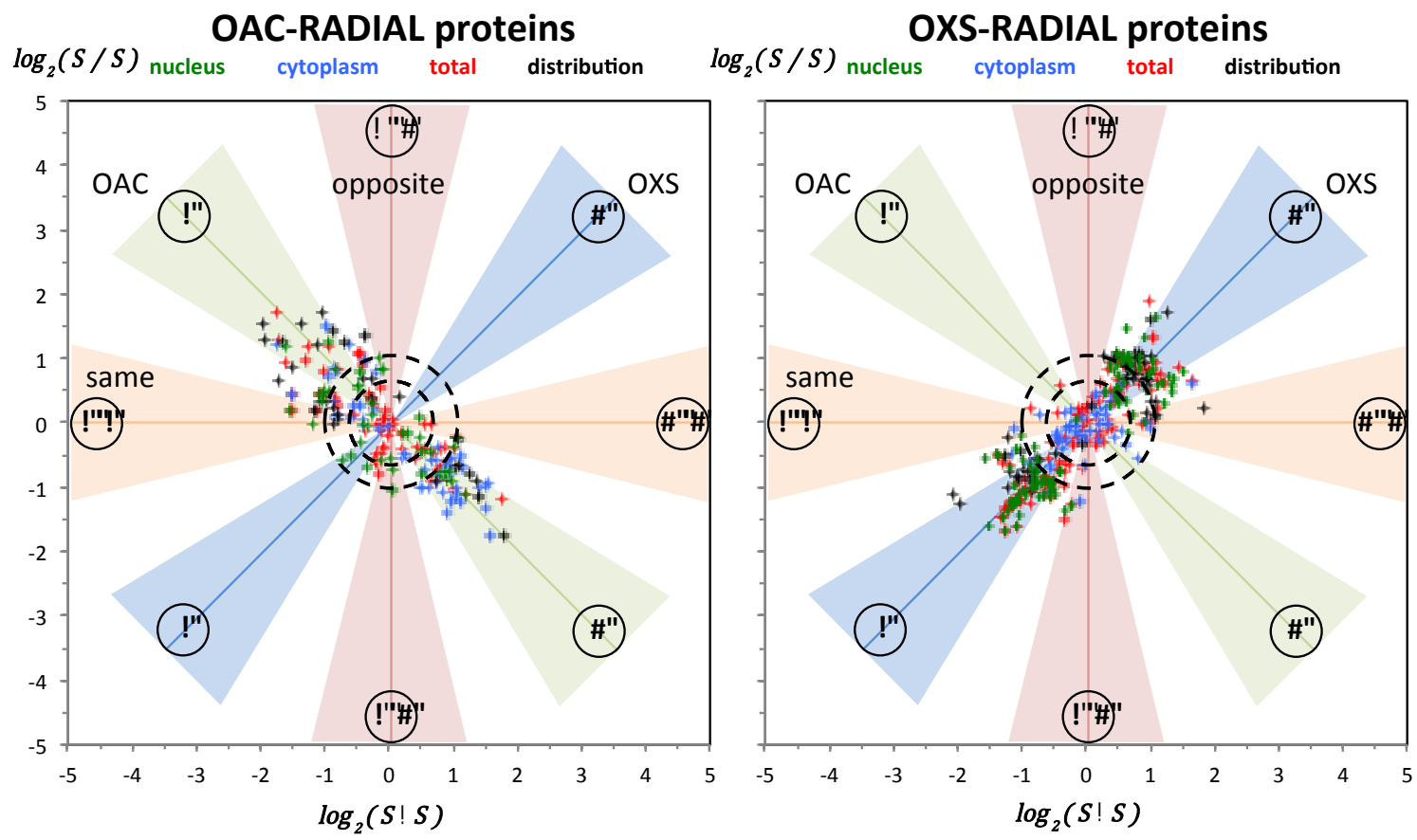

Figure 2. Illustration of the fuzzy selection procedure used to assign the proteins to a SELECTION class. The outer dashed circle corresponds to S-radius $=1.05$ and the inner dashed circle to E-radius $=0.65$. All OAC-RADIAL proteins have at least one SILAC pair that is significant according to the stringent criteria along the OAC axis, but no SILAC pair that is significant along the OXS axis. The inverse is true for the OXS-RADIAL proteins.

proteins according to the magnitude of the changes observed, we then applied the Method 4 procedure using the strict, moderate and relaxed sets of selection criteria. The corresponding number/distribution of the significant search set proteins identified is shown in Table 2. For most analyses and the network searches, we used the set of 401 proteins chosen with moderate selection criteria. For each of these 401 set proteins, Supplementary Table 2 includes columns showing the SELECTION criteria (OXSRADIAL, OAC-RADIAL, OXS-OAC-RADIAL, and RADIAL), the MAGNITUDE of the cutoffs that the protein satisfied (MODERATE, STRICT, STRINGENT), as well as a summary of the number of proteins corresponding to each descriptor. Again, we stress that all of these 401-set proteins had at least one SILAC ratio (Method 1) or one pair of SILAC ratios (Method 2) that satisfied at least the moderate selection criteria (87 proteins, 314 satisfied the STRICT or STRINGENT criteria) for the magnitude of the changes and all were adequately quantified in both experiments.

This selection procedure does not distinguish increases/decreases in abundance or whether redistribution is $\mathrm{N} \rightarrow \mathrm{C}$ or $\mathrm{C} \rightarrow \mathrm{N}$. Nor does it consider whether the behavior of a protein is the same or different between the two experiments. The only evaluation is whether the protein is amongst the set of proteins showing the most significant changes. Notable is that the number of proteins in the OXS-OACRADIAL selection set is not strongly dependent on the criteria used for selection of significant proteins (Table 2, Method 4). These are the 49-set proteins that are those with the strongest changes for OXS and OAC individually and also show strong similarities or differences between the two experiments. This suggests that there may be a relatively restricted number of proteins which dominate cross-talk between OXS and OAC.

\section{C. “Trademarks" for OXS and OAC.}

As described in the main text, it is desirable to identify proteins that show changes that are dominant for OXS or for OAC. If a protein responds only to OXS, then the abundance changes in both compartments $\left(S_{n}\right.$ and $\left.S_{c}\right)$ and the mechanisms used to achieve the compartmental changes in abundance $\left(S_{t}\right.$ and $\left.S_{n} / S_{c}\right)$ should only show significant changes for OXS. We did not consider that the fuzziness of the SELECTION class provided sufficient discrimination. We therefore identified proteins for which the 
magnitude of the $\log _{2}$ fold-change for all significant SILAC ratios was at least four-fold greater for OXS compared to OAC, or vice versa. In the joint spatial razor plots here and in the main text, the radial aperture of the OXS region (blue slices) and of the OAC region (green slices) correspond to this cutoff. This is a fairly strong constraint. For example, for $S^{O X S}=2$, the SILAC pair is assigned to class OXS if $0.84 \leq S^{O A C} \leq 1.19$. Those SILAC pairs that did not satisfy this cutoff for OXS or OAC were assigned to either the SAME or OPPOSITE class, i.e. the SAME and OPPOSITE regions included all areas not within the OAC and OXS slices. Smaller changes in $S$ near the origin are less certainly characteristic of these regions. Hence, only SILAC pairs with radius > Exclusion-radius (0.65) were assigned to the OAC, OXS, SAME and OPPOSITE regions in the joint spatial razor plots. These SILAC pairs were then used to classify the protein as belonging to the OAC, OXS, SAME, OPPOSITE or MIXED classes (see main text). The column CLASS in Supplementary Table 2 identifies the "trademark" OXS and OAC proteins. The extent to which such groups of proteins constitute valid trademarks for oxidative stress or DNA replication/cell cycle can only be finally evaluated by experiments involving other kinds of cellular stimulation. The SAME set of proteins might be a trademark for concurrent engagement of both processes.

\section{Basal abundance and selection of significant proteins.}

An often underestimated characteristic of cellular function is the high degree of functional non-linearity and its reflection in large differences in the basal abundance of proteins and other components. In the present context, suppose for example that two proteins A, B have nominal basal abundances in the nucleus of $\mathrm{A}_{\text {basal }}=1000$ and $\mathrm{B}_{\text {basal }}=10$. Suppose that experimentally $S_{n}^{A}=1.3, S_{n}^{B}=2.0$, i.e. the nominal nuclear abundances for the stimulated cells are $\mathrm{A}_{\text {stim }}=1300$ and $\mathrm{B}_{\text {stim }}=20$. In relative terms, the change in $\mathrm{B}$ appears more significant, but in absolute terms the nominal change in $\mathrm{A}$ is 300 units and in B is 10 units. It is not entirely obvious which is the more significant change since this will depend on the "amplification" of these changes in a complex adaptive system. Matters get even more complicated if all increase in $\mathrm{A}$ is directed to a subcellular location that differs from the basal location. A full understanding of cellular function will in the longer term require quantitative modeling of interconnected systems, including spatial dependence.

This impinges on results such as the present study because the Significance B score used by MaxQuant is a non-linear function that evaluates significance relative to other proteins of similar abundance. This tends to favor selection of high abundance proteins since their experimental scatter is reduced by higher MS intensities. In practical terms this means that there are some "significant" proteins in Supplementary Table 2 that are high abundance proteins for which the individual SILAC ratios $S^{O X S}$ or $S^{O A C}$ are accepted as significant in relation to other high abundance proteins, even though their radius in the joint spatial razor plot may be less than the S-radius. This is probably the best that can be done in the absence of sufficient information to quantitatively model highly interconnected, non-linear systems.

\section{References.}

1. Cox, J.; Mann, M. MaxQuant enables high peptide identification rates, individualized p.p.b.-range mass accuracies and proteome-wide protein quantification. Nat. Biotechnol. 2008, 26, 1367-1372.

2. Cox, J.; Matic, I.; Hilger, M.; Nagaraj, N.; Selbach, M.; Olsen, J.V.; Mann, M. A practical guide to the MaxQuant computational platform for SILAC-based quantitative proteomics. Nat. Protoc. 2009, 4, 698-705. 
3. Mulvey, C. M.; Tudzarova, S.; Crawford, M.; Williams, G. H.; Stoeber, K.; Godovac-Zimmermann, J. Subcellular proteomics reveals a role for nucleo-cytoplasmic trafficking at the DNA replication origin activation checkpoint. J. Proteome Res. 2013, 12, 1436-1453.

4. Baqader, N; Radulovic, M; Crawford, M; Stoeber, K; Godovac-Zimmermann,J. (2014). Nuclear Cytoplasmic Trafficking of Proteins is a Major Response of Human Fibroblasts to Oxidative Stress. J. Proteome Res. 2014, 13, 4398-4423. 
Needs to be cleaned up, printed as PDF and appended to the SFig PDF. Up to you whether you want to introduce numbered Supplementary References. refs in Figs S-1 and S-10.

\section{Supplementary Figure 1.}

FERNANDEZ-GARCIA, P., PELAEZ, R., HERRERO, P. \& MORENO, F. 2012. Phosphorylation of yeast hexokinase 2 regulates its nucleocytoplasmic shuttling. J Biol Chem, 287, 42151-64.

KUMMEL, A., EWALD, J. C., FENDT, S. M., JOL, S. J., PICOTTI, P., AEBERSOLD, R., SAUER, U., ZAMBONI, N. \& HEINEMANN, M. 2010. Differential glucose repression in common yeast strains in response to HXK2 deletion. FEMS Yeast Res, 10, 322-32.

NEARY, C. L. \& PASTORINO, J. G. 2010. Nucleocytoplasmic shuttling of hexokinase II in a cancer cell. Biochem Biophys Res Commun, 394, 1075-81.

PATRA, K. C., WANG, Q., BHASKAR, P. T., MILLER, L., WANG, Z., WHEATON, W., CHANDEL, N., LAAKSO, M., MULLER, W. J., ALLEN, E. L., JHA, A. K., SMOLEN, G. A., CLASQUIN, M. F., ROBEY, R. B. \& HAY, N. 2013. Hexokinase 2 is required for tumor initiation and maintenance and its systemic deletion is therapeutic in mouse models of cancer. Cancer Cell, 24, 213-28.

PEIRIS-PAGES, M., SOTGIA, F. \& LISANTI, M. P. 2015. Chemotherapy induces the cancer-associated fibroblast phenotype, activating paracrine Hedgehog-GLI signalling in breast cancer cells. Oncotarget, 6, 10728-45.

ROBEY, R. B. \& HAY, N. 2005. Mitochondrial hexokinases: guardians of the mitochondria. Cell Cycle, 4, 654-8.

ROBEY, R. B. \& HAY, N. 2006. Mitochondrial hexokinases, novel mediators of the antiapoptotic effects of growth factors and Akt. Oncogene, 25, 4683-96.

\section{Supplementary Figure 10.}

AHMED, S. M., DAULAT, A. M., MEUNIER, A. \& ANGERS, S. 2010. G protein betagamma subunits regulate cell adhesion through Rap1a and its effector Radil. J Biol Chem, 285, 6538-51.

AHMED, S. M., THERIAULT, B. L., UPPALAPATI, M., CHIU, C. W., GALLIE, B. L., SIDHU, S. S. \& ANGERS, S. 2012. KIF14 negatively regulates Rap1a-Radil signaling during breast cancer progression. J Cell Biol, 199, 951-67.

ANDO, K., FUKUHARA, S., MORIYA, T., OBARA, Y., NAKAHATA, N. \& MOCHIZUKI, N. 2013. Rap1 potentiates endothelial cell junctions by spatially controlling myosin II activity and actin organization. J Cell Biol, 202, 901-16.

ANDREU, Z. \& YANEZ-MO, M. 2014. Tetraspanins in extracellular vesicle formation and function. Front Immunol, 5, 442.

ARENDT, B. K., WALTERS, D. K., WU, X., TSCHUMPER, R. C. \& JELINEK, D. F. 2014. Multiple myeloma dell-derived microvesicles are enriched in CD147 expression and enhance tumor cell proliferation. Oncotarget, 5, 5686-99.

BARCZYK, M., CARRACEDO, S. \& GULLBERG, D. 2010. Integrins. Cell Tissue Res, 339, 269-80.

BILLINGS, P. C., HERRICK, D. J., KUCICH, U., ENGELSBERG, B. N., ABRAMS, W. R., MACARAK, E. J., ROSENBLOOM, J. \& HOWARD, P. S. 2000. Extracellular matrix and nuclear localization of beta ig-h3 in human bladder smooth muscle and fibroblast cells. J Cell Biochem, 79, 261-73.

BRAVO-CORDERO, J. J., MARRERO-DIAZ, R., MEGIAS, D., GENIS, L., GARCIA-GRANDE, A., GARCIA, M. A., ARROYO, A. G. \& MONTOYA, M. C. 2007. MT1-MMP proinvasive activity is regulated by a novel Rab8-dependent exocytic pathway. EMBO J, 26, 1499-510.

CAO, H., EPPINGA, R. D., RAZIDLO, G. L., KRUEGER, E. W., CHEN, J., QIANG, L. \& MCNIVEN, M. A. 2015. Stromal fibroblasts facilitate cancer cell invasion by a novel invadopodia-independent matrix degradation process. Oncogene.

CAPALBO, L., D'AVINO, P. P., ARCHAMBAULT, V. \& GLOVER, D. M. 2011. Rab5 GTPase controls chromosome alignment through Lamin disassembly and relocation of the NuMA-like protein Mud to the poles during mitosis. Proc Natl Acad Sci U S A, 108, 17343-8.

CHOI, S. I., MAENG, Y. S., KIM, T. I., LEE, Y., KIM, Y. S. \& KIM, E. K. 2015. Lysosomal trafficking of TGFBIp via caveolae-mediated endocytosis. PLoS One, 10, e0119561. 
CLANCY, J. W., SEDGWICK, A., ROSSE, C., MURALIDHARAN-CHARI, V., RAPOSO, G., METHOD, M., CHAVRIER, P. \& D'SOUZA-SCHOREY, C. 2015. Regulated delivery of molecular cargo to invasive tumourderived microvesicles. Nat Commun, 6, 6919.

DAI, J. Y., DOU, K. F., WANG, C. H., ZHAO, P., LAU, W. B., TAO, L., WU, Y. M., TANG, J., JIANG, J. L. \& CHEN, Z. N. 2009. The interaction of HAb18G/CD147 with integrin alpha6beta1 and its implications for the invasion potential of human hepatoma cells. BMC Cancer, 9, 337.

DAS, S., HEHNLY, H. \& DOXSEY, S. 2014. A new role for Rab GTPases during early mitotic stages. Small GTPases, 5.

DETCHOKUL, S., WILLIAMS, E. D., PARKER, M. W. \& FRAUMAN, A. G. 2014. Tetraspanins as regulators of the tumour microenvironment: implications for metastasis and therapeutic strategies. Br J Pharmacol, 171, 5462-90.

GINGRAS, D. \& BELIVEAU, R. 2010. Emerging concepts in the regulation of membrane-type 1 matrix metalloproteinase activity. Biochim Biophys Acta, 1803, 142-50.

GONZALEZ, D. M. \& MEDICI, D. 2014. Signaling mechanisms of the epithelial-mesenchymal transition. Sci Signal, 7, re8.

GRASS, G. D., BRATOEVA, M. \& TOOLE, B. P. 2012. Regulation of invadopodia formation and activity by CD147. J Cell Sci, 125, 777-88.

GUO, Y. S., ZHAO, R., MA, J., CUI, W., SUN, Z., GAO, B., HE, S., HAN, Y. H., FAN, J., YANG, L., TANG, J. \& LUO, Z. J. 2014. betaig-h3 promotes human osteosarcoma cells metastasis by interacting with integrin alpha2beta1 and activating PI3K signaling pathway. PLoS One, 9, e90220.

HAN, B., CAI, H., CHEN, Y., HU, B., LUO, H., WU, Y. \& WU, J. 2015. The role of TGFBI (betaig-H3) in gastrointestinal tract tumorigenesis. Mol Cancer, 14, 64.

HEMLER, M. E. 2003. Tetraspanin proteins mediate cellular penetration, invasion, and fusion events and define a novel type of membrane microdomain. Annu Rev Cell Dev Biol, 19, 397-422.

JACOB, A. \& PREKERIS, R. 2015. The regulation of MMP targeting to invadopodia during cancer metastasis. Front Cell Dev Biol, 3, 4.

KEAN, M. J., WILLIAMS, K. C., SKALSKI, M., MYERS, D., BURTNIK, A., FOSTER, D. \& COPPOLINO, M. G. 2009. VAMP3, syntaxin-13 and SNAP23 are involved in secretion of matrix metalloproteinases, degradation of the extracellular matrix and cell invasion. J Cell Sci, 122, 4089-98.

KESSENBROCK, K., PLAKS, V. \& WERB, Z. 2010. Matrix metalloproteinases: regulators of the tumor microenvironment. Cell, 141, 52-67.

KIM, J. E., KIM, S. J., LEE, B. H., PARK, R. W., KIM, K. S. \& KIM, I. S. 2000. Identification of motifs for cell adhesion within the repeated domains of transforming growth factor-beta-induced gene, betaig-h3. J Biol Chem, 275, 30907-15.

KIRK, P., WILSON, M. C., HEDDlE, C., BROWN, M. H., BARCLAY, A. N. \& HALESTRAP, A. P. 2000. CD147 is tightly associated with lactate transporters MCT1 and MCT4 and facilitates their cell surface expression. EMBO J, 19, 3896-904.

KLEZOVITCH, O. \& VASIOUKHIN, V. 2015. Cadherin signaling: keeping cells in touch. F1000Res, 4, 550.

LE FLOCH, R., CHICHE, J., MARCHIQ, I., NAIKEN, T., ILC, K., MURRAY, C. M., CRITCHLOW, S. E., ROUX, D., SIMON, M. P. \& POUYSSEGUR, J. 2011. CD147 subunit of lactate/H+ symporters MCT1 and hypoxia-inducible MCT4 is critical for energetics and growth of glycolytic tumors. Proc Natl Acad Sci U S A, $108,16663-8$.

LINDER, S. \& SCITA, G. 2015. RABGTPases in MT1-MMP trafficking and cell invasion: Physiology versus pathology. Small GTPases, 6, 145-52.

MCCREA, P. D., MAHER, M. T. \& GOTTARDI, C. J. 2015. Nuclear signaling from cadherin adhesion complexes. Curr Top Dev Biol, 112, 129-96.

MIYATA, T., OHNISHI, H., SUZUKI, J., YOSHIKUMI, Y., OHNO, H., MASHIMA, H., YASUDA, H., ISHIJIMA, T., OSAWA, H., SATOH, K., SUNADA, K., KITA, H., YAMAMOTO, H. \& SUGANO, K. 2004. 
Involvement of syntaxin 4 in the transport of membrane-type 1 matrix metalloproteinase to the plasma membrane in human gastric epithelial cells. Biochem Biophys Res Commun, 323, 118-24.

POINCLOUX, R., LIZARRAGA, F. \& CHAVRIER, P. 2009. Matrix invasion by tumour cells: a focus on MT1MMP trafficking to invadopodia. J Cell Sci, 122, 3015-24.

POST, A., PANNEKOEK, W. J., PONSIOEN, B., VLIEM, M. J. \& BOS, J. L. 2015. Rap1 Spatially Controls ArhGAP29 To Inhibit Rho Signaling during Endothelial Barrier Regulation. Mol Cell Biol, 35, 2495-502.

RODRIGUEZ, D., MORRISON, C. J. \& OVERALL, C. M. 2010. Matrix metalloproteinases: what do they not do? New substrates and biological roles identified by murine models and proteomics. Biochim Biophys Acta, 1803, 39-54.

SCHRODER, H. M., HOFFMANN, S. C., HECKER, M., KORFF, T. \& LUDWIG, T. 2013. The tetraspanin network modulates MT1-MMP cell surface trafficking. Int J Biochem Cell Biol, 45, 1133-44.

SERIO, G., MARGARIA, V., JENSEN, S., OLDANI, A., BARTEK, J., BUSSOLINO, F. \& LANZETTI, L. 2011. Small GTPase Rab5 participates in chromosome congression and regulates localization of the centromereassociated protein CENP-F to kinetochores. Proc Natl Acad Sci U S A, 108, 17337-42.

STEFFEN, A., LE DEZ, G., POINCLOUX, R., RECCHI, C., NASSOY, P., ROTTNER, K., GALLI, T. \& CHAVRIER, P. 2008. MT1-MMP-dependent invasion is regulated by TI-VAMP/VAMP7. Curr Biol, 18, 92631.

STRONGIN, A. Y. 2006. Mislocalization and unconventional functions of cellular MMPs in cancer. Cancer Metastasis Rev, 25, 87-98.

STUFFERS, S., SEM WEGNER, C., STENMARK, H. \& BRECH, A. 2009. Multivesicular endosome biogenesis in the absence of ESCRTs. Traffic, 10, 925-37.

TAKAHASHI, M., DILLON, T. J., LIU, C., KARIYA, Y., WANG, Z. \& STORK, P. J. 2013. Protein kinase Adependent phosphorylation of Rap1 regulates its membrane localization and cell migration. J Biol Chem, 288, 27712-23.

TANG, J., WU, Y. M., ZHAO, P., YANG, X. M., JIANG, J. L. \& CHEN, Z. N. 2008. Overexpression of HAb18G/CD147 promotes invasion and metastasis via alpha3beta1 integrin mediated FAK-paxillin and FAKPI3K-Ca2+ pathways. Cell Mol Life Sci, 65, 2933-42.

TANG, W. \& HEMLER, M. E. 2004. Caveolin-1 regulates matrix metalloproteinases-1 induction and CD147/EMMPRIN cell surface clustering. J Biol Chem, 279, 11112-8.

ULLAH, M. S., DAVIES, A. J. \& HALESTRAP, A. P. 2006. The plasma membrane lactate transporter MCT4, but not MCT1, is up-regulated by hypoxia through a HIF-1alpha-dependent mechanism. J Biol Chem, 281, 9030-7.

VALACCA, C., TASSONE, E. \& MIGNATTI, P. 2015. TIMP-2 Interaction with MT1-MMP Activates the AKT Pathway and Protects Tumor Cells from Apoptosis. PLoS One, 10, e0136797.

VAN NIEL, G., CHARRIN, S., SIMOES, S., ROMAO, M., ROCHIN, L., SAFTIG, P., MARKS, M. S., RUBINSTEIN, E. \& RAPOSO, G. 2011. The tetraspanin CD63 regulates ESCRT-independent and -dependent endosomal sorting during melanogenesis. Dev Cell, 21, 708-21.

WANG, H., FOTHERINGHAM, L., WITTCHEN, E. S. \& HARTNETT, M. E. 2015. Rap1 GTPase Inhibits Tumor Necrosis Factor-alpha-Induced Choroidal Endothelial Migration via NADPH Oxidase- and NFkappaB-Dependent Activation of Rac1. Am J Pathol.

WANG, Z., DILlON, T. J., POKALA, V., MISHRA, S., LABUDDA, K., HUNTER, B. \& STORK, P. J. 2006. Rap1-mediated activation of extracellular signal-regulated kinases by cyclic AMP is dependent on the mode of Rap1 activation. Mol Cell Biol, 26, 2130-45.

WEEN, M. P., OEHLER, M. K. \& RICCIARDELLI, C. 2012. Transforming growth Factor-Beta-Induced Protein (TGFBI)/(betaig-H3): a matrix protein with dual functions in ovarian cancer. Int J Mol Sci, 13, 10461-77.

WEIDLE, U. H., SCHEUER, W., EGGLE, D., KLOSTERMANN, S. \& STOCKINGER, H. 2010. Cancer-related issues of CD147. Cancer Genomics Proteomics, 7, 157-69. 
WILLIAMS, K. C. \& COPPOLINO, M. G. 2011. Phosphorylation of membrane type 1-matrix metalloproteinase (MT1-MMP) and its vesicle-associated membrane protein 7 (VAMP7)-dependent trafficking facilitate cell invasion and migration. J Biol Chem, 286, 43405-16.

WILLIAMS, K. C. \& COPPOLINO, M. G. 2014. SNARE-dependent interaction of Src, EGFR and beta1 integrin regulates invadopodia formation and tumor cell invasion. J Cell Sci, 127, 1712-25.

WILLIAMS, K. C., MCNEILLY, R. E. \& COPPOLINO, M. G. 2014. SNAP23, Syntaxin4, and vesicle-associated membrane protein 7 (VAMP7) mediate trafficking of membrane type 1-matrix metalloproteinase (MT1-MMP) during invadopodium formation and tumor cell invasion. Mol Biol Cell, 25, 2061-70.

WU, J., BAKERINK, K. J., EVANGELISTA, M. E. \& THOMAS, G. H. 2014. Cytoplasmic capes are nuclear envelope intrusions that are enriched in endosomal proteins and depend upon betaH-spectrin and Annexin B9. PLoS One, 9, e93680.

XIONG, L., EDWARDS, C. K., 3RD \& ZHOU, L. 2014. The biological function and clinical utilization of CD147 in human diseases: a review of the current scientific literature. Int J Mol Sci, 15, 17411-41.

YANEZ-MO, M., BARREIRO, O., GORDON-ALONSO, M., SALA-VALDES, M. \& SANCHEZ-MADRID, F. 2009. Tetraspanin-enriched microdomains: a functional unit in cell plasma membranes. Trends Cell Biol, 19, 434-46.

ZUCKER, S., PEI, D., CAO, J. \& LOPEZ-OTIN, C. 2003. Membrane type-matrix metalloproteinases (MTMMP). Curr Top Dev Biol, 54, 1-74. 
